\title{
EMCS Retrofit Analysis Interim Report
}

\author{
R.C. Diamond, T. I. Salsbury, G. C. Bell, \\ Y.J. Huang, and A.O. Sezgen \\ Energy Performance of Buildings Group \\ Indoor Environment Department \\ Environmental Energy Technologies Division \\ Lawrence Berkeley National Laboratory \\ Berkeley, California 94720
}

R. Mazzucchi and J. Romberger

SBW Consulting, Inc.

March 1999

This work was supported by the Assistant Secretary for Energy Efficiency and Renewable Energy, Office of Building Technology and Community Systems, and the Federal Energy Management Program, of the U.S. Department of Energy under Contract No. DE-AC03-76SF00098. 


\section{DISCLAIMER}

This report was prepared as an account of work sponsored by an agency of the United States Government. Neither the United States Government nor any agency thereof, nor any of their employees, make any warranty, express or implied, or assumes any legal liability or responsibility for the accuracy, completeness, or usefulness of any information, apparatus, product, or process disclosed, or represents that its use would not infringe privately owned rights. Reference herein to any specific commercial product, process, or service by trade name, trademark, manufacturer, or otherwise does not necessarily constitute or imply its endorsement, recommendation, or favoring by the United States Government or any agency thereof. The views and opinions of authors expressed herein do not necessarily state or reflect those of the United States Government or any agency thereof. 


\section{DISCLAIMER}

Portions of this document may be illegible in electronic image products. Images are produced from the best available original document. 


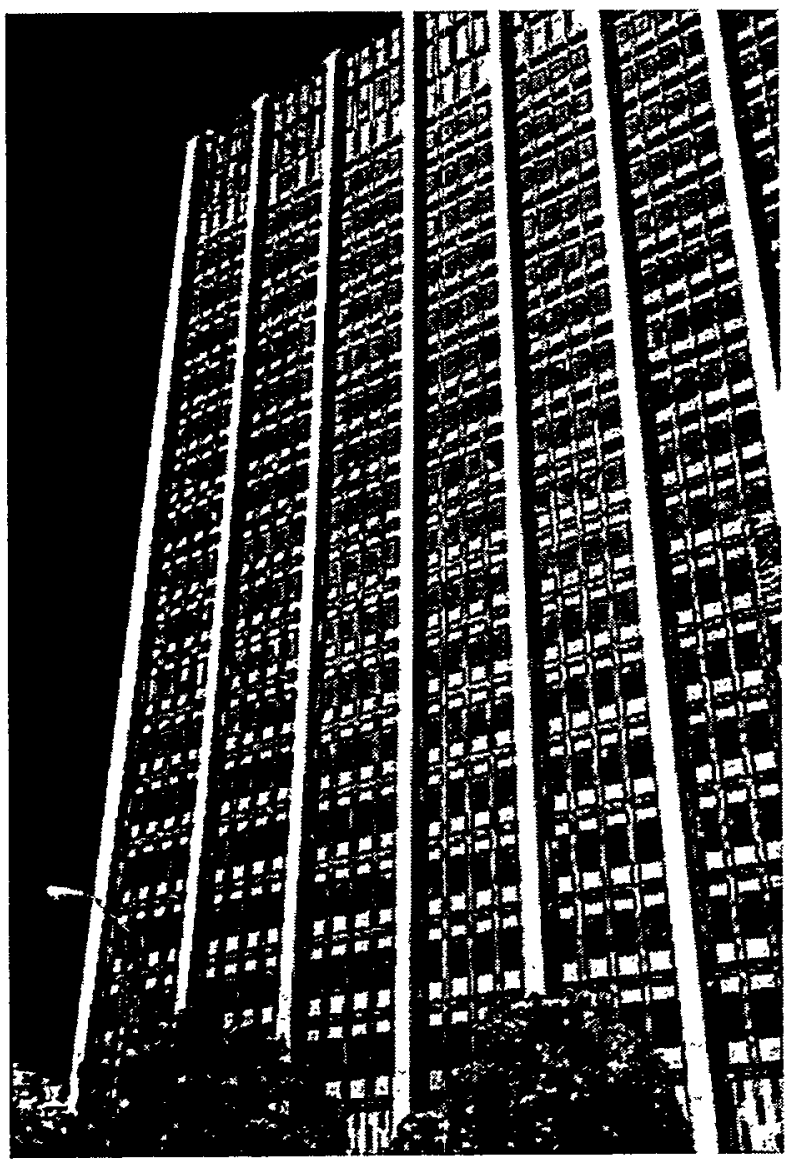

Phillip Burton Federal Building

EMCS Retrofit Analysis

Interim Report

March 1999

Rick Diamond, Tim Salsbury, Geoffrey Bell, Joe Huang, and Ozman Sezgen

Lawrence Berkeley National Laboratory

Richard Mazzucchi and Jeff Romberger

SBW Consulting, Inc. 


\section{Acknowledgments}

We would like to thank several individuals for their time and help in carrying out this work. From the "client", the US General Services Administration (GSA), Julius DeLeon, Peter Gaddy, Hollis Hughes, Bob Lee, Sam Luzano, Terry Pierce, Beth Shearer, and Warren Sitterly, all helped us with their time and energy for this project. The utility, Pacific, Gas \& Electric Company, oversaw the retrofit and data collection, Steve Blanc being the prime mover for this activity, with additional help from Sharon Harris in providing the utility billing data. David Guthrie from Alerton helped track down information on the EMCS design and installation and answered numerous questions about the system. Ed Spivey and Tracy Cornish from Bosek Gibson and Associates developed the DOE-2 simulation model used for the analysis. Anne Sprunt Crawley, Dean McCauley, Dennis Clough and Mark Bailey, all from the US Department of Energy, supported this work. We would also like to thank our LBNL colleagues, Bill Carroll, Dennis Debartolomeo, Philip Haves, Judy Jennings, Rob Hitchcock, Saki Khalsa, Kristopher Kinney, Steve Kromer, Francis Rubinstein, Mary Ann Piette, and Dale Sartor for their timely comments and help along the way.

This work was supported by the Assistant Secretary for Energy Efficiency and Renewable Energy, Office of Building Technology and Community Systems, and the Federal Energy Management Program, of the US Department of Energy under Contract No. DE-AC03-76SF00098. 


\section{Executive Summary}

This report presents the interim results of analyses carried out in the Phillip Burton Federal Building in San Francisco from 1996 to 1998. The building is the site of a major demonstration of the BACnet communication protocol. The energy management and control systems (EMCS) in the building were retrofitted with BACnet compatible controllers in order to integrate certain existing systems on one common network. In this respect, the project has been a success. Interoperability of control equipment from different manufacturers has been demonstrated in a real world environment.

Besides demonstrating interoperability, the retrofits carried out in the building were also intended to enhance control strategies and capabilities, and to produce energy savings. This report presents analyses of the energy usage of HVAC systems in the building, control performance, and the reaction of the building operators. The report does not present an evaluation of the performance capabilities of the BACnet protocol. A monitoring system was installed in the building that parallels many of the EMCS sensors and data were archived over a three-year period. We defined pre-retrofit and post-retrofit periods and analyzed the corresponding data to establish the changes in building performance resulting from the retrofit activities.

We also used whole-building energy simulation (DOE-2) as a tool for evaluating the effect of the retrofit changes. The results of the simulation were compared with the monitored data. Changes in operator behavior were assessed qualitatively with questionnaires.

The report summarizes the findings of the analyses and makes several recommendations as to how to achieve better performance. We maintain that the full potential of the EMCS and associated systems is not being realized. The reasons for this are discussed along with possible ways of addressing this problem. We also describe a number of new technologies that could benefit systems of the type found in the Philip Burton Federal Building.

\section{Predicted Savings from the ECMS Retrofit (Section 2)}

The initial challenge in evaluating energy savings is to establish a baseline for comparison. We reviewed the past five years of utility billing data, compiled a log of the major changes in the operation of the building and renovation, and identified comparison buildings. While there was some variation in the monthly utility consumption over the past five years, the average annual consumption of gas and was mostly constant, despite numerous changes in the operation and renovation of the building. With an Energy Use Index (EUD) of $76 \mathrm{kBtu} / \mathrm{ft} 2$, the building was not a high user of energy compared to similar large office buildings.

The original estimate (ESS 1994), established through simulation studies, of the savings from the EMCS retrofit was $\$ 355,500$, an $18 \%$ reduction in annual utility costs, based on the estimated 1993 utility costs of $\$ 1,975,000$. Seventy percent of the predicted savings 
$(\$ 266,625)$ were due to the DDC air-side control, $25 \%$ due to lighting control and the remaining $5 \%$ to improved control of the boilers and chillers. The cost savings prediction for the DDC control of the air-handlers ( $70 \%$ of the $18 \%$ total reduction) was $13 \%$.

Similarly, a calibrated computer simulation (Bosek Gibson, 1997) predicted annual cost savings from the EMCS retrofit of $\$ 358,999$. The electricity savings were predicted to be $3,175,725 \mathrm{kWh} /$ year, or 20 percent of the building's total electrical consumption. The savings for activating the mixed-air controllers/economizers added $\$ 42,781$ to give total savings of $\$ 401,780$, a $23 \%$ reduction in utility costs.

The 1994 estimated cost for the EMCS retrofits and repair was $\$ 2,320,000$. The updated Phase II Summary (ESS Progress Meeting Notes 6/2/97) gives the savings estimate for the controls retrofit as $\$ 536,000$ and gives $\$ 3.5$ million as the cost.

\section{Energy Savings from the EMCS Retrofit (Section 3)}

Based on the monitored data, the overall total energy use in the building fell by $8 \%$, consisting of a $1 \%$ reduction in the electricity use and a $18 \%$ reduction in gas consumption. The utility billing records indicated higher savings of $10 \%$, with $1 \%$ for electricity and $20 \%$ for gas. Differences in the gas savings are due to missing monitored data in January 1996 and variations in the heat content of the gas not fully accounted for in the monitored data. The cost savings from the utility data were $4 \%$, as most of the savings were in gas and most of the cost is in electricity.

The analysis in Section 3 shows that almost 3\% of the savings from the HVAC system may have been masked by increases in the electricity used by unmonitored systems in the building. Based on extrapolations of unmonitored fans in the building, the total savings from the HVAC (electricity and gas) was estimated to be approximately $9,000 \mathrm{kWh} /$ day, which is a reduction of $20 \%$ from pre-to post-retrofit (Table 3-6). The savings in the total monitored gas and electricity were only about 6,603 (gas) +367 (electric) $=6,970$ $\mathrm{kWh}$ /day (Table 3-5).

Conversion of the constant volume HVAC system to a variable-air-volume system represented the most significant change to the control strategy as regards energy use. The monitored data showed significant reductions in the energy used by the fans as a result of the upgrade from a constant volume to a variable volume system. In terms of the primary plant, the simulation results suggest that the VAV capability in isolation benefited only the cooling plant, while the load of the heating plant was marginally increased. Gas savings were due mostly to the activation of the mixing controllers and economizers in the air-handling units, which provided $100 \%$ outside air before the retrofits. However, a comparison of the simulation and monitored data results indicated that a significant proportion of the savings in gas may have been due to other changes made to the boiler plant. These changes included installation of electric hot water heaters and an EGR exhaust return system fitted on boiler \#1. 
Automated scheduling of system operating times did not lead to discernible savings as the manual operation previously employed was of a high standard. In fact, problems with the automatic scheduling were evident in one of the main air-handlers in the post-retrofit period. The monitored data indicated that the switching on of this unit was delayed on a number of occasions. Although this additional downtime led to reductions in energy consumption, the comfort conditions in the building may have been detrimentally affected. The building operators confirmed the existence of the scheduling problem in the post-retrofit period.

\section{Results from the simulation-based evaluation (Section 4)}

The building energy program, DOE-2, was used to evaluate the changes in energy use caused by the retrofits. The simulation-based evaluation enabled the effects of the control retrofits to be isolated from other changes that may have occurred in the real building, such as: weather variations, occupancy changes, unmonitored equipment load changes, etc. In Section 4, we compared the predictions made by the simulation with the actual changes calculated from the monitored data.

Table 4-2 shows the overall energy use predictions of the simulation. Incorporation of the retrofits saves $8 \%$ of total energy, comprised of about $5 \%$ in electricity and almost $13 \%$ in gas savings (Table 4-3). The results indicate that VAV control is responsible for almost all of the savings in electricity. Activation of the (temperature) economizer results in only $27 \mathrm{kWh} /$ day electricity savings, which is a negligible fraction of the total building electric. VAV control increases gas consumption by $2.5 \%$ due to a trade-off between fan savings and primary plant savings. All gas savings are due to activation of the mixed-air controllers and economizers in the main air-handling units. According to the simulation results, this change in isolation saves about $13.2 \%$ of the annual gas consumption. When the VAV control is active at the same time as the mixed-air control/economizer, the savings drop to $12.5 \%$. There are negligible savings from changing the temperature economizer to be enthalpy-based.

Savings in the gas consumption calculated from the monitored data were accentuated due to the mixed air control in the main air-handlers operating at $100 \%$ outside air during the first few months of the pre-retrofit period. Based on simulation results, we corrected for the lack of mixing control in the monitored data. The correction led to a fall in the total gas savings from $18 \%$ to $11 \%$; the total building energy savings also fell from $8 \%$ to $5 \%$.

\section{Performance of the HVAC Controls (Section 5)}

Improvements in the control performance caused by the retrofits are more difficult to evaluate than changes in energy usage. Occupant comfort is one important measure of control performance, but no quantitative measurements of this were made during the course of this research.

The results of the analysis indicate that certain aspects of control performance deteriorated following the retrofits. Both operation scheduling and attainment of 
setpoints in the main air-handling units have been detrimentally affected. These may have been due to set-up problems encountered when the new systems were installed. There is a definite learning period associated with a new system and a later evaluation of control performance may yield a fairer assessment of the retrofit benefits in this respect.

\section{Overall Findings from the Operator Interviews (Section 6)}

One of the main findings from the questionnaires distributed among operators is that they felt better able to respond to complaints from occupants in the building. Once a complaint had been received, the EMCS could be interrogated to isolate the problem more accurately than had been previously possible. Although there were several enhancements that the operators would like to have seen made to the user interfaces, the general responses were positive. A boost to the morale of the personnel was reported and the interviewees were excited about working with the new technology. There were, however, reported shortages in human resources assigned to work with the new system. In fact, the number of personnel was reduced to $40 \%$ of the pre-retrofit numbers about the same time as the introduction of the new system.

A significant finding from the interviews is that the EMCS has not been viewed as a tool for energy management. The operators did not mention using the EMCS to track energy consumption, or to track the energy performance of building systems or end-uses. They feel that their job is to operate the building to minimize occupant complaints. There is no incentive for them to reduce energy use, nor is there a "culture" of energy efficiency in building management.

\section{Recommendations (Section 8)}

\section{Operator Behavior}

The building operators and users of the EMCS have an important role to play in maximizing the benefits of the system. Improved accessibility and integration have made vast amounts of information available to the operators. In addition to real-time sensor signals and measurements, large amounts of trended data are now available. The main problem is that of information overload where there is generally too much information to be usefully processed.

The results of the interviews with the building operators indicated a number of ways in which the interaction between the operators and the system may be improved:

- Improvements to user interface

- More operator training

- Energy-saving incentives

- Better utilization of trend data 


\section{Control Strategies}

One of the purposes of an integrated control system is to facilitate more advanced control strategies. These strategies make use of information from various loops in the system in order to better co-ordinate and optimize operation. In the Phillip Burton Federal Building, with the exception of installing VAV, control strategies were not changed significantly from pre- to post-retrofit, although retrofits still to be completed do represent strategic changes. It is clear that the concept of integration creates many new possibilities for improved control and energy management. Areas for improvement include:

- $\quad$ Setpoint scheduling/reset between different control loops

- $\quad$ Sequencing to reduce the canceling effect of different subsystems

- Coordination of control loops and operational times

- Optimization of setpoints and operational schedules for energy/comfort criteria

\section{Application of New Technologies}

The advances that have been made in facilitating access to information from distributed building systems and controllers have outpaced the development of ways in which to handle and process this information. Numerous research projects have demonstrated that EMCS data can be used for applications such as fault detection and diagnosis, advanced control strategies, predictive maintenance, performance optimization, etc. In practice, little analysis of EMCS data is carried out and the full potential of the EMCS is therefore not realized:

Three new technologies are listed below, which are at a stage of development where application to real buildings is viable. Each of these technologies could operate using the currently available EMCS hardware.

- Fault detection and diagnosis

- $\quad$ Advanced control solutions

- Building life-cycle information integration

\section{"Classic" Recommendations}

The following recommendations are given because we find they apply to nearly every project we evaluate. As basic as they may seem, we rarely find that they have been carried out in practice. By explicitly requiring these steps, the building owners and operators will be in a far better position to realize the energy goals for their projects. These recommendations are to:

Document the design intent. The designer needs to document design intent for every retrofit measure. A description of each measure, how it operates and why, are basic requirements that should be spelled out in plain English for every project. 
Document the predicted savings. Similar to above, the designer should spell out how the measure will achieve energy savings, what baseline was used for comparison and what assumptions were made.

Document the sequence of operations. For control retrofits, the sequence of operations needs to be spelled out in plain English and specified in the contract documents. It is important that there be "as built" specifications so the actual sequences can be compared to the original design intent. For control retrofits, there should be as much documentation as possible of the pre-existing control sequences.

Document the Commissioning Plan. A thorough commissioning plan and operations manual are essential to ensure correct operation of the building's systems. Too often the equipment is "commissioned" but the overall systems performance is neglected. Owners should require a complete commissioning plan and implementation strategy.

If these measures were adopted in more buildings we would see higher quality projects, greater energy savings, and more credible stories to tell industry and building owners about the benefits of energy efficiency. 


\section{Table of Contents}

\section{Introduction}

1.1. Objectives 1

1.2. Players 1

1.3. Report Structure 2

2. Building Description

2.1. HVAC System Description

2.1.1. Heating _ . 4

2.1.2. Cooling 4

2.1.3. Air Distribution__ 4

2.2. Control Retrofits __ 5

2.3. Sequence of Operations ___ 8

2.4. Utility Bill Histories ___ 9

2.5. Predicted Savings from the ECMS Retrofit

3. Energy Analysis _ 18

3.1. Building Sensor Suite__ 18

3.1.1. Monitored HVAC Equipment ___ 19

3.1.2. Comparison of Monitored Data with Utility Bills _ 19

3.2. Weather Data in Pre- and Post-Retrofit Periods ___ 21

3.3. Energy Usage in Monitored HVAC

3.4. Air-Handling Unit Performance___ 31

4. Simulation-based evaluation__ 36

4.1. Configurations _ـ_ 36

4.2. Results of the simulation study ___ 37

4.3. Using the simulation results to correct for full outside air in pre-retrofit period $\_41$

5. Control Performance __ 43

5.1. AHU Setpoint Tracking__ 43

5.2. Automated Scheduling__ 46

5.3. Fan Control _ 47

5.4. Damper Control ___ 48

6. The Building Operator's Perspective__ 49

6.1. Background of the BACnet Control System __ 49

6.2. Interview Questions _ 49 
6.3. Responses from the First-Round Interviews 50

6.4. Responses to the Follow-Up Interviews 51

6.5. Overall Findings from the Operator Interviews 52

7. Conclusions 53

7.1. Energy Benefits 53

7.2. Control Benefits 54

7.3. Operator Usage Benefits 55

8. Recommendations 56

8.1. Operator Usage 56

8.2. Control Strategies 57

8.3. Application of New Technologies 58

8.4. "Classic" Recommendations 59

9. Bibliography 60 


\section{List of Tables}

Table 2-1. Building Usage by Floor

Table 2-2: Control Strategy Retrofits

Table 2-3: Building change chronology independent of EMCS retrofits ___ 7

Table 2-4: Historic annual average electricity consumption and cost __ 9

Table 2-5 Historic Annual Average Gas Consumption and Cost __ 13

Table 2-6 Annual Utility Costs _ـ 15

Table 3-1: Comparison of monitored data and utility billing data___ 20

Table 3-2: Annualized comparisons of monitored and utility data___ 20

Table 3-3: Comparison of savings calculated from utility data and from monitored data_ _ 21

Table 3-4: Mean outside air conditions during considered periods __ 21

Table 3-5: Relative changes in mean daily monitored energy use from pre- to post-retrofit periods _ 24

Table 3-6: Energy use of fans (monitored and extrapolated estimates) __ 27

Table 3-7: Mean power in air-handling unit

Table 4-1: Simulation cases __ 36

Table 4-2: Simulation annual building energy usage results ___ 37

Table 4-3: Daily average savings resulting from the retrofits __ 37

Table 4-4: Annual savings - simulation and real data comparison _ 38

Table 4-5: Comparison of simulation and actual subsystem energy usage ( $k$ Wh/year) ___ 39

Table 4-6: Complete breakdown of the annual energy use from the DOE-2 results __ 41

Table 4-7: Revised monitored data savings based on correcting for the mixing damper control in the pre-

retrofit period _ 42

Table 5-1: Mean absolute errors (MAE) and means of AHU controlled variables __ 44 


\section{List of Figures}

Figure 2-1: Monthly electricity consumption of the whole building, 1992-1998.

Figure 2-2: Monthly electricity consumption of the whole building, as rolling 12-month averages, $1992-$ 1998.

Figure 2-3: Monthly maximum electricity demand of the whole building, 1992-1998.

Figure 2-4: Monthly maximum electricity demand of the whole building, as rolling 12-month averages, 1992-1998.

Figure 2-5: Monthly gas consumption of the whole building, $1992-1998$.

Figure 2-6: Monthly gas consumption of the whole building, as rolling 12-month averages, 1992-1998. 12

Figure 2-7: Total utility costs per month

Figure 2-8: Utility costs as a 12 month rolling average

Figure 2-9: Energy Use Intensities (EUI) for comparison buildings.

Figure 2-10: Energy Use Intensities (EUI) cost comparisons (\$1993).

Figure 3-1: Pre-retrofit (solid line) and post-retrofit (dashed line) daily maximum and minimum ambient air temperatures.

Figure 3-2: Daily energy consumption of main HVAC systems

Figure 3-3: Mean energy use for pre- and post-retrofit periods _ 24

Figure 3-4: Changes in floor 7 energy use ___ 25

Figure 3-5: Energy used by lights and plugs on floor seven — 26

Figure 3-6: Pre-retrofit energy breakdown of systems. Total energy $=84,112 \mathrm{kWh} / \mathrm{day} \_28$

Figure 3-7: Post-retrofit energy breakdown of systems. Total energy $=77,142 \mathrm{kWh} /$ day 28

Figure 3-8: Pre-retrofit cost breakdown of systems. Total cost approximately \$3,843/day._L 29

Figure 3-9: Post-retrofit cost breakdown of systems. Total cost approximately $\$ 3,746 /$ day.

Figure 3-10: Daily energy costs __ 31

Figure 3-11: Mean daily $\mathrm{kW}$ power of AHU subsystems ___ 34

Figure 3-12: Energy usage apportioned between AHU subsystems (pre-retrofit top pie; post-retrofit bottom

pie)

Figure 4-1: Pre-retrofit energy breakdown in simulation.__ 40

Figure 4-2: Post-retrofit energy breakdown in simulation.

Figure 5-1: Mean daily values of the controlled temperatures in one AHU

Figure 5-2: Mean absolute errors of AHU controlled variables _ 45

Figure 5-3: Controlled temperatures in the monitored AHU in the post-retrofit period ___ 46

Figure 5-4: Scheduled start-stop times___ 47 


\section{Introduction}

In 1996, the Phillip Burton Federal Building and U.S. Courthouse located at 450 Golden Gate Avenue in San Francisco was selected as the site for the first large-scale commercial demonstration of the BACnet (Building Automation and Controls Network) standard. The building was selected for this demonstration, in part, because it had few pre-existing EMCS (Energy Management and Control Systems) and recent renovations have made it comparable to typical commercial office buildings.

\subsection{Objectives}

The project tests the ability of EMCS equipment from multiple manufacturers to cooperatively monitor and control building systems by utilizing the BACnet standard. One important element of the project is that the operators may access various proprietary systems through a single user interface. This aspect creates significant potential for improving the ability of the operators to supervise the systems and to respond to alarms more effectively. In addition to forming the basis of a BACnet demonstration, the EMCS retrofits included certain enhancements to the control strategies in the building. Preliminary simulation studies indicated the potential for large energy savings in the building as a result of the control system retrofits.

The main benefits of the EMCS retrofits may be categorized as follows:

- Energy savings through the incorporation of more energy-efficient control strategies

- Improved operator supervision through improved access to various building systems from different manufacturers

- Better control by installation of VAV terminal boxes with motorized actuators and $\mathrm{DDC}$, and enhancements to control algorithms

\subsection{Players}

The U.S. General Services Administration (GSA) owns and manages the operation of the building. The Pacific Gas and Electric Company (PG\&E) provides utility services. Both parties are involved in evaluating the performance of the EMCS retrofits in the building. GSA is providing the building as the test site for the new technology and PG\&E provides design and project management services. Because the site is a major federal facility, DOE's Federal Energy Management Program (FEMP) is motivated to communicating the lessons learned from the retrofits to other federal agencies. As the building is a major demonstration of the BACnet protocol, DOE's Commercial Buildings Research Program would also like to show the lessons learned from the retrofit to a wide audience in the commercial building-energy community.

Lawrence Berkeley National Laboratory's (LBNL) objective has been to evaluate the changes in building performance brought about by the EMCS retrofits. This report is primarily concerned with the heating, ventilating, and air-conditioning (HVAC) systems. Lighting and other aspects of the building are discussed elsewhere (Rubinstein et al., 1998). 
A contract set up between PG\&E, New Horizon Technologies and SBW Consulting Inc led to the installation of a suite of sensors to collect data associated with HVAC and lighting systems prior to the installation of the new EMCS. Measurements from 123 sensors in the building logged at 15-minute intervals have been archived since September 19, 1995. Archiving will cease at the end of November 1998. These data have been used to establish pre-retrofit performance baselines and to allow the benefits of the retrofits to be ascertained. Utility bills associated with the building have also been archived and these have been used to evaluate overall changes in building energy usage.

\subsection{Report Structure}

Section 2 of this report describes the building, its systems, historical energy use, and the retrofits that have taken place.

Section 3 presents results of energy analyses carried out using data from the sensor suite installed in the building. The changes in energy use from the pre-to post-retrofit periods are evaluated for the monitored systems in the building. Certain extrapolations are also performed to ascertain the savings in unmonitored systems.

Section 4 presents results from a simulation-based evaluation of the effects of the retrofits on building performance. The DOE- 2 simulation program was used to model the building and its systems in the post-retrofit state. A pre-retrofit simulation was created by removing the changes to the control strategy made as part of the retrofits. The effects of the retrofits on building performance were then established by comparing the pre- and post-retrofit simulation results.

Section 5 presents an assessment of the performance of certain critical control operations in the building, which were influenced by the retrofits. The data archived from the monitoring sensor suite were used in these analyses.

Section 6 is concerned with evaluating any changes in the way in which the operators monitor the building as a result of the retrofits. Changes in the ways the operators interact with the systems were assessed qualitatively by distributing questionnaires to certain personnel. The results of these questionnaires are presented in Section 6.

Section 7 of the report summarizes the findings and presents conclusions.

In Section 8, we make recommendations based on the findings of the work

Appendix A contains the analysis plan and Appendix B lists the data channels that were logged in the building. 


\section{Building Description}

The Phillip Burton Federal Building is located in the downtown area of San Francisco; it is the second largest office building in the city, and the largest Federal office building west of the Mississippi River. The building was constructed in 1962, has 22 floors of which 20 are tenant-occupied. The estimated total number of occupants is 2645 and the total floor area is 1.4 million square feet (130 thousand square meters) of which 1.2 million square feet (112 thousand square meters) are conditioned space. Several Federal agencies are housed in the building.

The building is steel framed with curtain wall construction and has single-pane windows. The floors are 4" concrete-filled metal decking, with carpet or linoleum tile. The telecommunications and electrical supplies are installed in floor ducts. The roof is a flat BUR membrane constructed on rigid insulation, concrete slab, and metal decking. Ceiling construction is made from 2' by 4' T-bars laid in a grid. Table 2-1 gives a floorby-floor break down of the building usage.

Table 2-1. Building Usage by Floor

\begin{tabular}{|c|c|}
\hline Floor(s) & Usage \\
\hline Sub Basement & Mechanical rooms, storage, floor height $=12^{\prime}-6^{\prime \prime}$ \\
\hline Basement & Parking deck, post office, floor height $=14^{\prime}-5^{\prime \prime}$ \\
\hline Floor 1 & $\begin{array}{l}\text { Large central lobby, offices, snack bar and health club, floor height }= \\
18^{\prime}-0^{\prime \prime}\end{array}$ \\
\hline Floor 2 & $\begin{array}{l}\text { Cafeteria, two courtrooms, credit union, judges chambers, infirmary } \\
\text { and storage (est. } 170 \text { people) floor height } 2 \text { through } 20=13^{\prime}-9 \text { " }\end{array}$ \\
\hline Floor 3-5 & GSA, partitioned space (est. 250 people) \\
\hline Floor 6 & RSS (est. 250 people) \\
\hline Floor 7 & Computer rooms, GSA, IRS, many small offices \\
\hline Floor 8 & Supply rooms and small offices \\
\hline Floor 9 & Conference and offices spaces \\
\hline Floor 10 & Offices \\
\hline Floor 11 & Offices \\
\hline Floor $12-13$ & FBI offices \\
\hline Floor 14 & Offices \\
\hline Floor 15 & Law offices, court rooms and conference rooms \\
\hline Floor 16 & Storage, offices and judges chambers \\
\hline Floor 17 & 6 district court rooms, 2 courts open to $18^{\text {th }}$ story (est. 95 people) \\
\hline Floor 18 & Most of floor is open to below \\
\hline Floor 19 & Similar to $17^{\text {th }}$ floor \\
\hline Floor 20 & Mechanical room, cells and some spaces open to below \\
\hline
\end{tabular}




\subsection{HVAC System Description}

\subsubsection{Heating}

The boiler plant consists of three gas-fired, steam boilers located in the basement of the building. These high-pressure boilers serve steam to the heating coils in the air-handling units and to shell and tube heat exchangers generating domestic hot water. The steam generated by the boilers is piped to the eight main air-handling units at 150 psig. Seven smaller air-handlers, located in the basement and sub-basement receive steam that has been reduced in pressure. Fourteen air-handlers in the penthouse receive steam at the reduced pressure of 15 psig. Condensate from the steam heating system is returned for use by a de-aerating feed water heater. There is no central condensate tank and two pumps are used to return the condensate back to de-aerator.

There is a fourth "pony" boiler that provides steam to the heat exchanger for the domestic hot water and cafeteria hot water when the three main boilers are not operating. This boiler operates during the nighttime in order to maintain service hot water.

\subsubsection{Cooling}

Three water-cooled chillers serving eight large dual-duct air-handling units and five multi-zone systems cool the building. There are two air-cooled chillers on the roof, which serve chilled water to fourteen air handlers in the penthouse. These air-handling units provide air-conditioning to 24 courtrooms located on floors 16 to 19 in the building. Two additional air-cooled chillers provide chilled water to fan-coil units serving floors 12 and 13, which house FBI offices. Condenser water from these chillers acts as the heatrejection medium for several water-cooled air-conditioning units located throughout the building.

There are six cooling towers on the roof in two groups: three on the west side and three on the east side of the building.

\subsubsection{Air Distribution}

Eight large air-handling units provide conditioned air to the building. Thirteen packaged chilled water and steam heated units provide conditioned air to the courtrooms. A multizone unit provides conditioned air to the offices and holding cell area occupied by the U.S. Marshall's Service, as well as to the machine spaces located on the $20^{\text {th }}$ floor. The main supply fans also condition a large portion of the FBI floors 12 and 13. The fan-coil units provide air to the areas on the FBI floors that are occupied 24 hours per day.

The hot and cold decks in the dual-duct air-handling units are controlled by pneumatic systems. Variable frequency drives (VFD) are installed on the supply and return fans and varying the speed of the supply fan controls the average of the hot and cold duct static pressures. The static pressure sensors are located at the ends of the ducts on each floor, typically on the North side of the building. The dual duct VAV boxes are fully DDC. The courtroom air-handling units are all constant-volume systems. Several cold-ductonly terminals are also constant-volume. 


\subsection{Control Retrofits}

At the time of this report, the systems accessible from the BACnet supervisory controller workstations were as follows:

- Eight main air-handling units

- Approximately 1000 terminal units

- Miscellaneous packaged and computer room units

- Selected central plant equipment

- Courtroom HVAC systems serving Floors 17 through 20, including 13 singlezone and one multi-zone air-handler, all served by a dedicated chiller system.

Future work will link the following to the BACnet system:

- Lighting control system installed on the GSA floors 3-5.

- A pre-BACnet EMS installed on the FBI floors.

- The local utility company.

As part 'of the EMCS installation, several improvements were planned to the control strategies and these are listed in Table 2-2. The changes that have been made at the time of this report are identified in bold text, along with the completion dates.

Table 2-2: Control Strategy Retrofits

\begin{tabular}{|l|l|}
\hline RETROFIT DESCRIPTION & $\begin{array}{l}\text { COMPLETION } \\
\text { DATE }\end{array}$ \\
\hline VAV terminal box control (single and dual duct) & $\mathbf{1 0 / 9 6 - 1 2 / 9 7}$ \\
\hline Automated plant scheduling & $\mathbf{0 3 / 9 7}$ \\
\hline Temperature and enthalpy based economizer (CO, override) & $\mathbf{0 8 / 9 7}$ \\
\hline Replace pneumatically controlled VAV boxes with DDC boxes & $\mathbf{1 1 / 9 7}$ \\
\hline Time of day control for exhaust fans & to be done \\
\hline Night setback & to be done \\
\hline Supply air temperature reset & to be done \\
\hline Chiller sequencing, lead-lag and rotation & to be done \\
\hline Chilled water temperature reset & to be done \\
\hline Cooling tower condensate temperature reset & to be done \\
\hline $\begin{array}{l}\text { Cooling tower fan power conservation based on ambient } \\
\text { conditions }\end{array}$ & to be done \\
\hline Cooling tower fan lead-lag, rotation & to be done \\
\hline
\end{tabular}

There is uncertainty regarding specifically when or if particular control features were implemented. The building operators received training regarding the control software and are now in the process of identifying improved control parameters through a traditional trial and error process. Such a process is likely to continue indefinitely, as the operators become more aware of the capabilities of the new EMCS system and gain experience with exercising the control capabilities. 
For our analysis, we used January through December 1996 as the pre-retrofit period, January through December 1997 as the retrofit period and January through December 1998 as the post-retrofit period.

The following system details applied to the pre-retrofit period:

- The main air-handlers used $100 \%$ outside air until March 1996, when the mixing control became operational (BGA 97, p.44). Note that mixing damper control became operational across main air-handlers gradually as asbestos abatement program was completed.

- Additional boiler use was needed for the increased air flow during the $100 \%$ OA period (personal communication, W. Sitterly 5/1997)

- The dual-duct and single-duct VAV terminal units were operated at constant volume (BGA 97, p.45).

- Half of the VFDs were in "by-pass" mode [ESS 3/30/94 p8]

- Remaining VFDs were manually set and held at $80 \%$ load [ibid.]

The following activities affected the air handling systems during the post-retrofit period.

- Scheduled start/stop - this control strategy allows the air systems to start and stop based upon a programmable time-of-day control.

- VAV terminal box control - before the retrofits, the terminal boxes were operated as constant volume mixing boxes. Although the control drawings showed the existing system control of the dual duct mixing boxes to be variable volume, a field change order resulted in the installation of constant volume controls. The boxes were equipped for VAV control, but were field modified to provide $\mathrm{CV}$ control. The space thermostat was originally intended to modulate both the hot and cold dampers. However, the thermostat connection to the hot damper controller was removed, which resulted in a hot damper operating to maintain a constant air flow from the box, compensating for the amount of cold air being delivered as a function of the space temperature. Variable-volume control was activated as the VAV box controls were modified.

- Economizer control - the mixing boxes are controlled based upon the supplyair setpoints, the return-air temperature, and the outside-air temperature. When the majority of the system is in the cooling mode, the outside-air is used if its temperature is less than that of the return-air. $\mathrm{CO}_{2}$ sensors override economizer operation and provide $100 \%$ outside-air when $\mathrm{CO}_{2}$ levels exceed $800 \mathrm{ppm}$.

Table 2-3 lists the other changes in the building. The first four items occurred before the end-use monitoring period and are listed for information only. The last item, lighting controls retrofit, is ongoing at this time with an extensive research and demonstration 
component focused on floors 3,4, and 5. It is anticipated that the results of this research will be used to implement appropriate lighting control strategies for the balance of the building in the future.

The asbestos abatement process was a multi-year activity involving efforts on two floors at a time over the period 1987-1995. This involved moving two floors of tenants out of the building at the outset, and then transferring employees from one floor to another until the entire building was treated. During the process the air-handlers were set to $100 \%$ outside air to ensure that asbestos fibers were not distributed by the ventilation system and that positive pressure was maintained. Lighting and plug loads were increased due to the energy associated with having the lights on continuously on the floors being treated and the loads associated with various fans and tools used to complete the asbestos abatement.

Similarly the lighting retrofit was conducted over a multi-year period, with floors 9,10 , and 11 converted from T-12 with magnetic ballast to T-8 with energy saving ballasts, and the $\mathrm{T}-12$ lamps on floors 12,13 , and 14 converted from magnetic to electronic ballasts once asbestos abatement was completed. Remaining conversions from T-12 with magnetic ballasts to T-8 with electronic ballasts are scheduled to begin in 1999.

An unusual change occurred when the six story building to the south of 450 Golden Gate was demolished in the summer of 1996 , and replaced with a sixteen level structure later in the summer. This change had the affect of initially increasing the solar gains on the structure immediately after the demolition, and then decreasing the solar gains as the new structure was constructed.

Table 2-3: Building change chronology independent of EMCS retrofits

\begin{tabular}{|l|l|l|}
\hline CHANGE DESCRIPTION & IMPACT & $\begin{array}{l}\text { COMPLETION } \\
\text { DATE }\end{array}$ \\
\hline $\begin{array}{l}\text { Initial building construction } \\
\text { completed }\end{array}$ & 1962 \\
\hline Asbestos abatement program & $\begin{array}{l}\text { Increased ventilation and } \\
\text { lighting loads on affected } \\
\text { floors }\end{array}$ & $1987-1995$ \\
\hline $\begin{array}{l}\text { Variable frequency drives installed } \\
\text { on supply fans }\end{array}$ & $\begin{array}{l}\text { Reduced fan power draw and } \\
\text { electric loads }\end{array}$ & 1995 \\
\hline $\begin{array}{l}\text { Fitness center addition } \\
\text { on SSBW-1 air handler }\end{array}$ & $\begin{array}{l}\text { Added plug and HVAC loads } \\
\text { on }\end{array}$ & $1995-1996$ \\
floors other than 9-14 & $\begin{array}{l}\text { Increase lighting efficiency } \\
\text { and reduce electric load }\end{array}$ & 1996 \\
\hline $\begin{array}{l}\text { Calibrate, adjust, repair motion } \\
\text { detectors in conference and rest } \\
\text { rooms }\end{array}$ & $\begin{array}{l}\text { Reduce lighting hours of } \\
\text { operation and electric load }\end{array}$ & March 1996 \\
\hline $\begin{array}{l}\text { Economizers on main air-handlers } \\
\text { enabled }\end{array}$ & $\begin{array}{l}\text { Reduce chiller hours of } \\
\text { operation and electric load }\end{array}$ & March 1996 \\
\hline
\end{tabular}




\begin{tabular}{|l|l|l|}
\hline $\begin{array}{l}\text { Operate 15psi pony boiler to } \\
\text { maintain night-time hot water } \\
\text { temperatures }\end{array}$ & $\begin{array}{l}\text { Increase DHW system } \\
\text { efficiency }\end{array}$ & April 1996 \\
\hline $\begin{array}{l}\text { Increase DHW temperature to 155 } \\
\text { degrees }\end{array}$ & $\begin{array}{l}\text { Increase standby loss and } \\
\text { natural gas consumption }\end{array}$ & April 1996 \\
\hline $\begin{array}{l}\text { EGR exhaust return system installed } \\
\text { on boiler \#1 }\end{array}$ & $\begin{array}{l}\text { Improved boiler efficiency, } \\
\text { reduced natural gas load }\end{array}$ & Oct 1996 \\
\hline Instantaneous water heaters installed & $\begin{array}{l}\text { Added electric load, } \\
\text { decreased natural gas load }\end{array}$ & Nov 1996 \\
\hline $\begin{array}{l}\text { Install JCI pneumatic system and } \\
\text { lock-out chilled water valve during } \\
\text { warm-up }\end{array}$ & $\begin{array}{l}\text { Improved cooling system } \\
\text { performance }\end{array}$ & Summer 1996 \\
\hline 6 story building to south torn down & $\begin{array}{l}\text { Increased insulation and } \\
\text { cooling loads on South facing } \\
\text { zones }\end{array}$ & Summer 1996 \\
\hline 16 story building to south constructed & $\begin{array}{l}\text { Reduced insulation and } \\
\text { cooling loads on South facing } \\
\text { zones }\end{array}$ & Fall 1996 \\
\hline $\begin{array}{l}\text { Lighting controls retrofit (floors 3 } \\
\text { and 5) }\end{array}$ & $\begin{array}{l}\text { Reduce lighting hours and } \\
\text { electrical load }\end{array}$ & 1997 \\
\hline
\end{tabular}

\subsection{Sequence of Operations}

The post-retrofit sequences of operations as specified in the as-built system documentation are described below.

\section{Main air-handling units (from Johnson Control Drawings)}

The eight main air-handling units have the following temperature control strategy:

- Economizer:

- reset to full outside air when the fans are not running

- modulate dampers to maintain $55 \mathrm{~F}\left(12.8^{\circ} \mathrm{C}\right)$ when fans are running

- utilize temperature-based economizer

- during modulation of dampers, minimum outside air damper position is fixed

- Cooling coil:

- chilled water valve is modulated to maintain $56 \mathrm{~F}\left(13.3^{\circ} \mathrm{C}\right)$

- Heating coil:

- steam heating valve is modulated to a setpoint, which was supposed to be determined based on a schedule related to the hot-deck static pressure. However information from the building indicates that this is not yet implemented and the setpoint is fixed at 90F $\left(33.3^{\circ} \mathrm{C}\right)$.

- Warm-up control (when the return air temperature is below $60 \mathrm{~F}\left(15.6^{\circ} \mathrm{C}\right)$ ):

- close chilled-water valve

- operate economizer on full return air

- set hot-deck temperature to $100 \mathrm{~F}\left(37.8^{\circ} \mathrm{C}\right)$ 
The fans in the main air-handlers are controlled by operating the variable-frequency drives in order to maintain the average of the hot- and cold-deck static pressures to a setpoint of 1.0" W.G. (249 Pa). A high limit is set on the static pressure of $8.0 \mathrm{~W}$.G. $(1992 \mathrm{~Pa})$, at which point the fans cut off. During the warm-up period, the fans are modulated to maintain 1.0" W.G. in the hot deck only. PI control algorithms are used in the local loop controllers.

\section{VAV Terminal Units (from Trane documentation)}

PI control is used to control zone temperatures by varying primary airflow between maximum and minimum limits. Before the retrofits, the terminal units were operated at constant volume airflow rate.

\subsection{Utility Bill Histories}

In order to evaluate the performance of the retrofits we needed to establish a pre-retrofit baseline. Given the changes to the building over the past ten years, there is no single year that best typifies "pre-retrofit" consumption. While we discuss the selection of the preand post-periods in Section 3 Energy Analysis, we provide here a summary of the historic energy use of the building.

Electricity and natural gas are provided to the building by the local utility, PG\&E. The electrical service has two main feeds at $12 \mathrm{kV}$, with two whole-building meters. No submetering exists at present for tenants, although it is planned for the future. These meters measure all mechanical, electrical, lighting and miscellaneous loads.

Table 2-4: Historic annual average electricity consumption and cost

\begin{tabular}{|c|r|r|r|}
\hline Year & $\begin{array}{c}\text { Electricity } \\
\text { Use } \\
\text { [kWh/day] }\end{array}$ & $\begin{array}{c}\text { Electricity } \\
\text { Demand } \\
\text { [Max kW] }\end{array}$ & $\begin{array}{c}\text { Electricity } \\
\text { Cost } \\
\text { [\$] }\end{array}$ \\
\hline 1992 & 50,505 & 5,342 & $1,490,559$ \\
\hline 1993 & 51,327 & 6,148 & $1,876,290$ \\
\hline 1994 & 45,178 & 7,538 & $1,615,053$ \\
\hline 1995 & 47,809 & 5,493 & $1,695,891$ \\
\hline 1996 & 48,307 & 5,018 & $1,551,552$ \\
\hline 1997 & 48,704 & 4,752 & $1,514,342$ \\
\hline 1998 & 47,275 & 4,939 & $1,511,504$ \\
\hline
\end{tabular}

Figure 2-1 shows monthly electricity consumption of the whole building from 1992 to 1998. Electricity use has been fairly constant over the past seven years, with the most recent year (1998) averaging $47,275 \mathrm{kWh} /$ day, down from a high of $51,327 \mathrm{kWh} / \mathrm{day}$ in 1993.

Figure 2-2 shows the same data, but each month represents the average of the previous twelve months, which gives a better indication of the overall trends. The annual average over the past seven years has been $48,380 \mathrm{kWh} /$ day, with a standard deviation of 2,039 
$\mathrm{kWh}$ /day, an average variation from year-to-year of about 4 percent. At an average cost of $\$ 0.0815 / \mathrm{kWh}$, the annual cost for electricity in 1998 together with additional charges was $\$ 1,511,504$.

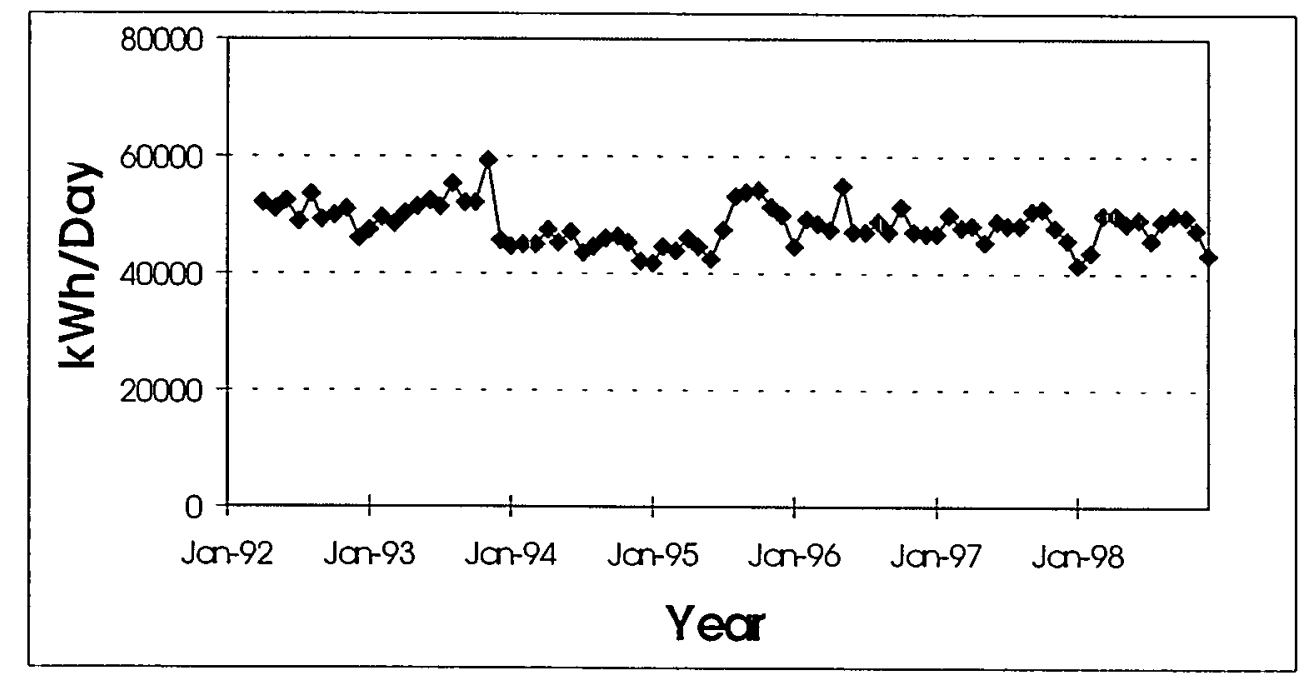

Figure 2-1: Monthly electricity consumption of the whole building, 1992-1998.

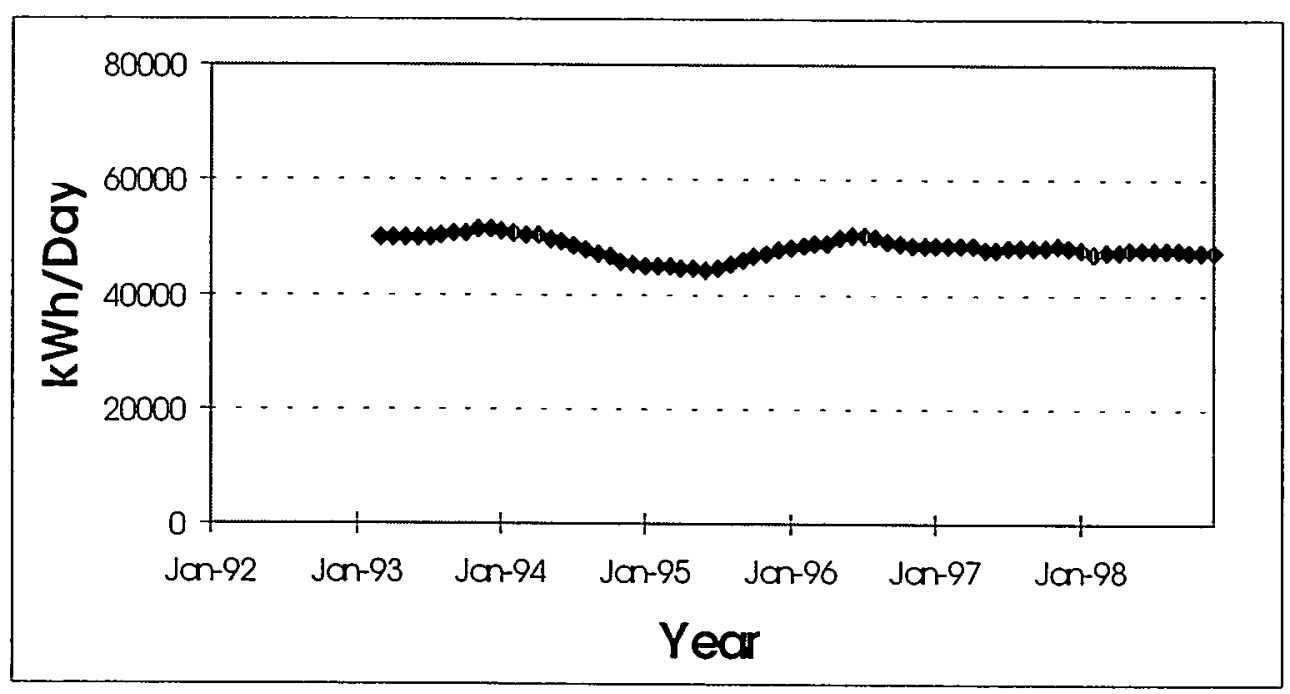

Figure 2-2: Monthly electricity consumption of the whole building, as rolling 12-month averages, 1992-1998.

The month-to-month variation in electricity use is small, varying less than $10 \%$ from the mean, and showing little seasonal variation. In 1996 the lowest month was January $(44,500 \mathrm{kWh} /$ day $)$ and the highest was October (51,360 kWh/day).

Figure 2-3 shows electricity demand from 1992 to 1998. The maximum electricity demand for the building typically occurs in July and August; the average between 199296 was $5375 \mathrm{~kW}$. The yearly variation in annual maximum demand has been between a 
high of $7538 \mathrm{~kW}$ in August 1994 and a low of $4752 \mathrm{~kW}$ in October 1997. Figure 2-4 shows electricity demand from 1992 to 1998 as rolling twelve-month averages.

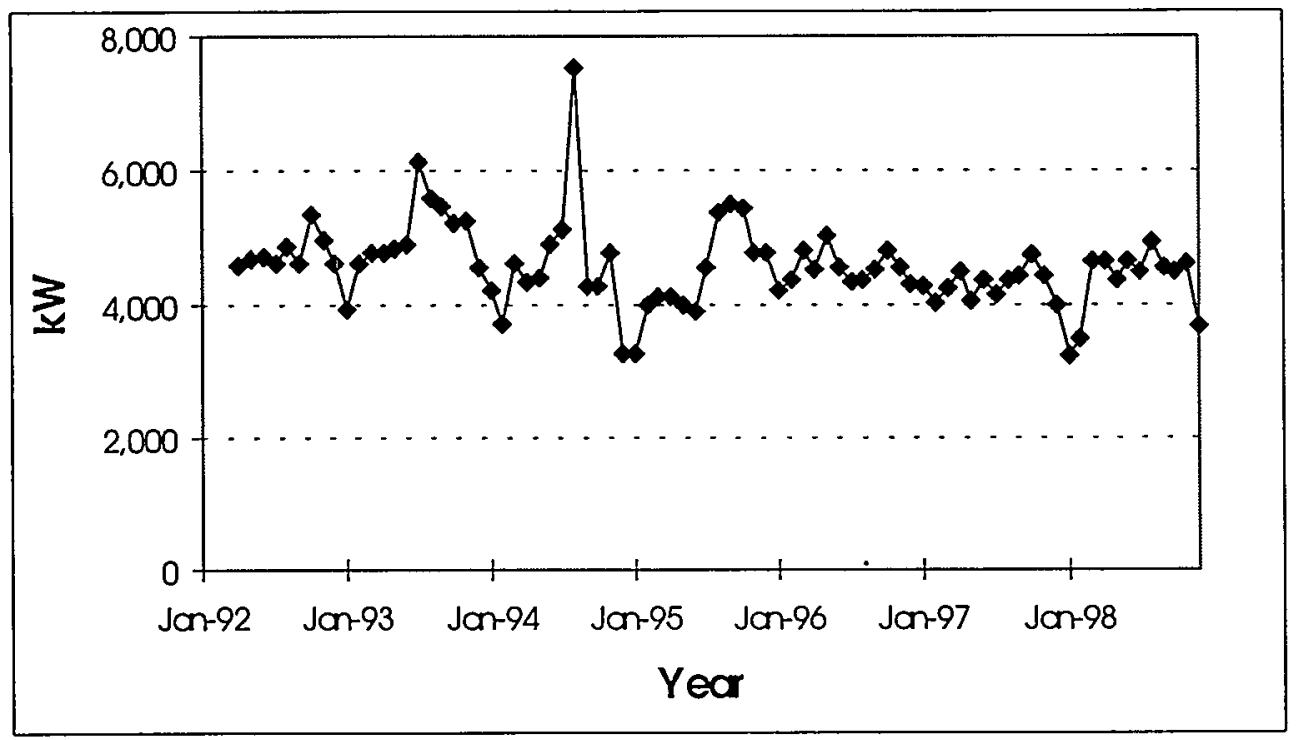

Figure 2-3: Monthly maximum electricity demand of the whole building, 1992-1998.

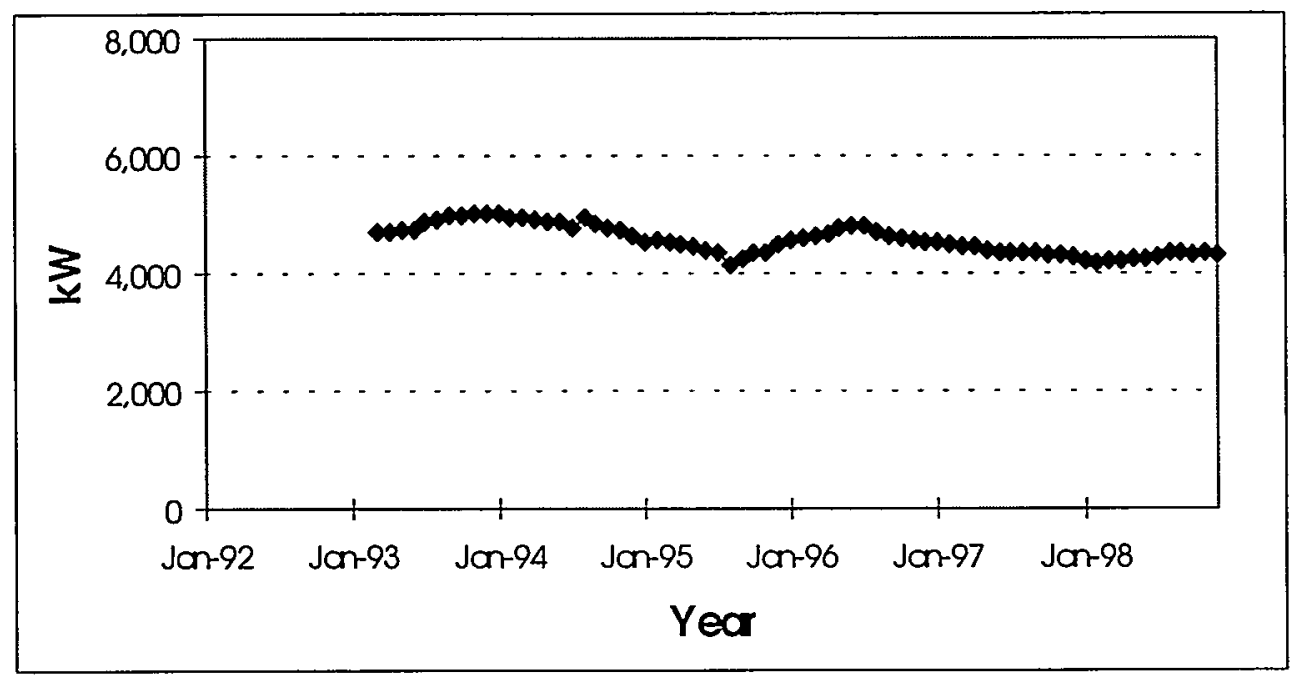

Figure 2-4: Monthly maximum electricity demand of the whole building, as rolling 12month averages, 1992-1998.

Figure 2-5 shows annual gas use has jumped around between 1992 and 1998, with a high of 1452 Therms/day (1994) and a low of 980 Therms/day (1998). The annual mean for the six years was 1,193 Therms/day, with a standard deviation of 181 Therms/day, a variation of 15 percent. At an average cost of $\$ 0.32 /$ therm, the annual cost for gas in 1996 was $\$ 146,800$. Figure 2.6 shows the trends of the rolling twelve-month average gas consumption from 1992 to 1998. 


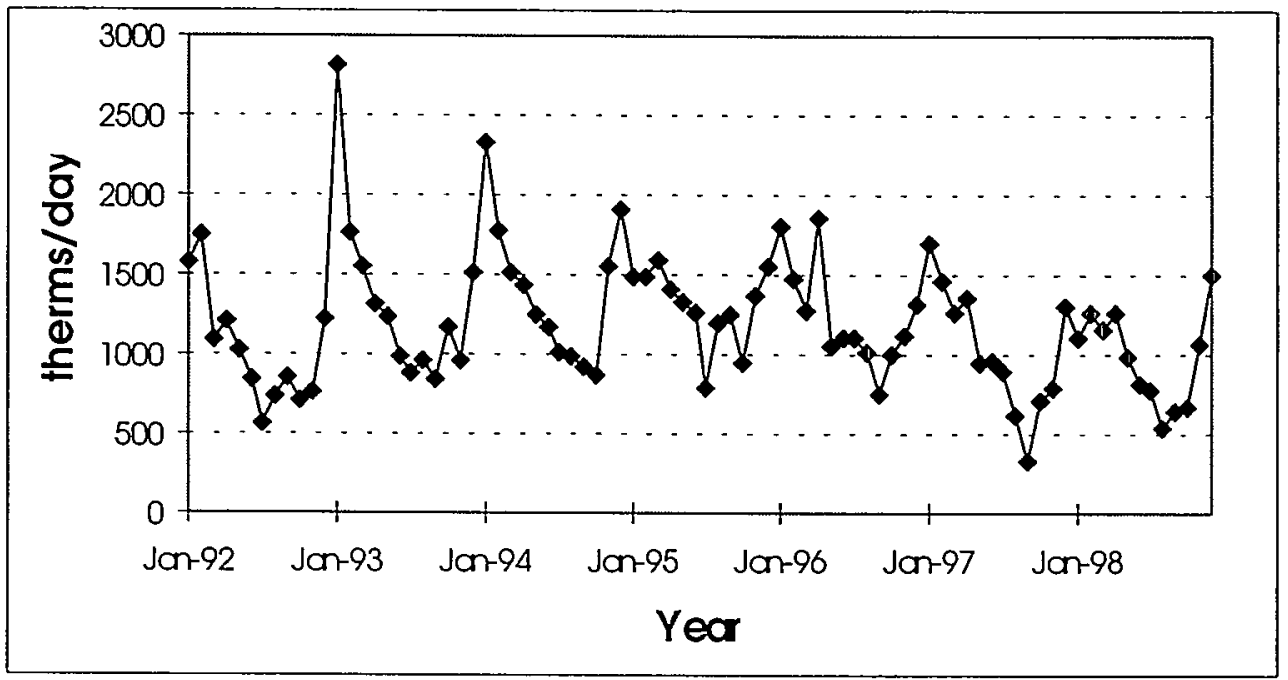

Figure 2-5: Monthly gas consumption of the whole building, $1992-1998$.

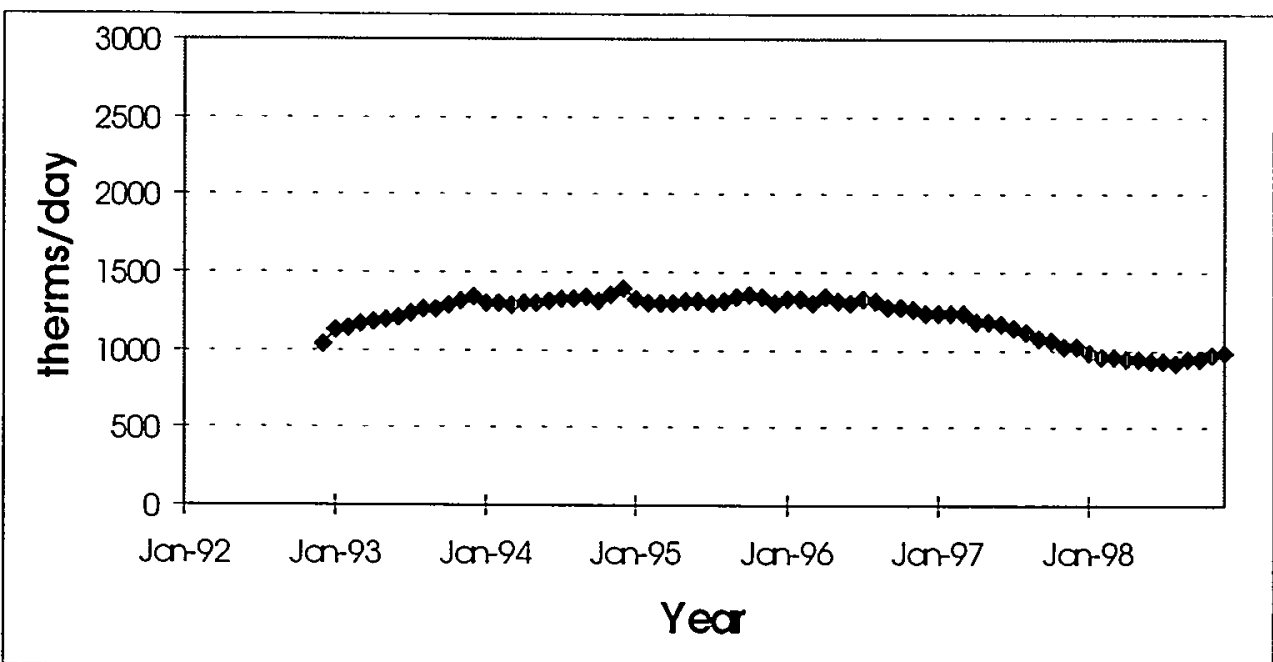

Figure 2-6: Monthly gas consumption of the whole building, as rolling 12-month averages, 1992-1998.

The gas use varies month-to-month, with high consumption in winter months and low consumption in summer. In 1996 the peak month was March (1860 Therms/day) and the low month was August (750 Therms/day). 
Table 2-5 Historic Annual Average Gas Consumption and Cost

\begin{tabular}{|c|r|r|r|}
\hline Year & \multicolumn{1}{|c|}{$\begin{array}{c}\text { Gas } \\
\text { Use } \\
\text { [therms/day] }\end{array}$} & $\begin{array}{c}\text { Gas } \\
\text { Use } \\
{[\mathbf{k W h} / \text { day] }}\end{array}$ & \multicolumn{1}{c|}{$\begin{array}{c}\text { Gas } \\
\text { Cost } \\
{[\$]}\end{array}$} \\
\hline 1992 & 1,029 & 30,049 & 122,905 \\
\hline 1993 & 1,337 & 39,362 & 165,927 \\
\hline 1994 & 1,391 & 41,940 & 169,081 \\
\hline 1995 & 1,303 & 38,162 & 130,596 \\
\hline 1996 & 1,238 & 36,258 & 146,824 \\
\hline 1997 & 1,025 & 30,020 & 153,012 \\
\hline 1998 & 980 & 28,702 & 124,942 \\
\hline
\end{tabular}

Total utility costs. Figure 2-7 shows the total utility costs from 1992-1998, while Figure 2-8 shows a rolling 12-month average of the utility costs, which shows a decreasing trend. The combined gas and electric costs for 1996 were $\$ 1,698,800$, of which the majority (91\%) was for electricity. Using gross floor area (1.4 million square feet) this is a cost of $\$ 1.21$ per square foot. We have two estimates for the occupied floor area: 774,519 and $1,020,000$ square feet. Using these two values gives $\$ 2.19$ and $\$ 1.66$ per square foot, respectively, for energy costs. 


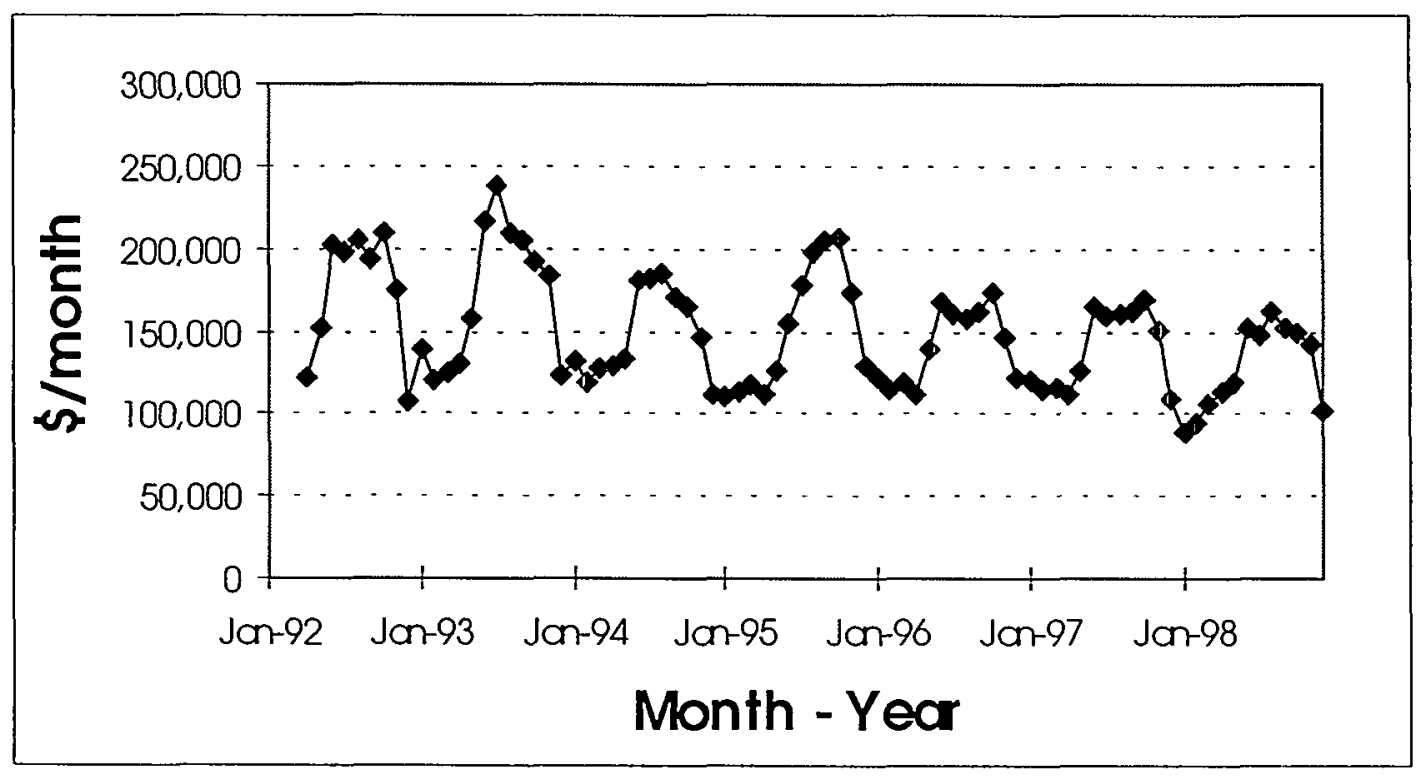

Figure 2-7: Total utility costs per month

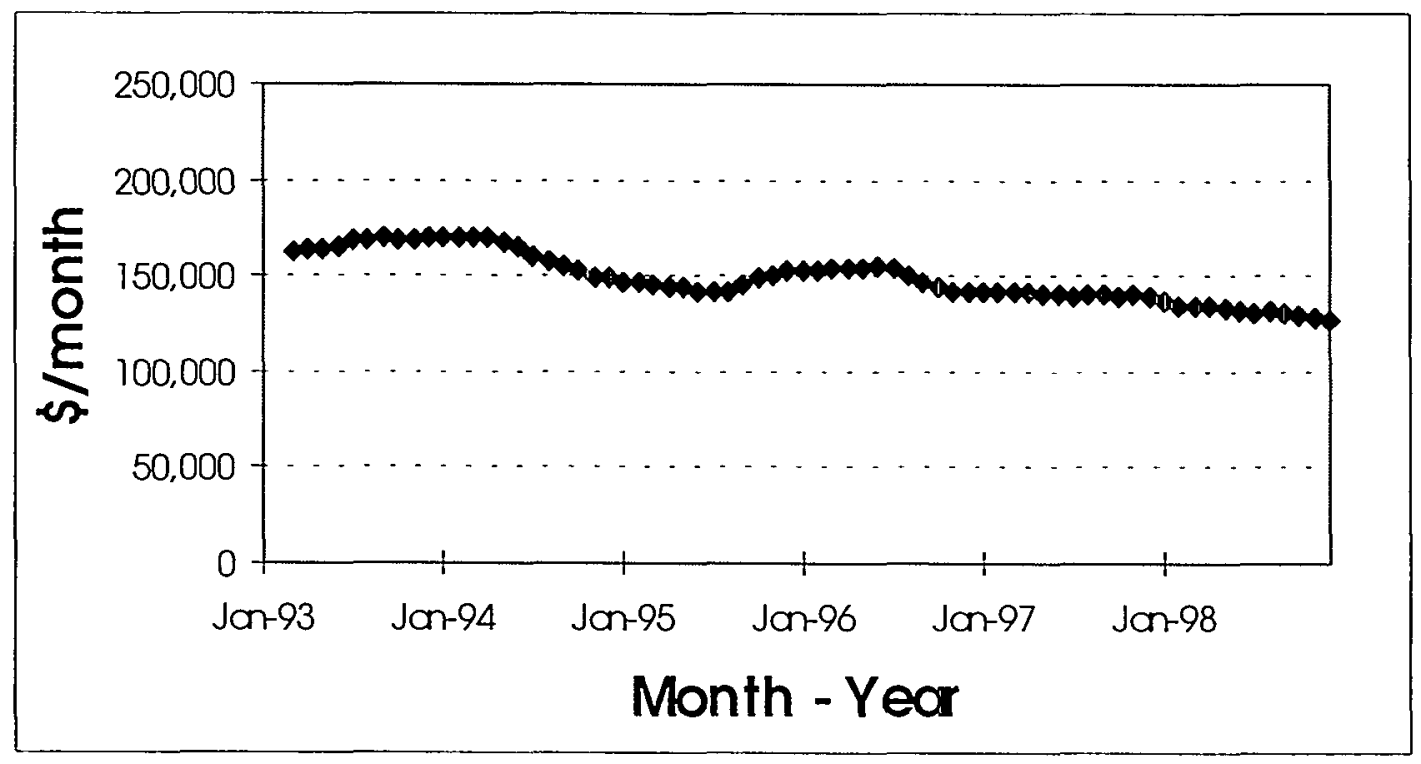

Figure 2-8: Utility costs as a 12 month rolling average 
Table 2-6 Annual Utility Costs

\begin{tabular}{|l|l|l|l|}
\hline Year & \multicolumn{1}{|c|}{$\begin{array}{c}\text { Electricity } \\
\text { Cost } \\
{[\$]}\end{array}$} & \multicolumn{1}{c|}{$\begin{array}{c}\text { Gas } \\
\text { Cost } \\
{[\$]}\end{array}$} & $\begin{array}{c}\text { Total } \\
\text { Utility Costs } \\
{[\$]}\end{array}$ \\
\hline 1992 & $1,490,559$ & 122,905 & $1,613,464$ \\
\hline 1993 & $1,876,290$ & 165,927 & $2,042,217$ \\
\hline 1994 & $1,615,053$ & 169,081 & $1,784,134$ \\
\hline 1995 & $1,695,891$ & 130,596 & $1,826,487$ \\
\hline 1996 & $1,551,552$ & 146,824 & $1,698,376$ \\
\hline 1997 & $1,514,342$ & 153,012 & $1,667,354$ \\
\hline 1998 & $1,511,504$ & 124,942 & $1,636,446$ \\
\hline
\end{tabular}

Energy Use Intensities. The Electrical Use Intensity using gross floor area (1.4 million square feet) averages around $12 \mathrm{kWh} / \mathrm{ft}^{2}$-yr from 1993-96, with the value for 1996 at 13 $\mathrm{kWh} / \mathrm{ft}^{2}$-yr. In site conversion for electricity, this value is $44 \mathrm{kBtu} / \mathrm{ft}^{2}$-yr. The gas use intensity for 1996 was $32 \mathrm{kBtu} / \mathrm{ft}^{2}-\mathrm{yr}$, for a total energy use intensity of $76 \mathrm{kBtu} / \mathrm{ft}^{2}-\mathrm{yr}$.

\section{Comparison with other Buildings}

The PBFB is a difficult building to compare with other buildings because it is so much larger than the rest of the stock. The best buildings we have for comparison are other federal buildings in the same region from 1993 (EIA FBSS, 1995). Figure 2-9 shows the energy use intensity of the PBFB compared to 157 other GSA buildings in Regions 3, 6 and 9 (which correspond to mid Atlantic, Southwest and West, respectively), to 39 other GSA buildings just in Region 9 and to 92 federal office buildings in Region 9. For further comparison, these are also compared to the sample of office buildings in the US and the sample of commercial buildings over $200,000 \mathrm{ft} 2$ from the CBECS data set (EIA, 1994).

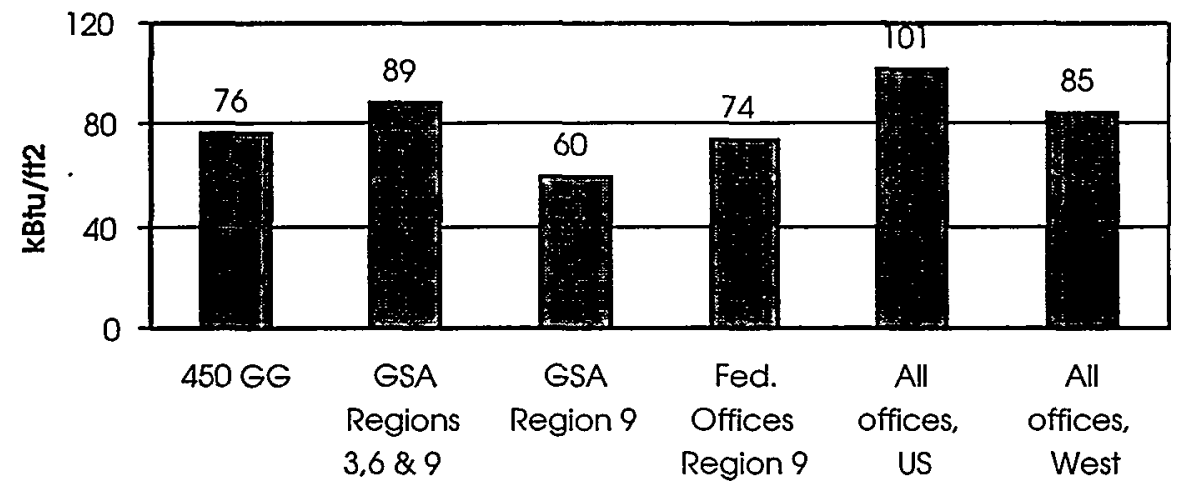


Figure 2-9: Energy Use Intensities (EUI) for comparison buildings.

From Figure 2-9, we can see that the 450 GG has a $25 \%$ less energy than the US stock of both offices and large commercial buildings, similar consumption to the other federal offices in Region 9 and consumes 20\% more than the GSA stock (office and non-office buildings) in Region 9.

Figure 2-10 shows dollars per square foot of floor area for the same comparison buildings in 1993 dollars. The PBFB energy costs were $\$ 1.21$ per square foot in 1993 , compared to $\$ 1.53 / \mathrm{ft} 2$ for other Federal office buildings in Region 9.

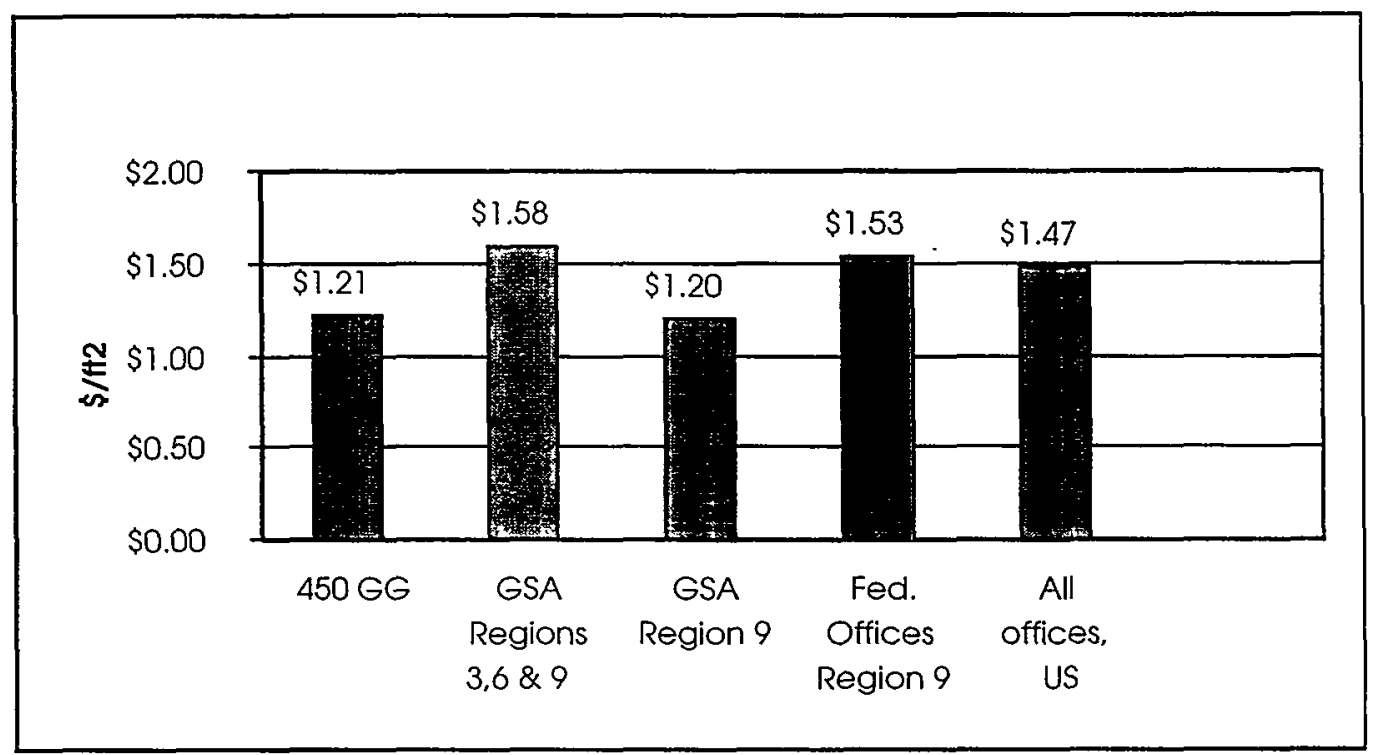

Figure 2-10: Energy Use Intensities (EUI) cost comparisons (\$1993).

\subsection{Predicted Savings from the ECMS Retrofit}

The preliminary savings predictions were based on assuming the following retrofit changes to the system:

- Individual floor scheduling for heating and cooling with optimized start

- After hour scheduling to match occupancy

- Economizer sequencing to maintain discharge temperature

- Supply air temperature will be reset based on fan speed and outside air temperature, resulting in fan energy savings and optimized cooling operation

In addition to these features, the graphics users' interface package with the EMCS was expected to improve the owner's scheduling capabilities and provide system diagnostics.

The predicted savings from the EMCS retrofits were based on the installation of individual pressure differential sensors on every other floor. These sensors would allow the EMCS to discriminate and control to a minimum of 1" w.g., thereby reducing system 
static pressure at low-end conditions and subsequently reducing fan energy consumption (Bosek Gibson 1996 p. 72).

The original estimate (ESS, 3/30/94) for the savings from the EMCS retrofit was for $\$ 355,500$, which is an $18 \%$ reduction in annual utility costs, based on the estimated 1993 utility costs of $\$ 1,975,000$. The DDC air-side control was predicted to be responsible for $70 \%$ of the total cost savings in the building $(\$ 266,625)$, which is $13 \%$ of total building cost savings. The lighting control retrofits were predicted to be responsible for $25 \%$ of the savings, and the remaining $5 \%$ was predicted to be due to improved control of the boilers and chillers.

The calibrated computer simulation (Bosek Gibson, 1997) predicted the annual savings from the EMCS retrofit to be $\$ 359,000$. The electricity savings were predicted to be $3,175,725 \mathrm{kWh} / \mathrm{yr}$, or 20 percent of the building's total electrical consumption. The savings for activating the mixing damper controllers/economizers added an additional $\$ 42,781$, for a total of $\$ 401,780$ savings.

This allocation of savings puts savings at their "point of origin". For example, DDC of air handlers reduces building heating and cooling loads (by reducing re-heat and re-cool loads, improved economizer controls, etc.) in addition to reducing fan energy (through optimum start/stop and improved VAV control). Thus the savings associated with heating and cooling are allocated to the DDC airside control, and not to chiller and boiler optimization.

The 1994 estimated cost for the EMCS retrofits and repair was $\$ 2,320,000$. The updated Phase II Summary attached to the 6/2/97 ESS Progress Meeting Notes gives the savings estimate for the controls retrofit as $\$ 536,000$ and gives $\$ 3.5$ million as the cost. 


\section{Energy Analysis}

In this section, archived data from a suite of sensors is used to analyze the energy use in the building and its systems. These data facilitate a more detailed analysis than is possible with utility records and allow the energy use in certain HVAC to be isolated. The purpose of the analysis is to ascertain changes in energy usage resulting from the retrofits. The analysis consisted of using data from two equivalent seasonal periods, one period before the installation of the retrofits, and one period after.

\subsection{Building Sensor Suite}

A measurement plan for the building was developed by PG\&E and provided to New Horizon Technologies in August 1995 (SBW, 1997). The last sensor was installed in September 19, 1995, at which time routine data logging was initiated. Appendix A provides details of the analysis plan. Eleven Synergistic C-180 data-loggers were installed to collect data at 15 -minute sample intervals from 123 individual sensors. The sensors fall into one of the following categories:

- True power consumption

- Natural gas consumption

- Steam production

- Temperature

- Relative Humidity

SBW Consulting Incorporated was contracted to retrieve data from the data loggers at regular intervals until the end of November 1998. Data retrieval was carried out over telephone lines using Synernet software and a custom interface. Clock and parameter sets within each data logger were checked each time they are interrogated and corrected if necessary from the polling computer. The polling computer time was calibrated to the Naval Observatory atomic clock before each polling session.

After the raw logger data files were retrieved, the data are converted to engineering units and stored into SAS files for each logger. The files were then merged into a single raw file and the following verification checks are made:

- Continuity checks are carried out to ensure that each 15-minute sample is present

- Range checks are performed in order to ensure logged values are within feasible ranges

- Relational checks to compare measurements with each other in order to ensure physical constraints are met

- Graphical checks are performed to identify and remove outlying points and data anomalies 
Details of the analysis plan and a list of all logged points is included in the appendices. Selected data from these channels are used to analyze the effect of the retrofits on system performance.

\subsubsection{Monitored HVAC Equipment}

The main energy consuming systems affected by the HVAC retrofits are: fans, chillers, and boilers. The following systems of these types were monitored by the data loggers:

- Fans:

8 courtroom fans (supply and return fans)

6 main air-handler fans ( 2 supply and 4 return fans)

- Chillers:

3 main chillers

2 courtroom chillers

2 FBI chillers

- Boilers:

Total gas consumption

The seven chillers listed above represent all the primary cooling plant in the building. Measurement of the total gas consumption includes all space heating and domestic hot water. The fans that were monitored represent only a subset (approximately one third by power rating) of the total number of fans in the building.

\subsubsection{Comparison of Monitored Data with Utility Bills}

Table 3-1 shows comparisons of monthly kWh electricity and kWh gas consumption for the pre- and post-retrofit periods. The monitored data from October 1996 were missing due to a fault with the data loggers. Similarly, there was a problem with the data logging during January 1996, which caused an absence of data samples for the first 25 days of the month. The missing data in the months of January and October lead to unrepresentative averages for these months.

Disregarding the months of January and October in 1996, the difference between the electricity consumption in the monitored and utility data varies between $-16 \%$ and $12 \%$. The gas consumption differences vary between $+3 \%$ and $-7 \%$. Monthly discrepancies may be attributable to different billing periods and practices, missing data, and rounding errors. The means of the monthly discrepancies, excluding the months of January and October in 1996, are small. The electricity consumption figures show only $1 \%$ and $-1 \%$ differences in the pre- and post-retrofit periods. The gas consumption figures show slightly greater differences at $-2 \%$.

The annualized average energy use figures for the whole of the pre- and post-retrofit periods, which are more important in this analysis, are quite consistent. Table 3-2 shows a comparison of the total gas and electricity use calculated from the monthly utility data and all available samples in the monitored data. The electricity consumption figures show only $1 \%$ and $-2 \%$ differences in the pre- and post-retrofit periods. The gas consumption figures differ by $1 \%$ and $-2 \%$ in the pre- and post-retrofit periods. 
Differences in the gas figures may be due to variations in natural gas heat content; a constant $1035 \mathrm{Btu} / \mathrm{ft}^{3}$ was assumed in the monitored data.

Table 3-1: Comparison of monitored data and utility billing data

\begin{tabular}{|c|c|c|c|c|c|c|c|c|}
\hline \multirow[t]{3}{*}{ Month } & \multicolumn{4}{|c|}{ Gas } & \multicolumn{4}{|c|}{ Electric } \\
\hline & Monitored & Utility & \multicolumn{2}{|c|}{ Difference } & Monitored & Utility & \multicolumn{2}{|c|}{ Difference } \\
\hline & \multicolumn{3}{|c|}{$\mathrm{kWh}$} & $\%$ & \multicolumn{3}{|c|}{$\mathrm{kWh}$} & $\%$ \\
\hline \multicolumn{9}{|c|}{ Pre-Retrofit } \\
\hline Jan-96 & $1,483,460$ & $1,632,280$ & 148,820 & 10 & $1,348,777$ & $1,425,600$ & 76,823 & 6 \\
\hline Feb-96 & $1,270,748$ & $1,247,413$ & $-23,335$ & -2 & $1,466,868$ & $1,476,000$ & 9,132 & 1 \\
\hline Mar-96 & $1,173,120$ & $1,159,990$ & $-13,130$ & -1 & $1,422,882$ & $1,555,200$ & 132,318 & 9 \\
\hline Apr-96 & $1,670,777$ & $1,635,209$ & $-35,568$ & -2 & $1,644,046$ & $1,375,200$ & $-268,846$ & -16 \\
\hline May-96 & 974,826 & 961,011 & $-13,815$ & -1 & $1,500,118$ & $1,648,800$ & 148,682 & 10 \\
\hline Jun-96 & 982,754 & 969,504 & $-13,250$ & -1 & $1,390,946$ & $1,504,800$ & 113,854 & 8 \\
\hline Jul-96 & $1,013,784$ & $1,001,691$ & $-12,093$ & -1 & $1,503,198$ & $1,411,200$ & $-91,998$ & -6 \\
\hline Aug-96 & 935,769 & 919,715 & $-16,054$ & -2 & $1,480,444$ & $1,418,400$ & $-62,044$ & -4 \\
\hline Sep-96 & 669,468 & 658,412 & $-11,056$ & -2 & $1,448,171$ & $1,504,800$ & 56,629 & 4 \\
\hline Oct-96 & $\mathrm{N} / \mathrm{A}$ & 912,628 & $\mathrm{~N} / \mathrm{A}$ & $\mathrm{N} / \mathrm{A}$ & N/A & $1,540,800$ & $\begin{array}{ll}N / A \\
\end{array}$ & N/A \\
\hline Nov-96 & $1,004,538$ & 985,232 & $-19,306$ & -2 & $1,400,690$ & $1,368,000$ & $-32,690$ & -2 \\
\hline Dec-96 & $1,200,464$ & $1,190,478$ & $-9,985$ & -1 & $1,433,017$ & $1,548,000$ & 114,983 & 8 \\
\hline \multicolumn{3}{|c|}{ Mean Difference (-Jan\&Oct) } & $-16,759$ & \multicolumn{3}{|c|}{\begin{tabular}{l|l|}
-2 & Mean Difference (-Jan\&Oct) \\
\end{tabular}} & 12,002 & 1 \\
\hline \multicolumn{9}{|c|}{ Post-Retrofit } \\
\hline $\operatorname{Jan}-98$ & $1,026,423$ & $1,009,130$ & $-17,293$ & -2 & $1,337,368$ & $1,281,600$ & $-55,768$ & -4 \\
\hline Feb-98 & $1,116,500$ & $1,033,058$ & $-83,442$ & -7 & $1,341,736$ & $1,346,400$ & 4,664 & 0 \\
\hline Mar-98 & $1,076,134$ & $1,048,434$ & $-27,701$ & -3 & $1,680,292$ & $1,497,600$ & $-182,692$ & -11 \\
\hline Apr-98 & $1,173,454$ & $1,106,247$ & $-67,207$ & -6 & $1,432,190$ & $1,598,400$ & 166,210 & 12 \\
\hline May-98 & 911,348 & 892,683 & $-18,665$ & -2 & $1,421,111$ & $1,411,200$ & $-9,911$ & -1 \\
\hline Jun-98 & 717,254 & 716,929 & -325 & 0 & $1,489,944$ & $1,432,800$ & $-57,144$ & -4 \\
\hline Jul-98 & 718,927 & 703,632 & $-15,295$ & -2 & $1,482,211$ & $1,368,000$ & $-114,211$ & -8 \\
\hline Aug-98 & 508,361 & 494,197 & $-14,163$ & -3 & $1,523,009$ & $1,569,600$ & 46,591 & 3 \\
\hline Sep-98 & 545,687 & 561,646 & 15,959 & 3 & $1,475,049$ & $1,497,600$ & 22,551 & 2 \\
\hline Oct-98 & 621,973 & 607,013 & $-14,960$ & -2 & $1,488,395$ & $1,440,000$ & $-48,395$ & -3 \\
\hline Nov-98 & 952,453 & 934,125 & $-18,328$ & -2 & $1,323,317$ & $1,382,400$ & 59,083 & 4 \\
\hline Dec-98 & $1,399,627$ & $1,364,153$ & $-35,474$ & -3 & $1,527,152$ & $1,382,400$ & $-144,752$ & -9 \\
\hline \multicolumn{3}{|c|}{ Mean Difference } & $-23,300$ & -2 & \multicolumn{2}{|c|}{ Mean Difference } & $-21,500$ & -1 \\
\hline
\end{tabular}

Table 3-2: Annualized comparisons of monitored and utility data

\begin{tabular}{|c|c|c|c|c|c|c|c|}
\hline \multirow[t]{3}{*}{ Year } & \multicolumn{3}{|c|}{ Gas } & \multicolumn{4}{|c|}{ Electric } \\
\hline & Monitored & Utility & Difference & Monitored & Utility & Differeno & \\
\hline & \multicolumn{3}{|c|}{$\mathrm{kWh}$} & \multicolumn{3}{|c|}{$\mathrm{kWh}$} & $\%$ \\
\hline \multicolumn{8}{|c|}{ Pre-Retrofit } \\
\hline 1996 & $13,091,090$ & $13,273,564$ & \begin{tabular}{l|l|l}
182,474 & \\
\end{tabular} & $17,609,790$ & $17,776,800$ & 167,010 & 1 \\
\hline \multicolumn{8}{|c|}{ Post-Ret } \\
\hline 1998 & $10,680,995$ & $10,471,248$ & $-209,747$ & $17,475,835$ & $17,208,000$ & $-267,835$ & -2 \\
\hline
\end{tabular}

Table 3-3 shows a comparison of the savings calculated from the utility data and the monitored data. The utility data shows greater savings in electricity at $2 \%$, compared with $1 \%$ calculated from the monitored data. More savings are also evident in the utility data in the gas consumption, at $21 \%$ compared with $18 \%$. The differences in the gas 
savings may be due in part to variations in heat content, but the missing monitored data in January 1996 is likely to have had a more significant effect.

Table 3-3: Comparison of savings calculated from utility data and from monitored data

\begin{tabular}{|l|r|r|r|r|}
\hline \multirow{2}{*}{ Utility } & Pre-Retrofit & Post-Retrofit & \multicolumn{2}{c|}{ Difference } \\
\cline { 2 - 5 } & $\mathrm{kWh} /$ day & $\mathrm{kwh} /$ day & $\%$ \\
\hline \multicolumn{5}{|c|}{ Utility Data } \\
\hline Total Energy & 84,565 & 75,977 & 8,588 & 10 \\
\hline Total Gas & 36,258 & 28,702 & 7,556 & 21 \\
\hline Total Electrcity & 48,307 & 47,275 & 1,032 & 2 \\
\hline \multicolumn{5}{|c|}{} \\
\hline Total Energy & Monitored Data \\
\hline Total Gas & 84,112 & 77,142 & 6,970 & 8 \\
\hline Total Electrcity & 35,866 & 29,263 & 6,603 & 18 \\
\hline
\end{tabular}

\subsection{Weather Data in Pre- and Post-Retrofit Periods}

The pre-retrofit and post-retrofit periods are taken to include the calender years of 1996 and 1998 respectively. Figure 3-1 shows the daily maximum and minimum ambient air temperatures in the monitored data during the pre- and post-retrofit periods. The preretrofit period exhibits higher minimum and maximum temperatures in February, October and through most of December. It is possible that the higher temperatures in February and December invoked a smaller load on the boiler plant for the pre-retrofit period. Conversely, the higher temperatures in October may have led to greater chiller loads. However, considering the whole of the calendar year periods, the differences are small, as shown in Table 3-4. The post-retrofit period is, on average, only 0.7 degree Kelvin colder than the pre-retrofit period.

Table 3-4: Mean outside air conditions during considered periods

\begin{tabular}{|l|r|r|l|}
\hline Period & $\begin{array}{l}\text { Temperature } \\
\text { (degC) }\end{array}$ & $\begin{array}{l}\text { Relative } \\
\text { Humidity (\%) }\end{array}$ & $\begin{array}{l}\text { Enthalpy } \\
(\mathrm{kJ} / \mathrm{kg})\end{array}$ \\
\hline Pre-retrofit & 14.6 & 71.7 & 32.7 \\
\hline Post-Retrofit & 13.9 & 72.9 & 31.7 \\
\hline
\end{tabular}



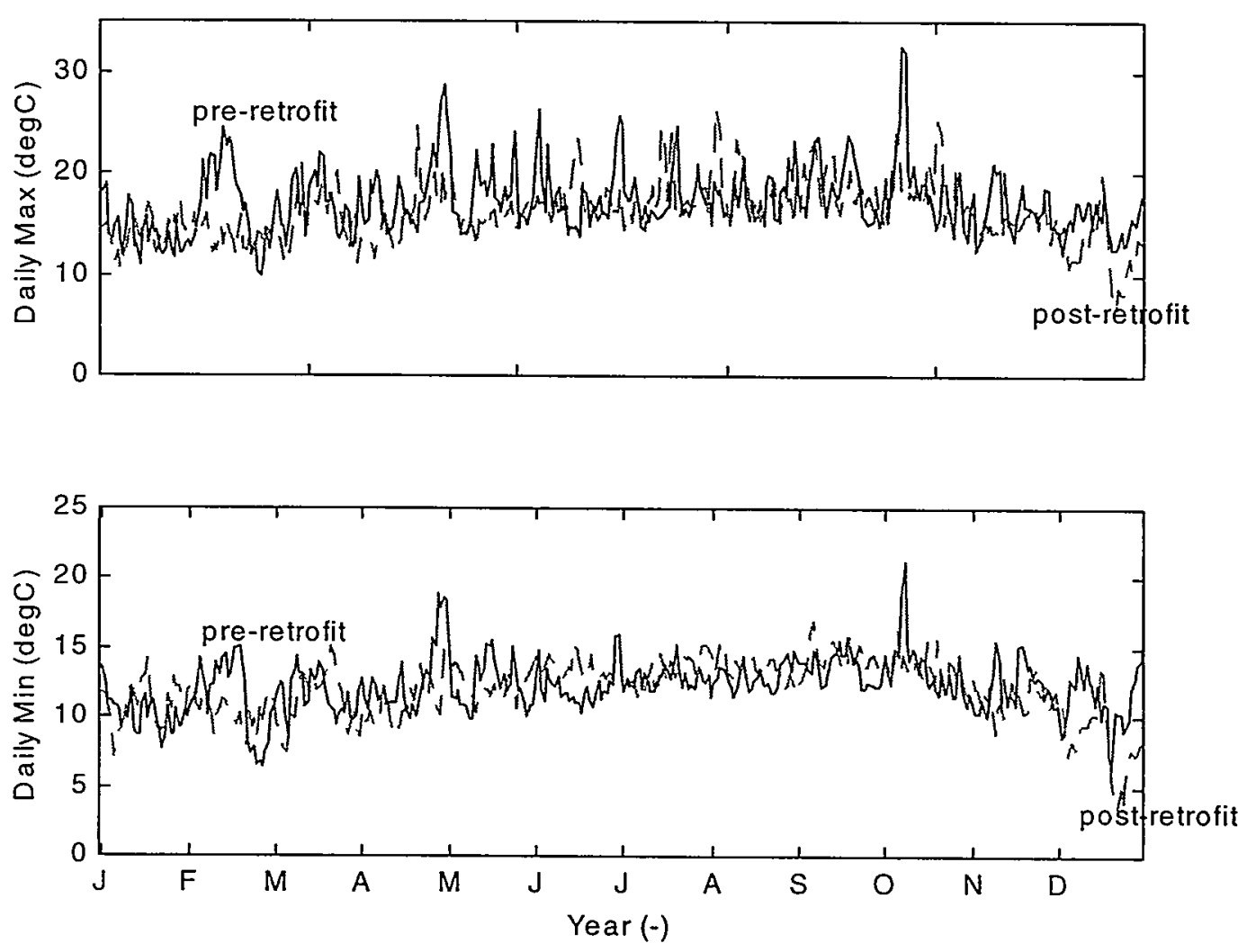

Figure 3-1: Pre-retrofit (solid line) and post-retrofit (dashed line) daily maximum and minimum ambient air temperatures

\subsection{Energy Usage in Monitored HVAC}

The energy usage of the monitored fans, chillers, and boilers are shown in Figure 3-2. In the figure, the daily energy use ( $\mathrm{kWh})$ is plotted for each day in the entire data set.

In Figure 3-2, the times when the energy for each of the systems approaches zero corresponds to the days when the systems were switched off, which is mostly during weekends and holidays. There are certain periods when the systems appear to have been left on for sustained periods, such as April 1996 for the boiler and fans, October 1997 for the fans, etc. This could be due to tenant-requested operation during these periods.

The boilers show the clearest seasonal variation in energy use, with January and February the peak months. Lowest boiler demand is in August and September. The annual chiller profile is more erratic, particularly during the retrofit period (all of 1997). Peaks are evident around September and October, but this is not consistent throughout the data. The fan energy is reasonably constant throughout the annual climatic cycle.

In terms of energy use, there is a marked reduction in the daily levels for the chillers between the pre- and post-retrofit periods. There is little reduction in the peak boiler 
energy, but the mean energy use is reduced as better tracking of seasonal load variations is evident in the post-retrofit period. The energy consumption of the boilers and fans increased during the month of April in the pre-retrofit period during the time when these systems appear to have been operated continuosly.

The overall changes in the building energy use are presented graphically in Figure 3-3, which shows the mean $\mathrm{kWh} /$ day energy use over the periods considered. Based on these figures, the total energy used in the building fell by $8.3 \%(84,112 \mathrm{kWh} /$ day to 77,142 $\mathrm{kWh} /$ day) between the pre- and post-retrofit periods. Significant relative reductions in energy use are evident in the monitored fans, chillers, and boilers. The relative savings for the different systems are listed in Table 3-5.
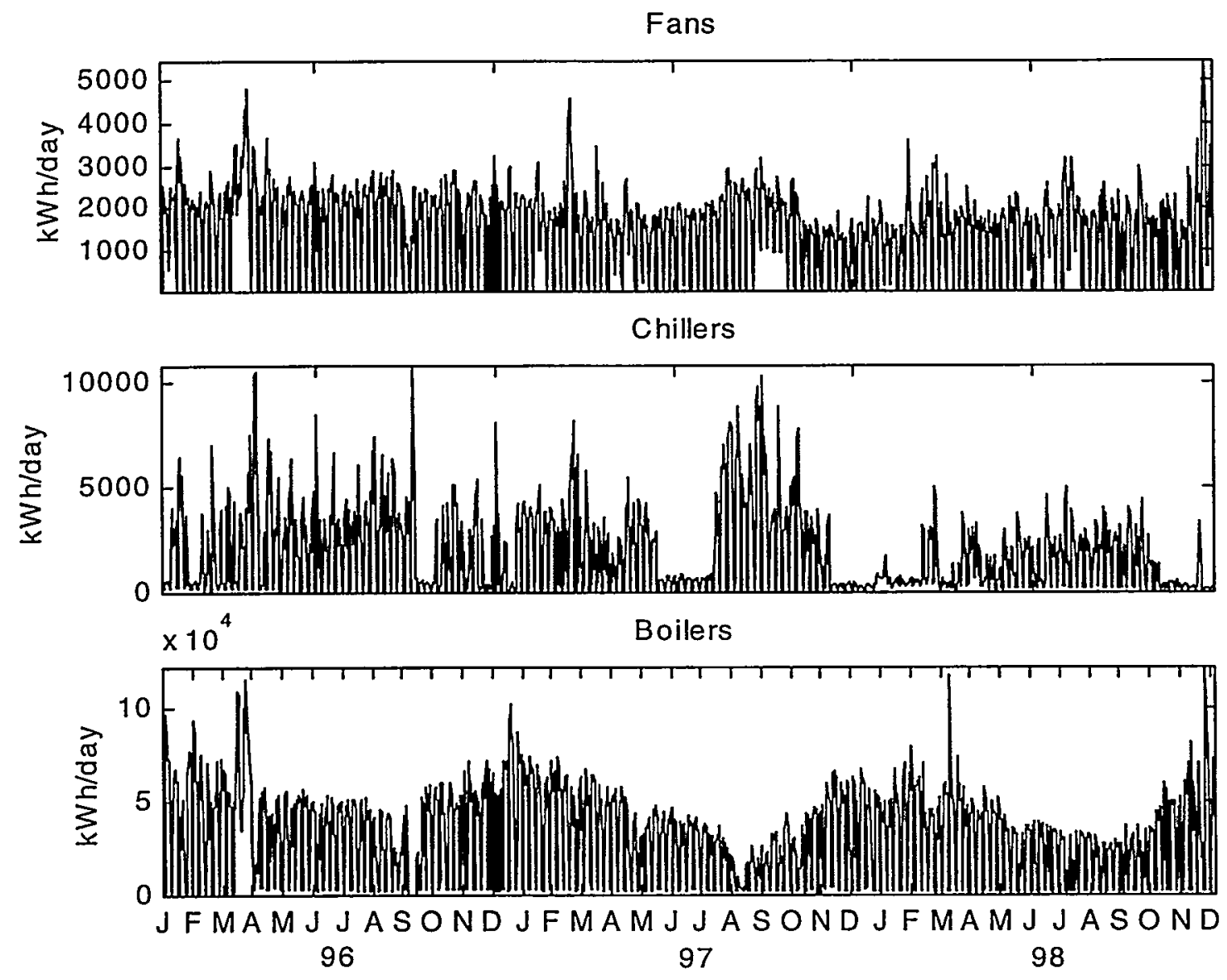

Figure 3-2: Daily energy consumption of main HVAC systems 


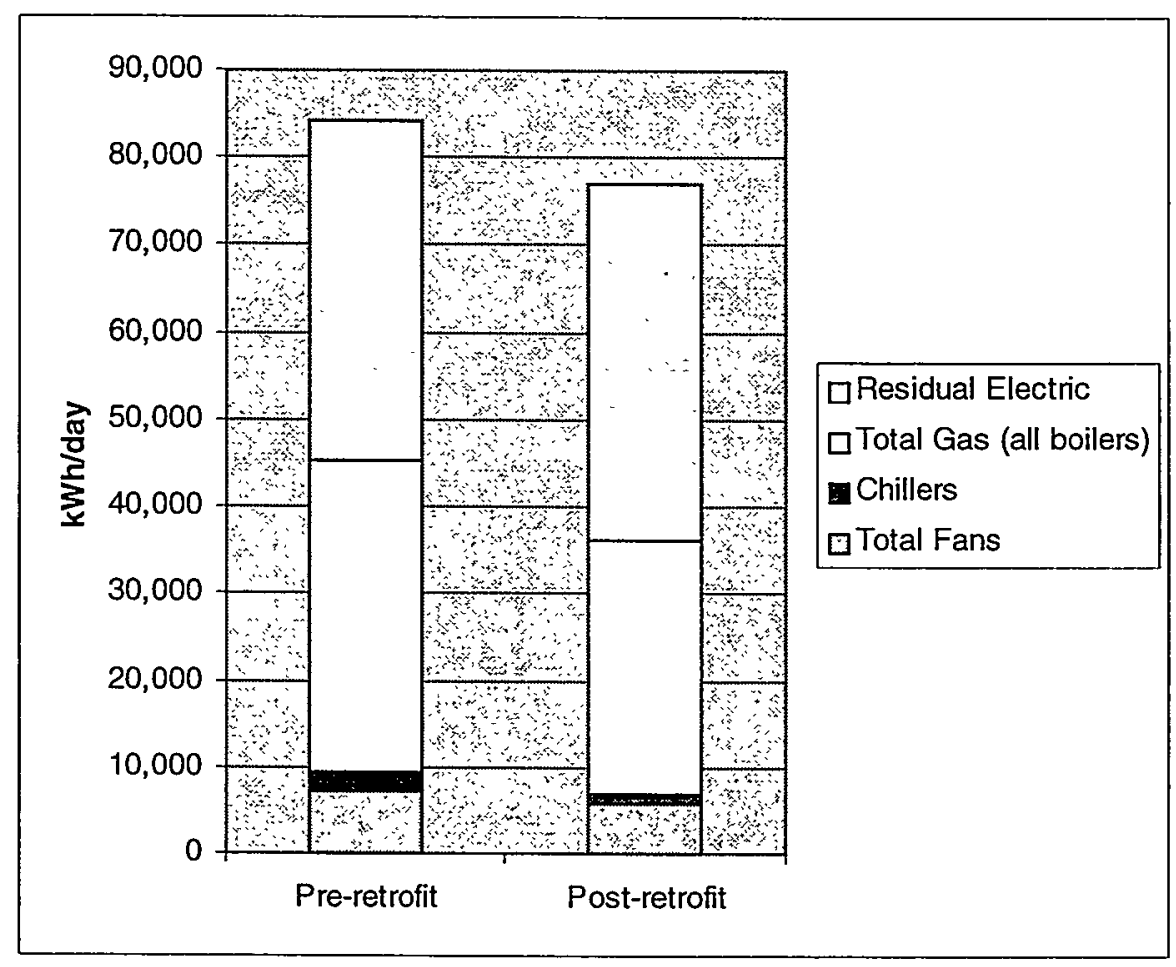

Figure 3-3: Mean energy use for pre- and post-retrofit periods

Table 3-5: Relative changes in mean daily monitored energy use from pre- to post-retrofit periods

\begin{tabular}{|l|r|r|r|r|}
\hline \multirow{2}{*}{ Equipment Type } & Pre-retrofit & Post-retrofit & \multicolumn{2}{|c|}{ Difference } \\
\cline { 2 - 5 } & kWh/day & $\mathrm{kWh} /$ day & $\mathrm{kWh} /$ day & $\%$ \\
\hline \multicolumn{5}{|c|}{ Overall Building } \\
\hline Total Energy Use \\
\hline Total Gas & 84,112 & 77,142 & 6,970 & 8.3 \\
\hline Total Electric & 35,866 & 29,263 & 6,603 & 18.4 \\
\hline \multicolumn{5}{|c|}{ Electricity Breakdown } \\
\hline $\begin{array}{l}\text { Monitored chillers (all } \\
\text { chillers) }\end{array}$ & 2,156 & 1,150 & 1,006 & 46.7 \\
\hline $\begin{array}{l}\text { Monitored fans (approx } \\
\text { 30\% of all fan power) }\end{array}$ & 1,720 & 1,379 & 341 & 19.8 \\
\hline Residual Electric & 44,370 & 45,350 & -980 & -2.2 \\
\hline \multicolumn{5}{|c|}{ Floor 7 Lights and Plugs } \\
\hline Lights & 378 & 365 & 13 & 3.4 \\
\hline Plugs & 257 & 400 & -143 & -55.6 \\
\hline
\end{tabular}

Note that the energy use figures listed in Table 3-5 for the fans include only those fans that were monitored, which were a subset of the total number of fans in the building. All chillers in the building were monitored. The "residual electric" listed in Table 3-5 is the total electricity minus that of the monitored fans and chillers. 
The monitored fans and chillers show significant individual reductions in energy use at $18 \%$ and $47 \%$ respectively. However, the full extent of the savings (i.e., $1,006+341=1,347 \mathrm{kWh} /$ day) do not carry through to the total building electricity use, which drops by only $367 \mathrm{kWh} /$ day. This implies an increase of $980 \mathrm{kWh} /$ day in the electricity used by the other systems in the building. This increase has the effect of masking the full extent of the HVAC savings visible in the total building electricity use figures. It may be noted from Table 3-5 that the plug loads to floor 7 of the building show a very large increase of 56\%. Figure 3-4 shows the plug and lighting energy use in the pre- and post-retrofit periods.

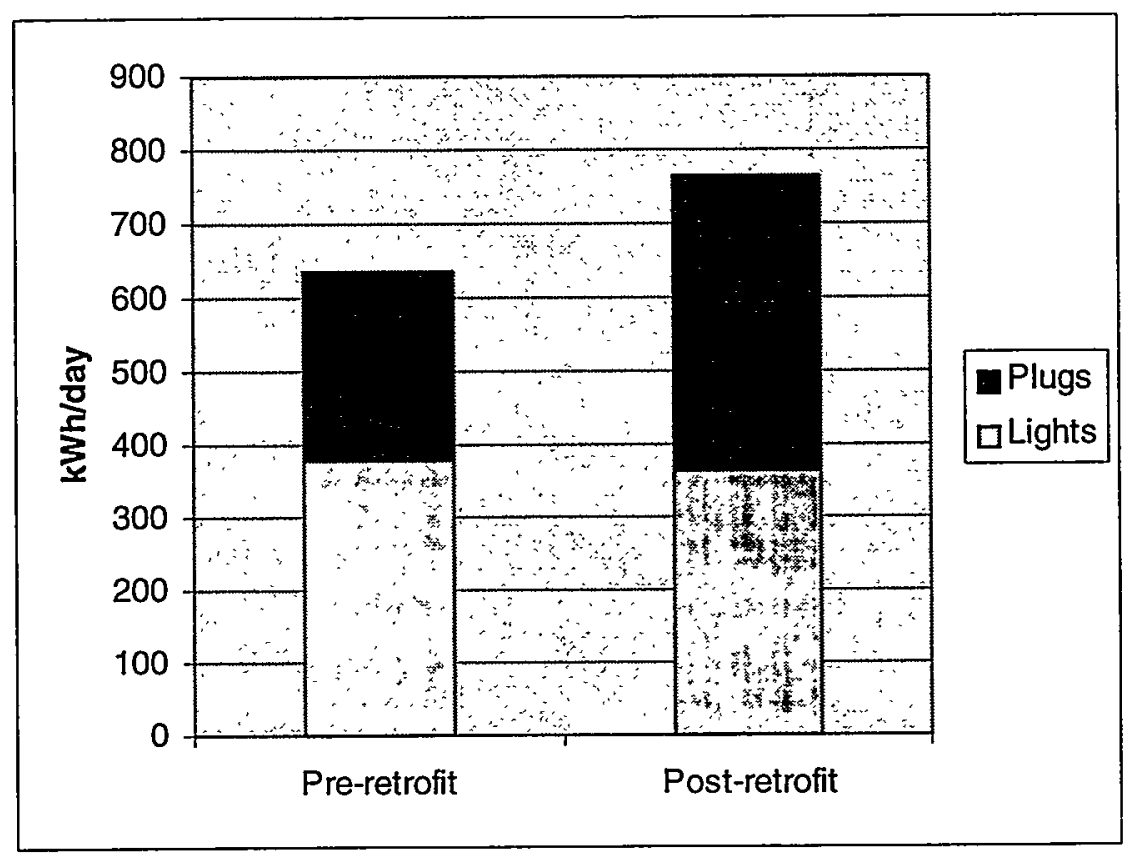

Figure 3-4: Changes in floor 7 energy use

Figure 3-5 shows the daily energy used by the lights and plugs over the whole period of the data. It can be observed that there is a step-like increase in the plug loads during January 1997. Building operators have confirmed that there were occupancy changes on this floor around this time, which most likely resulted in the installation of additional computing devices, and other energy-consuming appliances. In terms of energy, the plugs on this one floor increase building consumption by $143 \mathrm{kWh} /$ day. Although this increase is significant, it is not enough to explain the $980 \mathrm{kWh} /$ day total increase in the "residual electric" for the whole building, listed in Table 3-5. 
Plugs

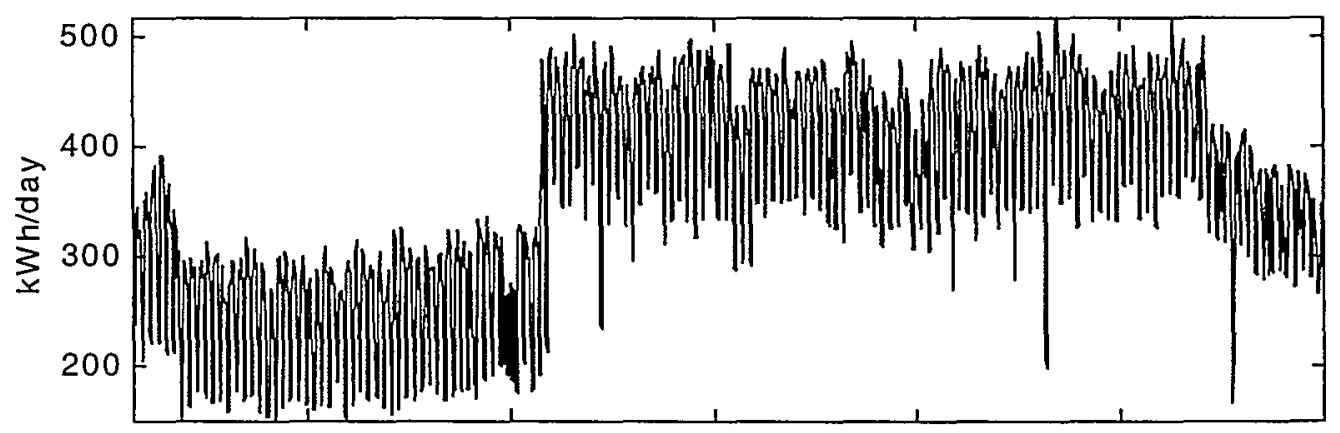

Lights

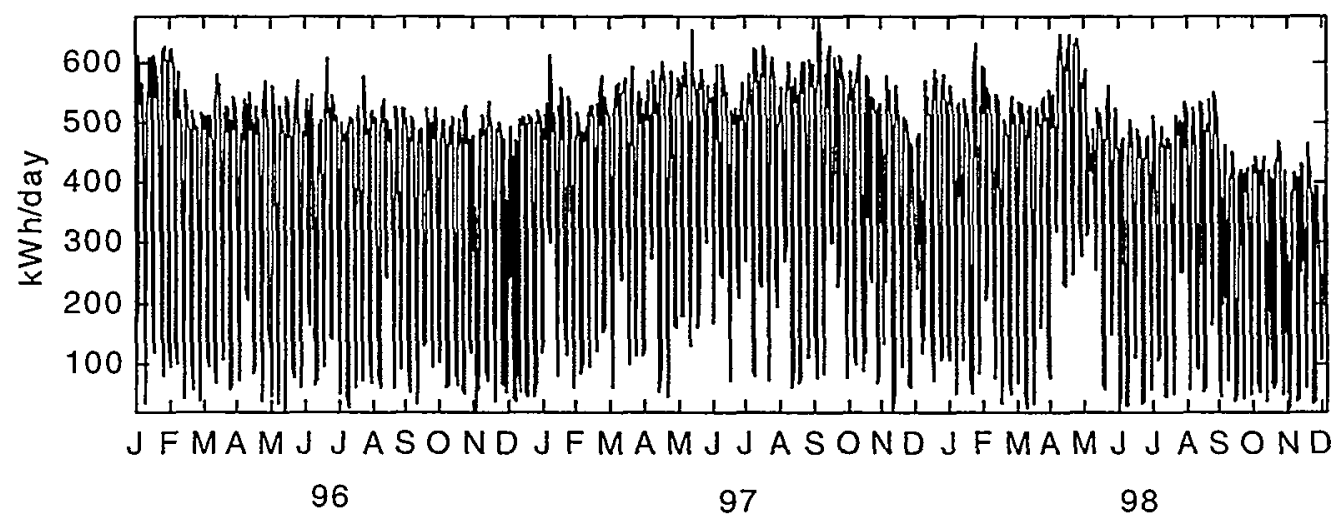

Figure 3-5: Energy used by lights and plugs on floor seven

In addition to plug and lighting loads, the "residual electric" in Table 3-5 also includes the main AHU fans that were not monitored and which were also likely to be using less energy as a result of the retrofits. Certain extrapolations may be performed to estimate the savings in these unmonitored fans. In terms of power ratings, the unmonitored AHU fans represented about 3.2 times the power of all the monitored fans. The pre-retrofit energy use in these unmonitored fans may be estimated by applying this multiple to the energy use figures for the monitored fans. The monitored fans used $1,720 \mathrm{kWh} / \mathrm{day}$ in the pre-retrofit period, so the estimate for the unmonitored AHU Fans in this same period is $5,504 \mathrm{kWh} /$ day. The unmonitored AHU fans are assumed to have the same percentage drop in energy use as the monitored fans. Table 3-6 summarizes the energy use of the monitored fans and the extrapolated fans. Note that the "residual electric", which is the total building electricity use minus that of the chillers and fans, is now lower than that listed in Table 3-5 to account for the additional extrapolated fan energy savings. 
Table 3-6: Energy use of fans (monitored and extrapolated estimates)

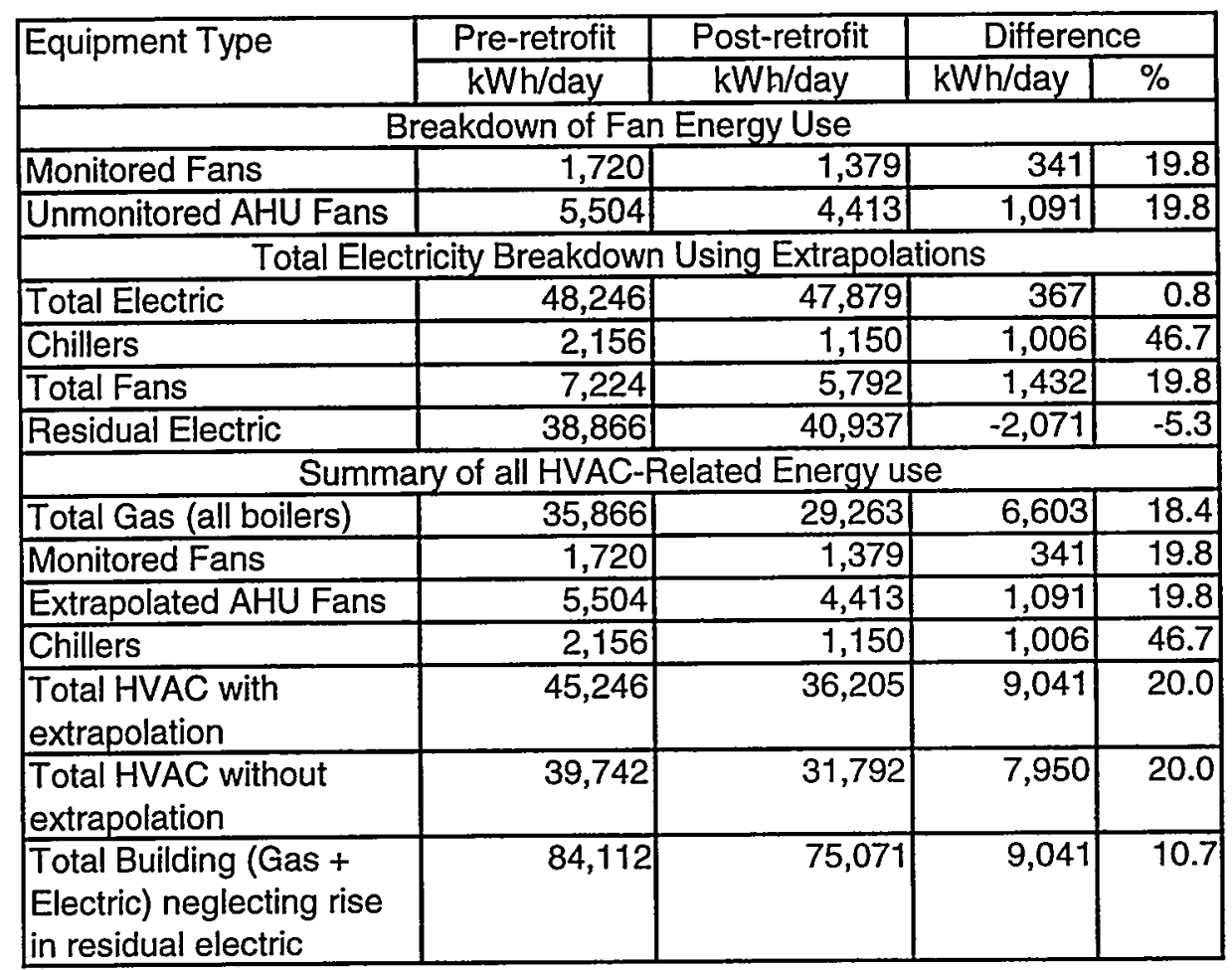

According to the extrapolations in Table 3-6, the total savings in the fans might have been $1,432 \mathrm{kWh} /$ day. Based on these figures, and the savings in the chillers, the total increases in the lights, plugs, and other unmonitored electrical appliances could have been around $2,071 \mathrm{kWh} /$ day. This evaluates to $104 \mathrm{kWh} /$ day for each floor of the building, which is of a similar magnitude to the increase observed on the $7^{\text {th }}$ floor. 


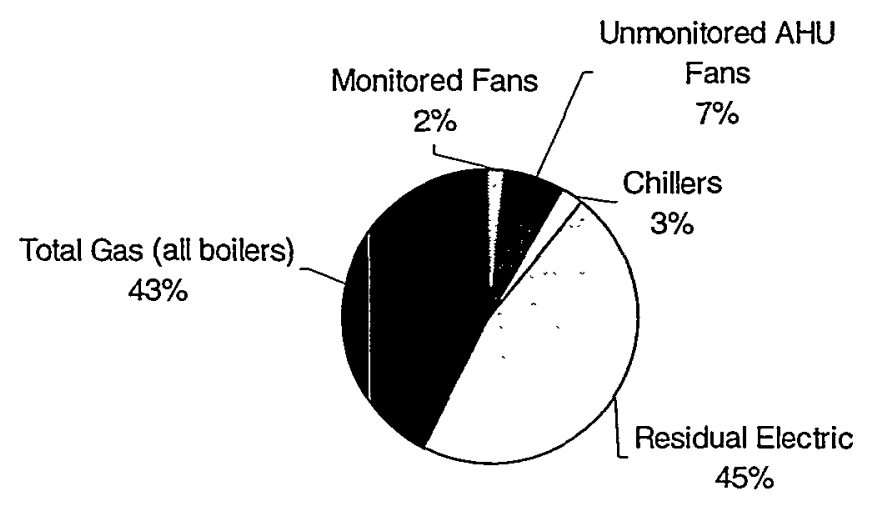

Figure 3-6: Pre-retrofit energy breakdown of systems. Total energy $=84,112 \mathrm{kWh} /$ day

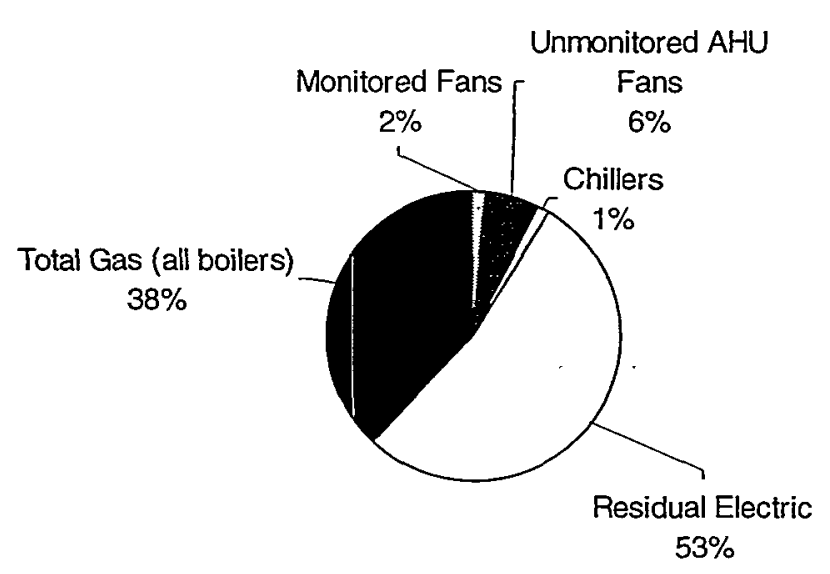

Figure 3-7: Post-retrofit energy breakdown of systems. Total energy $=77,142 \mathrm{kWh} /$ day

Even if there were no savings in the unmonitored fans, the $980 \mathrm{kWh} /$ day increase in the "residual electric" of Table 3-5 is not explained only by the changes on the $7^{\text {th }}$ floor. Hence, there must have been increases on other floors in the building. The full extent of these increases in unknown, but their role in total building energy consumption is highly significant.

The proportional energy usage breakdown of the systems for the pre- and post-retrofit periods are shown in Figures 3-6 and 3-7, which also shows the theoretical extrapolations of the unmonitored AHU fans. The "residual electric" is the total building electricity 
usage minus all other listed electrical systems. A large increase in this "residual electric" is now evident in the figure; from $45 \%$ to $53 \%$.

Figures 3-8 and 3-9 illustrate the proportion of cost attributed to the different systems in the pre- and post- retrofit periods respectively. Note that the "residual electric" equipment represents over $70 \%$ of total building energy costs in both the pre- and postretrofit periods. Figure 3-10 shows the energy costs, where all costs were calculated based on an averaged 1996 utility rate. Total electricity represents about $90 \%$ of the building energy costs. According to the calculations made using the monitored data, the savings in building energy costs were $2.5 \%$ from the pre- to post-retrofits periods (approximately $\$ 35,000 /$ year).

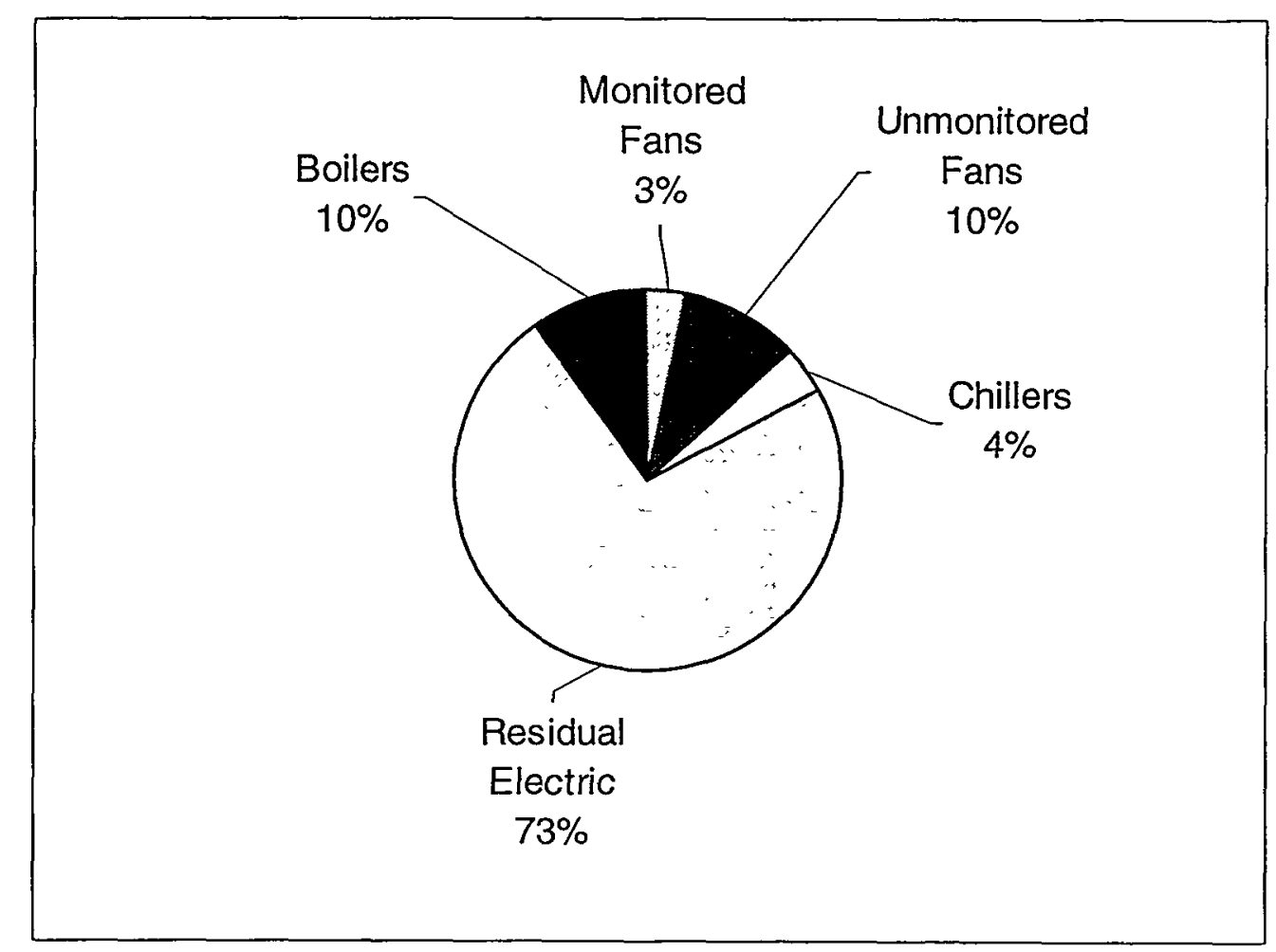

Figure 3-8: Pre-retrofit cost breakdown of systems. Total cost approximately $\$ 3,843 /$ day. 


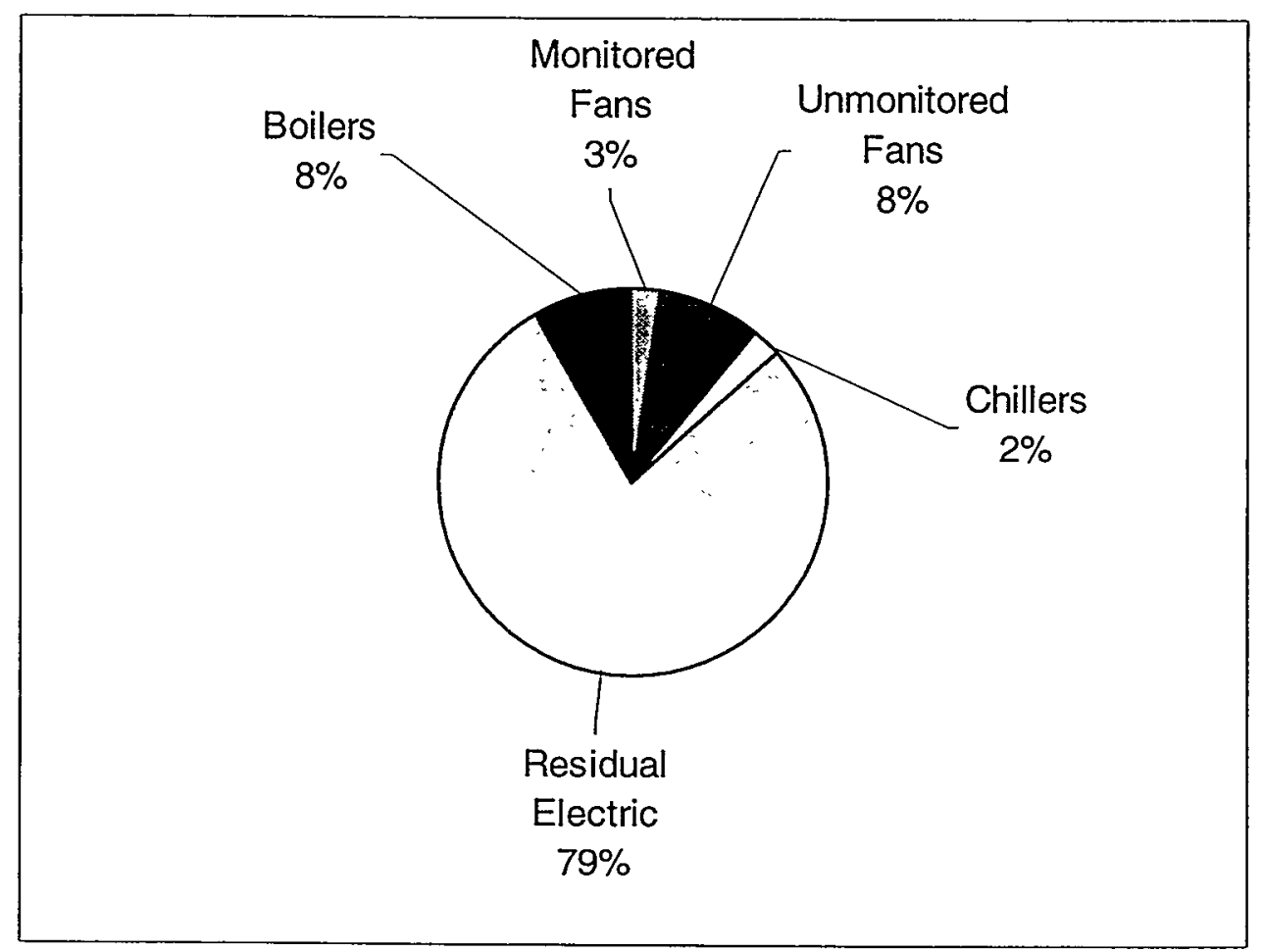

Figure 3-9: Post-retrofit cost breakdown of systems. Total cost approximately $\$ 3,746 /$ day.

If we assume that the extrapolations of additional fan energy savings are valid, the maximum amount of savings in the fans, chillers, and boilers was $\$ 246 /$ day $(=\$ 89,790 /$ year $)$ and $7,950 \mathrm{kWh} /$ day $(=2,901,750 \mathrm{kWh} /$ year $)$. As a percentage of total energy cost, this is equivalent to about a $6 \%$ saving. In terms of energy use, the saving is about $10.7 \%$. These figures are still well below some of the original saving predictions, which were around $\$ 500,000$ per annum (Applebaum and Bushby, 1998). However, the retrofitting process is still underway with several control strategy changes planned; further savings are thus possible, as outlined in the Bosek-Gibson simulation study (Bosek Gibson and Associates, 1997). 


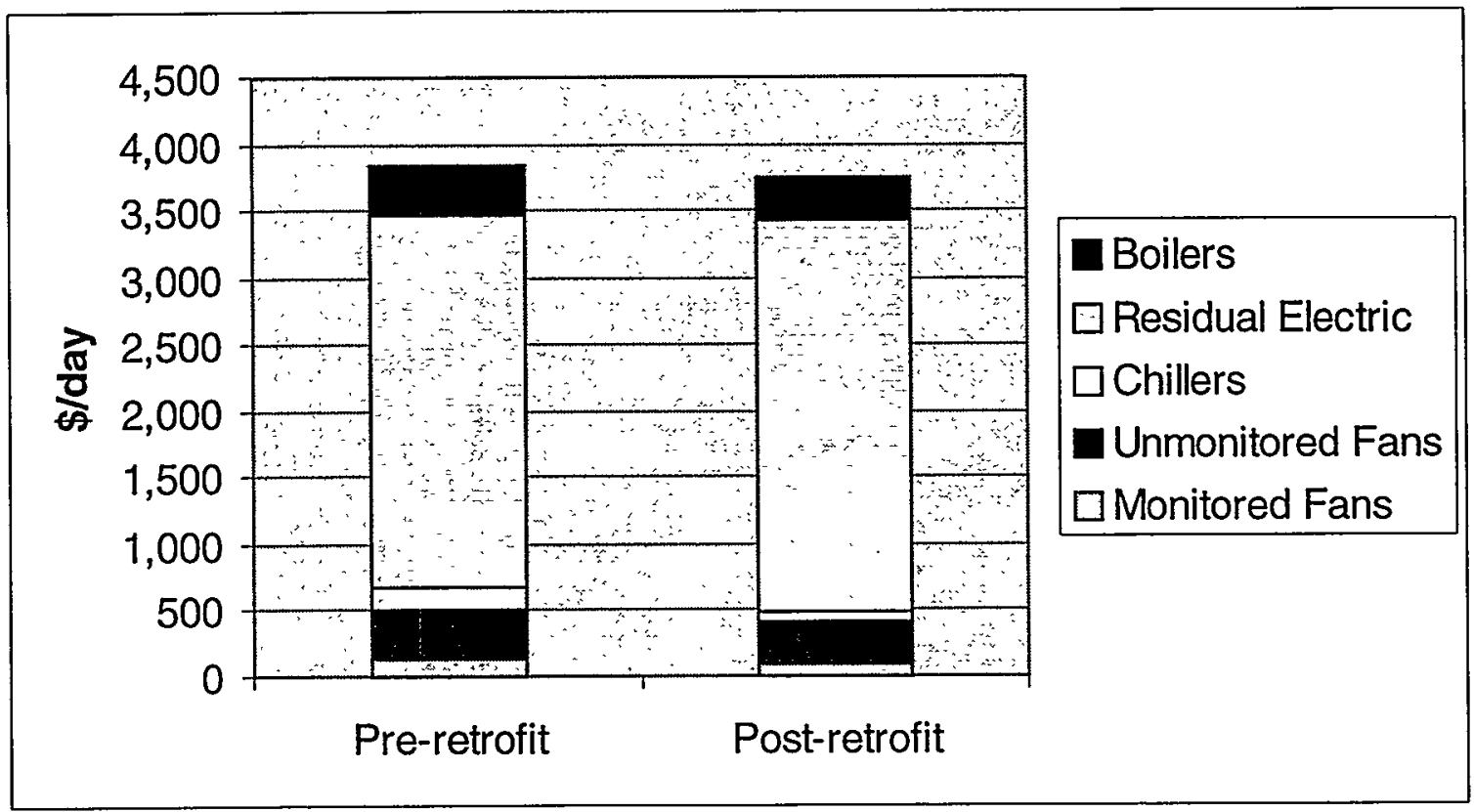

Figure 3-10: Daily energy costs

In terms of energy costs, the building is dominated by the "residual electric" of which about half is potentially from plugs and lights. Other unmonitored electrical equipment includes HVAC and DHW pumps, elevators, escalators, miscellaneous kitchen facilities, etc. The large unmonitored costs serve to mask the savings in the HVAC equipment due to the retrofits. Taking the chiller, fans, boilers, and extrapolated fans in isolation, the savings for this group of equipment are $20 \%$ by energy (Table $3-6$ ) and $23 \%$ by cost.

\subsection{Air-Handling Unit Performance}

Two of the main air-handling units were instrumented. Each unit was equipped with an equal number of temperature and humidity sensors, but direct measurements of the fan power were only available for the SUBSF2W unit. This air-handling unit is therefore analyzed here, since fan power is needed to proxy the air-flow-rate and energy usage. Eighteen data points were available from the data-logging system for the considered AHU:

1. Supply Fan Electric Power

2. Return Fan 1 Electric Power

3. Return Fan 2 Electric Power

4. Ambient Temperature

5. Ambient Relative Humidity

6. Averaged Mixed Temperature

7. Mixed Humidity

8. Mixed Temperature (point)

9. Averaged Off-Cooling Coil Temperature

10. Off-Cooling Coil Humidity

11. Of-Cooling Coil Temperature 
12. Averaged Off-Heating Coil Temperature

13. Off-Heating Coil Humidity

14. Off-Heating Coil Temperature

15. Humidity after Return Fan 1

16. Temperature after Return Fan 1

17. Humidity after Return Fan 2

18. Temperature after Return Fan 2

Since the air-handling unit was VAV, and controlled to a fixed static pressure setpoint, the following cubic equation could be formulated to equate power consumption $(W)$ and delivered air flow rate $(\dot{m})$ :

$$
\begin{aligned}
W & =\frac{\eta \dot{m}}{\rho}\left(P+\dot{m}^{2}\left[R+\frac{1}{2 \rho A^{2}}\right]\right) \\
& =\frac{\eta \dot{m}}{\rho}\left(P+\dot{m}^{2} R^{\prime}\right)
\end{aligned}
$$

where $P$ is the static pressure setpoint, $\rho$ is the air density, $\eta$ is the efficiency of the fan motor, $A$ is the cross sectional area of the fan, and $R$ is the resistance between the static pressure sensor and the ambient. An effective resistance, $R^{\prime}$, was introduced to simplify the expression by lumping together the velocity pressure and pressure drop due to the resistance between the static pressure sensor and the ambient. The mass flow rate for a given fan power is obtained by solving the cubic. In this exercise, $R^{\prime}$ was used as a calibration parameter. The following design data, obtained from the Bosek Gibson Report (March 7, 1997, page 37) was then applied to estimate its value:

- Static pressure: $1745 \mathrm{~Pa}$

- Target mass flow: $74 \mathrm{~kg} / \mathrm{s}$

A fan motor efficiency of 0.9 was assumed. Other design information relating to the AHU is:

- Maximum heating power: $854 \mathrm{~kW}$

- Maximum cooling power: $1267 \mathrm{~kW}$

The power was established from the data for the mixing box (labeled as "economizer" in Figure 3-11), heating coil, and cooling coil based on the change in enthalpy across each unit:

$$
\dot{Q}=\dot{m} \Delta h
$$

Figure 3-11 shows the calculated mean power values for each day. The overall mean power values for the pre- and post-retrofit periods are shown in Table 3-7. 
Table 3-7: Mean power in air-handling unit

\begin{tabular}{|l|r|r|r|r|}
\hline AHU Subsystem & Pre-retrofit & Post-retrofit & \multicolumn{2}{|c|}{ Difference } \\
\cline { 2 - 5 } & $\mathrm{kW}$ & $\mathrm{kW}$ & $\mathrm{kW}$ & $\%$ \\
\hline Heating & 126 & 93 & 33 & 26.2 \\
\hline Cooling & 25 & 13 & 12 & 48.0 \\
\hline Heat Recovery & 44 & 42 & 2 & 4.5 \\
\hline
\end{tabular}

Significant reductions in the heating and cooling power are evident from the pre- to postretrofit periods, with a $26 \%$ reduction in heating and a $48 \%$ reduction in cooling. There is a small drop in mixing box power of $4.5 \%$. These reductions may be attributable to the overall lower fan speeds, and hence lower airflow, due to the activation of VAV control in the building. Although the mixing box was not supposed to be operational before February 1996, there appears to have been some activity between January 1996 and February 1996. However, the longitudinal profile of the energy usage is smoother in the winter months of 1996 and 1997, indicating a possible improvement in control. It is possible that the mixing dampers were being operated manually at times before February 1996. Another feature to note from Figure 3-11 is that there is a base load of around $40 \mathrm{~kW}$ throughout the data in the mixing box. This could be due to leakage through the return air dampers, or errors in the correction used to account for the temperature rise across the supply fan. 

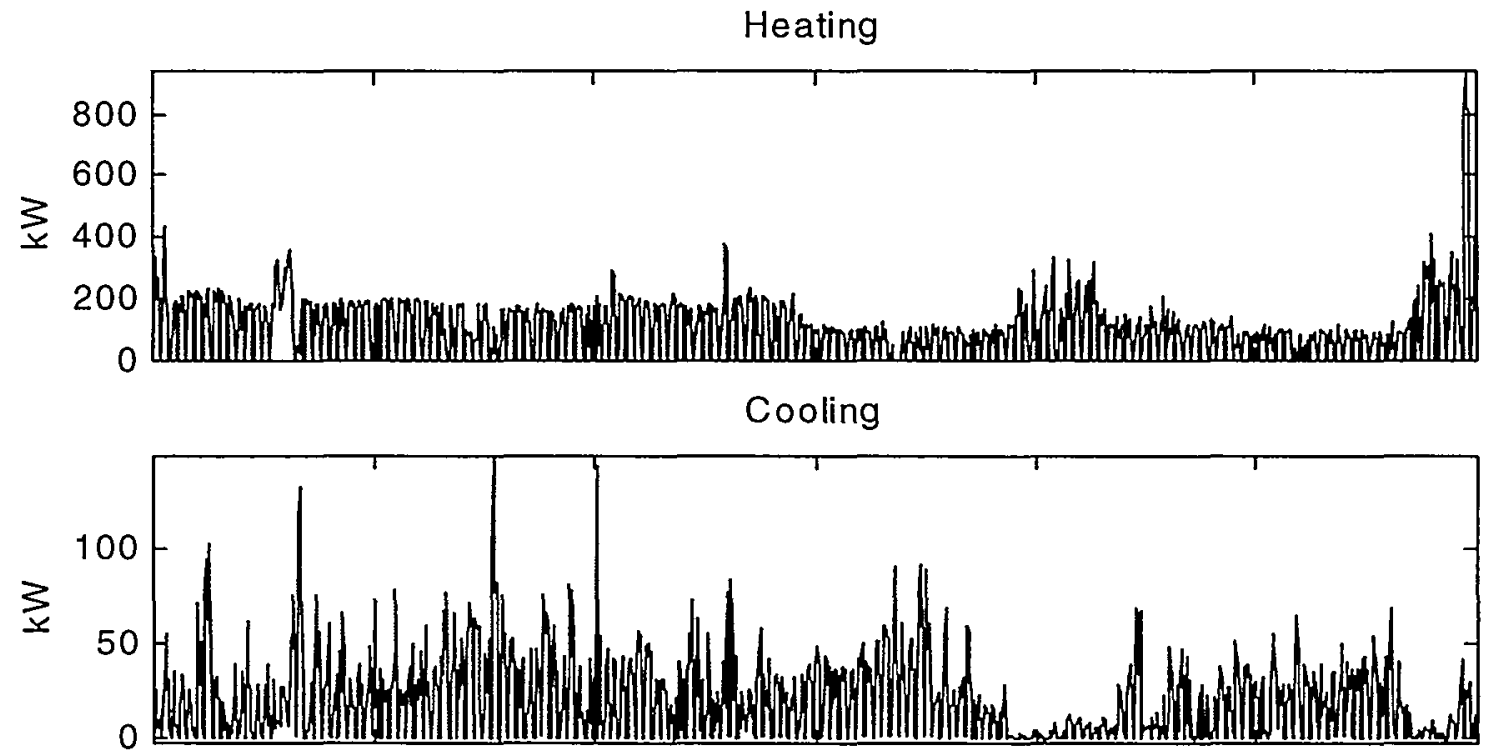

Economizer

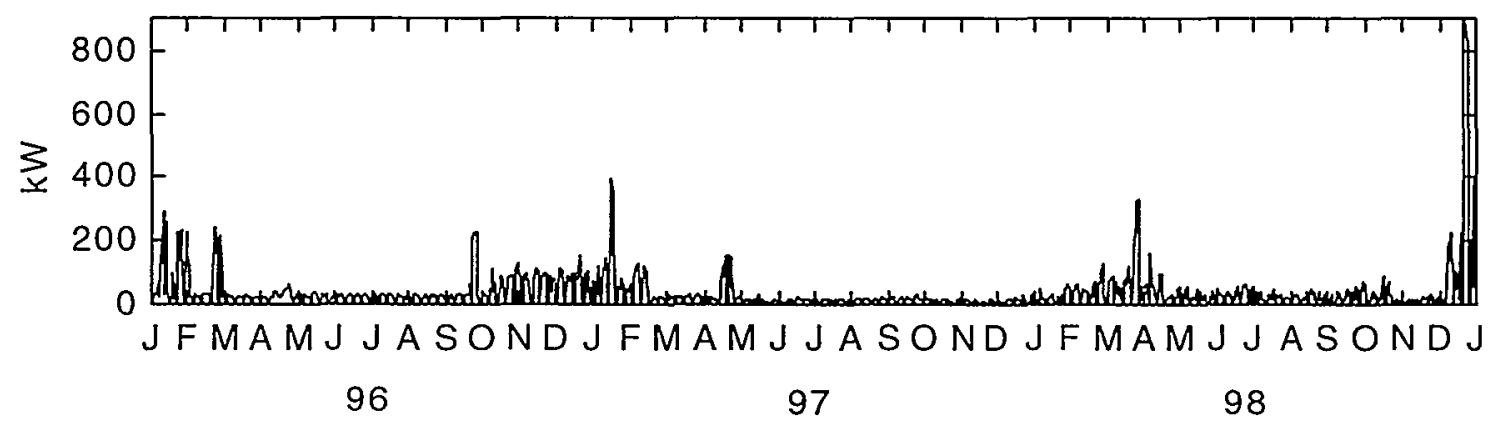

Figure 3-11: Mean daily kW power of AHU subsystems 

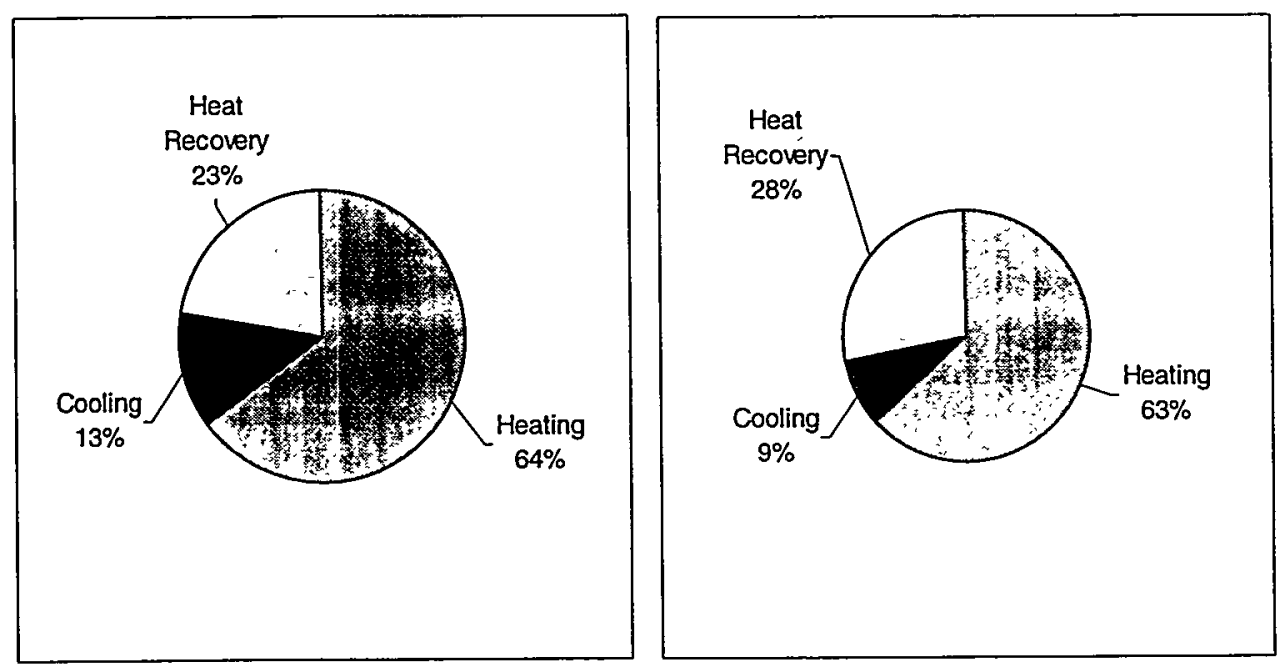

Figure 3-12: Energy usage apportioned between AHU subsystems (pre-retrofit top pie; post-retrofit bottom pie)

Figure 3-12 shows the contribution of each subsystem in the air-handling unit to the total AHU power. The figure shows that the mixing dampers (labeled as "heat recovery") appear to be operating more effectively in the post-retrofit period. In the pre-retrofit period, the mixing dampers provide $23 \%$ of the total power. This increases to $28 \%$ in the post-retrofit period. The cooling power reduces to $9 \%$ of the total and the heating reduces to $66 \%$ of the total. Since the setpoint of the mixed-air is approximately equal to that of the cold deck, the heating would be expected to benefit more from the activation of the dampers. However, Figure 3-12 shows that the mixing box leads to a larger relative reduction in cooling energy. It is possible that this is due to the cooler weather conditions (an average of $0.7 \mathrm{~K}$ ) in the post-retrofit period, which may have resulted in a greater heating load and a lower cooling load. 


\section{Simulation-based evaluation}

The DOE-2 simulation software was used to evaluate the changes in energy usage caused by the retrofits. The simulation-based evaluation enables the effects of the control retrofits to be isolated from other changes that may have occurred in the real building, such as: weather variations, occupancy changes, unmonitored equipment load changes, etc. In this section, the predictions made by the simulation are compared with the actual changes calculated from the monitored data.

\subsection{Configurations}

The DOE-2 simulation developed by Bosek, Gibson, and Associates was adapted for the purpose of this study. The simulation was configured to represent the post-retrofit building by modifying the control strategy to include the following measures:

- Full variable-air-volume (VAV) control in the main air-handling units and terminal units

- Temperature-based economizer

- Automated scheduling, based on observed real building schedules

No calibration of the simulation was performed; the existing simulation, as developed by Bosek, Gibson \& Associates, was simply adapted to include the operational schedules observed in the real building during the pre-retrofit period. The simulation was not calibrated since the purpose of the study was to evaluate relative, rather than absolute, changes in energy usage. The post-retrofit simulation represented the base case, or "Case 0 ". The other simulations were derived from Case 0 in the manner indicated in Table 41 , with Case 1 representing the pre-retrofit building.

Table 4-1: Simulation cases

\begin{tabular}{|l|l|}
\hline Case 0 (post-retrofit) & N/A \\
\hline Case 1 (pre-retrofit) & $\begin{array}{l}\text { Remove VAV facility } \\
\text { Fix mixing dampers to full outside air } \\
\text { Retain operational schedules }\end{array}$ \\
\hline Case 2 & Remove VAV facility \\
\hline Case 3 & Remove economizer \\
\hline Case 4 & Change temperature economizer to enthalpy-based \\
\hline
\end{tabular}

Note that the operational schedules for the systems were not changed between the preand post-retrofit cases, despite the installation of automated scheduling in the building. The reason for this is that the manual control in the building during the pre-retrofit period was to a very high standard and no discernible difference in operational schedules was evident upon activation of the automated control. Cases 2 and 3 were actual retrofits installed in the building, Case 4 was originally planned but not implemented at the time of this analysis. For consistency, all simulation runs were carried out using the 1996 San Francisco weather year. 


\subsection{Results of the simulation study}

Table 4-2 summarizes the results of the simulations, in terms of total building electric and gas usage. The annual electricity use estimated by the simulation for the pre-retrofit case was $45,146 \mathrm{kWh}$, compared with the monitored value of $48,246 \mathrm{kWh}$, which is a difference of $6 \%$ relative to the monitored data. The total building gas consumption was $33,140 \mathrm{kWh}$ in the simulation compared with the monitored data value of $35,866 \mathrm{kWh}$, an $8 \%$ difference.

- Table 4-2: Simulation annual building energy usage results

\begin{tabular}{|l|r|r|}
\hline \multirow{2}{*}{$\begin{array}{l}\text { Reference (change relative to } \\
\text { case 0) }\end{array}$} & Electricity Use & Gas Use \\
\cline { 2 - 3 } & $\mathrm{kWh} /$ day & $\mathrm{kWh} /$ day \\
\hline Case 0 (post-retrofit) & 42,710 & 28,985 \\
\hline Case 1 (pre-retrofit) & 45,146 & 33,140 \\
\hline Case 2 (no VAV) & 45,143 & 28,156 \\
\hline Case 3 (no mixed air control) & 42,736 & 33,356 \\
\hline Case 4 (enthalpy economizer) & 42,710 & 28,976 \\
\hline
\end{tabular}

Table 4-3 shows the savings resulting from the each retrofit. The results shows that the incorporation of the retrofits (i.e., change between Case 1 and Case 0 ) saves $5.4 \%$ in electricity and $12.5 \%$ in gas. The results indicate that VAV control is responsible for almost all of the total savings in electricity. Activation of damper control with a temperature economizer results in only $27 \mathrm{kWh} /$ year savings, which is a negligible fraction of the total building electric. VAV control actually increases gas consumption by $2.5 \%$ due to trade-off savings in fan energy. All gas savings are due to the control of the mixed air temperature. According to the simulation results, activation of this control with a temperature economizer in isolation saves about $13.2 \%$ of the annual gas consumption. When the VAV control is active at the same time, the savings drop to $12.5 \%$. There are negligible savings from changing the temperature economizer to be enthalpy based.

Table 4-3: Daily average savings resulting from the retrofits

\begin{tabular}{|l|r|r|r|r|}
\hline \multirow{2}{*}{ Reference } & \multicolumn{3}{|c|}{ Electricity Savings } & \multicolumn{2}{c|}{ Gas Savings } \\
\cline { 2 - 5 } & $\mathrm{kWh} / \mathrm{day}$ & $\%$ & $\mathrm{kWh} /$ day & $\%$ \\
\hline Case 0 (Post-Retrofit) & 2,437 & 5.4 & 4,155 & 12.5 \\
\hline Case 1 (Pre-Retrofit) & 0 & 0 & 0 & 0 \\
\hline VAV Control & 2,433 & 5.3 & -829 & -2.5 \\
\hline Mixed air control with temperature economizer & 27 & 0.1 & 4,371 & 13.2 \\
\hline Change to Enthalpy Economizer & 1 & 0 & -9 & 0 \\
\hline
\end{tabular}

Gas consumption benefits from activation of the mixed air control because the ambient air temperature falls below the mixed plenum setpoint during the winter months of the year. The controller prevents this from happening by modulating the mixing box dampers thereby increasing the inlet temperature of the air to the heating coils in the main air-handling units. This then reduces the load on the boilers. The chillers are not significantly affected by the mixing control because the mixed air setpoint is approximately equal to the cold deck setpoints. Hence, when the outside air temperature falls below the mixed air setpoint the cooling coils are already deactivated. The 
economizer control produces the savings in chiller energy when the outside air temperature is above the return air temperature.

Table 4-4 shows a comparison between the simulation results and those obtained from the monitored data. The simulation predicted fewer savings in the gas consumption than were actually observed: $12.5 \%$ versus $18.4 \%$. Electricity savings were evident in the simulation (5.4\%), whereas the monitored data showed negligible overall savings. However, as described in Section 3.2, increases in plug loads and other electrical appliances may have masked the savings in the HVAC due to the retrofits. For this purpose, Table 4-4 also shows the HVAC-only savings, which includes the extrapolated estimates of the unmonitored fan energy. Based on these values, the electricity savings are $5 \%$, which is very close to the simulation value of $5.4 \%$. Hence, the simulation adds corroborative evidence to the theory that there was a significant increase in the loads of the plugs and other electrical equipment from the pre- to post-retrofit period.

Table 4-4: Annual savings - simulation and real data comparison

\begin{tabular}{|l|r|r|r|r|r|r|}
\hline \multirow{3}{*}{ Utility Type } & \multicolumn{2}{|c|}{ Simulation } & \multicolumn{2}{c|}{ Monitored Data } & \multicolumn{2}{c|}{ Sub-Monitored HVAC } \\
\cline { 2 - 7 } & \multicolumn{2}{|c|}{ Savings } & \multicolumn{2}{c|}{ Savings } & \multicolumn{2}{c|}{ Savings } \\
\cline { 2 - 7 } & $\%$ & $\mathrm{kWh} /$ day & $\%$ & $\mathrm{kWh} /$ day & $\%$ & \multicolumn{1}{c|}{$\mathrm{kWh} /$ day } \\
\hline Electricity & 5.4 & 2,437 & 0.8 & 367 & 5 & 2,438 \\
\hline Gas & 12.5 & 4,155 & 18.4 & 6,603 & 18.4 & 6,603 \\
\hline
\end{tabular}

Table 4-5 shows a more detailed breakdown of the simulation results compared with those calculated from the monitored data. There are significant discrepancies between the simulation and monitored data in the fans and chillers. The simulation overestimates the electricity use for both these-electrical subsystems with the most significant overestimation occurring in the post-retrofit period for the chillers, where there is a $70 \%$ difference. The large difference in the post-retrofit energy use of the chillers could be due to the mean of the outside air temperature being lower in 1998 than 1996. This has an effect since the simulation used the 1996 weather data for both pre- and post-retrofit cases.

The differences between the gas consumption figures in the simulation and monitored data are smaller with an $8 \%$ and a $1 \%$ discrepancy in the pre- and post-retrofit periods respectively. The simulation underestimates the "other electric", which has the effect of counteracting the discrepancies in the fans and chillers on the total building energy use figures. The result is that the total building energy use (gas + electric) predicted by the simulation is within $11 \%$ of the monitored data. Note that the "actual" figures listed in Table 4-5 for the fans include the extrapolated estimates of the unmonitored fans in the building. 
Table 4-5: Comparison of simulation and actual subsystem energy usage (kWh/year)

\begin{tabular}{|l|r|r|r|r|r|r|}
\hline \multirow{3}{*}{ Subsystem } & \multicolumn{3}{|c|}{ Pre-Retrofit } & \multicolumn{3}{c|}{ Post-Retrofit } \\
\cline { 2 - 7 } & Simulation & \multicolumn{1}{|c|}{ Actual } & diff & Simulation & Actual & \multicolumn{1}{c|}{ diff } \\
\cline { 2 - 7 } & $\mathrm{kWh} /$ day & $\mathrm{kWh} / \mathrm{day}$ & \multicolumn{1}{c|}{$\%$} & $\mathrm{kWh} /$ day & $\mathrm{kWh} /$ day & \multicolumn{1}{c|}{$\%$} \\
\hline Fans & 12,756 & 7,224 & -43 & 10,377 & 5,792 & -44 \\
\hline Chillers & 3,886 & 2,156 & -45 & 3,832 & 1,150 & -70 \\
\hline Boilers & 33,140 & 35,866 & 8 & 28,985 & 29,263 & 1 \\
\hline Other Electric & 28,504 & 38,866 & 36 & 28,500 & 40,937 & 44 \\
\hline Total & 78,286 & 84,112 & 7 & 71,695 & 77,142 & 8 \\
\hline
\end{tabular}

Figures 4-1 and 4-2 show the energy breakdown of the simulated systems for the pre- and post-retrofit periods. In contrast to the pie charts in Section 3.2 (Figure 3-5), the energy breakdown does not change significantly after the retrofits. A greater portion of the energy goes to the fans and chillers in the simulation in both the pre- and post-retrofit periods. In the real data, the boilers mostly take up the balance during the pre-retrofit period. However, in the post-retrofit period, boiler consumption drops, and the deficit is taken up by the "other electric" - see Figure 3-5. Table 4-6 gives a complete breakdown of the DOE-2 simulation results. 


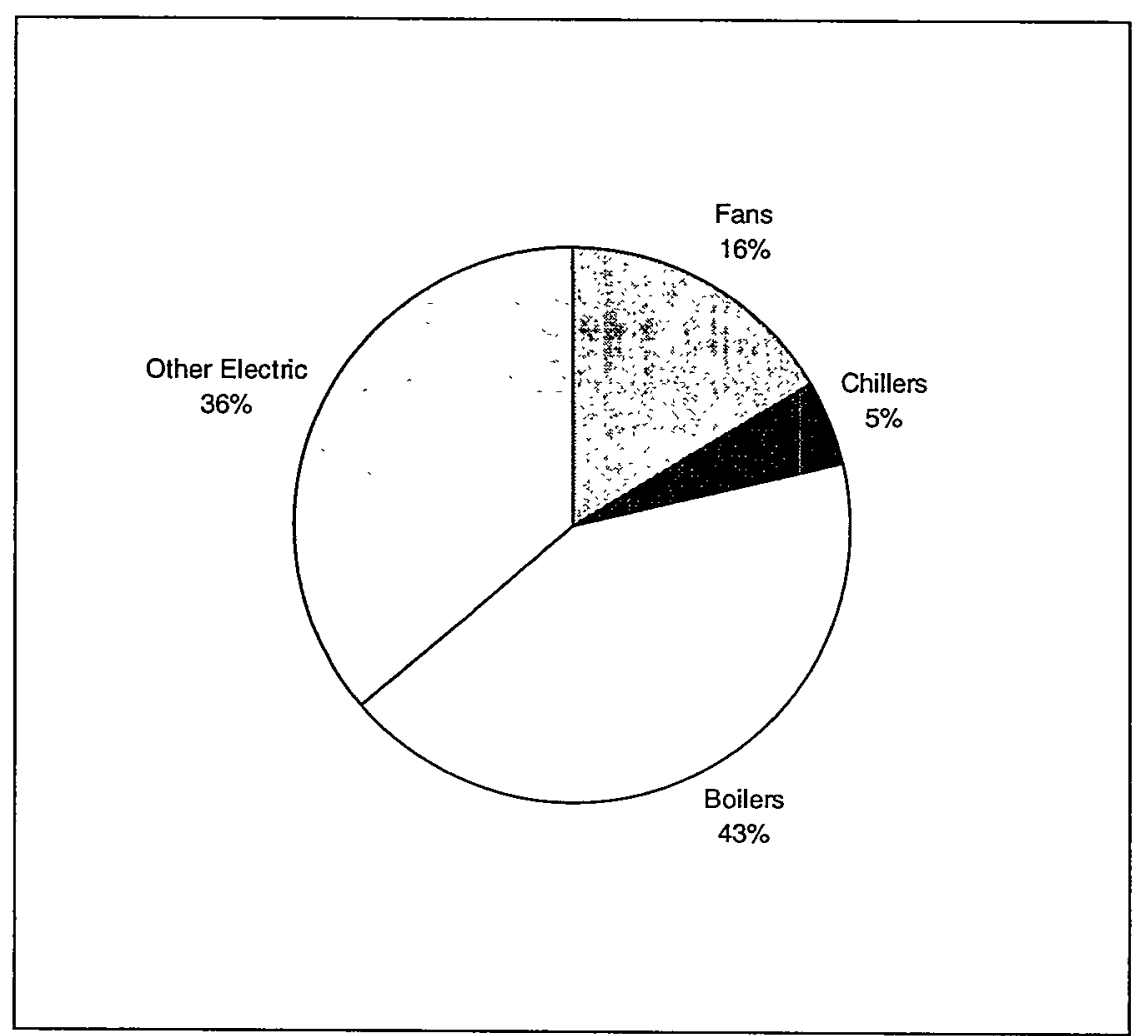

Figure 4-1: Pre-retrofit energy breakdown in simulation.

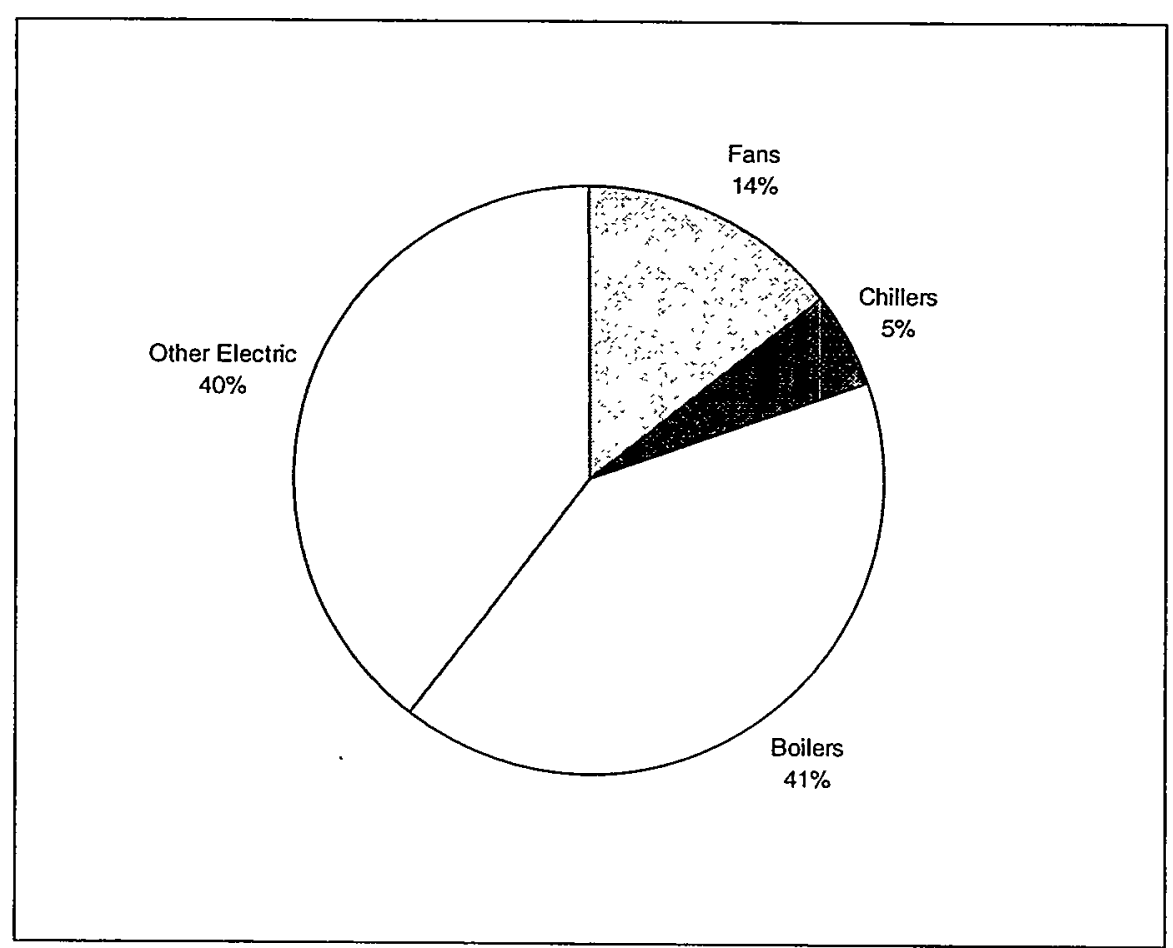

Figure 4-2: Post-retrofit energy breakdown in simulation. 
Table 4-6: Complete breakdown of the annual energy use from the DOE-2 results

\begin{tabular}{|c|c|c|c|c|c|c|}
\hline \multirow[t]{2}{*}{ Energy Type } & \multirow[t]{2}{*}{ Equipment } & Case0 & Case1 & Case2 & Case3 & Case 4 \\
\hline & & Post-Retrofit & Pre-Retrofit & No VAV & No Econ. & Enthalpy Econ. \\
\hline \multirow{10}{*}{$\begin{array}{l}\text { Electricity } \\
\text { (kWh/day) }\end{array}$} & Area Lights & 11,398 & 11,398 & 11,398 & 11,398 & 11,398 \\
\hline & Misc. equipment & 8,380 & 8,380 & 8,380 & 8,380 & 8,380 \\
\hline & Space Heat & 16 & 19 & 16 & 19 & 16 \\
\hline & Space Cool & 3,832 & 3,886 & 3,887 & 3,838 & 3,832 \\
\hline & Heat Reject & 559 & 561 & 564 & 557 & 559 \\
\hline & Pumps \& Misc. & 1,702 & 1,702 & 1,702 & 1,702 & 1,702 \\
\hline & Vent Fans & 10,377 & 12,756 & 12,751 & 10,397 & 10,377 \\
\hline & Domestic HW & 0 & 0 & 0 & 0 & 0 \\
\hline & Ext. Lights & 3,688 & 3,688 & 3,688 & 3,688 & 3,688 \\
\hline & Ext. Misc. & 2,757 & 2,757 & 2,757 & 2,757 & 2,757 \\
\hline \multirow[t]{2}{*}{ Gas (kWh/day) } & Space Heat & 28,605 & 32,760 & 27,777 & 32,977 & 28,597 \\
\hline & Domestic HW & 380 & 380 & 380 & 380 & 380 \\
\hline Total Electricity & \multirow[t]{2}{*}{ kWh/day } & 42,710 & 45,146 & 45,143 & 42,736 & 42,710 \\
\hline Total Gas & & 28,985 & 33,140 & 28,156 & 33,356 & 28,976 \\
\hline
\end{tabular}

\subsection{Using the simulation results to correct for full outside air in pre- retrofit period}

One of the problems with the energy analysis in Section 3 is that the mixing dampers were delivering full outside air in the main air-handling units until being (gradually) brought back under control around March 1996. The months of January and February are generally heating months in the Bay Area and the delivery of full fresh air would have had the effect of increasing the load on the boiler plant. Gas consumption in the preretrofit period would have therefore been higher than normal, leading to estimates of greater savings when comparing the pre- and post-retrofit periods. In this section, the results from the simulation study are used to correct the monitored data results by removing the extra energy use incurred by the lack of mixing in the air-handlers.

Table 4-3 showed how each retrofit affected the daily average energy in the building. One of the "retrofits" considered was the control of the mixing dampers in the main airhandling units. According to the results, this control measure leads to $4,371 \mathrm{kWh} /$ day savings in the gas consumption average over a complete yearly cycle. We use this figure to correct the monitored data. Since the mixing dampers came under control after March 1996, the pre-retrofit period was only affected in the heating season at the beginning of the year. If we assume that the heating season runs from December through February, we may postulate that two thirds of the simulation-estimated savings could have been made in the pre-retrofit period. Table 4-7 provides a revised summary of the building energy use based on correcting the gas consumption figures with two thirds of the simulationestimated savings for the mixing control. 
Table 4-7: Revised monitored data savings based on correcting for the mixing damper control in the pre-retrofit period

\begin{tabular}{|l|r|r|r|r|}
\hline \multirow{2}{*}{ Equipment Type } & Pre-retrofit & Post-retrofit & \multicolumn{2}{|c|}{ Difference } \\
\cline { 2 - 5 } & kWh/day & kWh/day & kWh/day & $\%$ \\
\hline \multicolumn{5}{|c|}{ Overall Building Energy Use } \\
\hline Total Energy & 80,958 & 77,142 & 3,816 & 4.7 \\
\hline Total Gas & 32,712 & 29,263 & 3,449 & 10.5 \\
\hline Total Electric & 48,246 & 47,879 & 367 & 0.8 \\
\hline
\end{tabular}

Table 4-7 shows that the correction for the mixing control has a significant effect of the gas consumption savings, which falls from $18.4 \%$ to $10.5 \%$. The total energy savings in the building also fall significantly, from $8.3 \%$ to $4.7 \%$. Even if the maximum gas savings predicted as being due to the mixing control $(4,371 \mathrm{kWh} /$ day) are used in the correction, there would still be savings of $2,232 \mathrm{kWh} /$ day $(7 \%)$ in the gas consumption. These results therefore imply that, contrary to the simulation results, the savings evident in the monitored data were due to more than the activation of the mixing control. Table 2-3 lists some of the other retrofitting activities that may have influenced the gas consumption. 


\section{Control Performance}

With the exception of VAV upgrade, the retrofits made in the building did not constitute significant changes to the control strategies, schedules, or local loop algorithms in the building. The main benefits of the changes are improved supervision capabilities, better tracking of control performance, and improved response times to system and control problems. The hypothesis is that these benefits will ultimately result in improved control performance. Although improved control can lead to reductions in energy use, this is not always the case. The main benefit of better control is improved thermal comfort conditions in the building. For the building operators, occupant satisfaction is the main priority; lowering of energy consumption is less important. In this section, selected aspects of the HVAC system control performance are evaluated in an effort to ascertain whether the retrofits have led to quantifiable improvements.

\subsection{AHU Setpoint Tracking}

The control of the subsystems in the eight main air-handling units is fundamentally important for both occupant comfort and energy consumption. Although the algorithms and final control devices in these units were not changed during the retrofits, installation of the BACnet system improved monitoring and supervisory capabilities. Figure 5-1 shows time-series plots of the three controlled variables in air-handling unit SSBW2: mixed-air temperature, hot-deck temperature, and cold-deck temperature. 'The graphs show the means of these variables, which were calculated for each day during the times when the supply fan was active. The setpoints specified in the sequence of operations are plotted on each graph as a solid line.

Figure 5-1 shows that the tracking of the three setpoints is poor before the beginning of the pre-retrofit period. The reasons for this poor performance are not clear. The setpoints may have been changed during this time, or the control loops may have been poorly tuned. Control performance improves during the course of the pre-retrofit period, which could have been due to re-tuning of the control loops or setpoint resetting. The setpoint in the hot deck generally appears to have been tracked better than the three other setpoints, although there are days when significant errors are evident. The tracking of the mixed-air setpoint is poor throughout the data. This is because the setpoint is usually below that of the outside- and return-air temperatures. The mixing dampers thus cause the full outside air to be supplied to the building for the majority of the time. The winter months are the only periods where the dampers are likely to be providing truly mixed air. Marginally better setpoint adherence occurs during the winter months, but it appears that the setpoint is still largely unattainable for the majority of the time. 


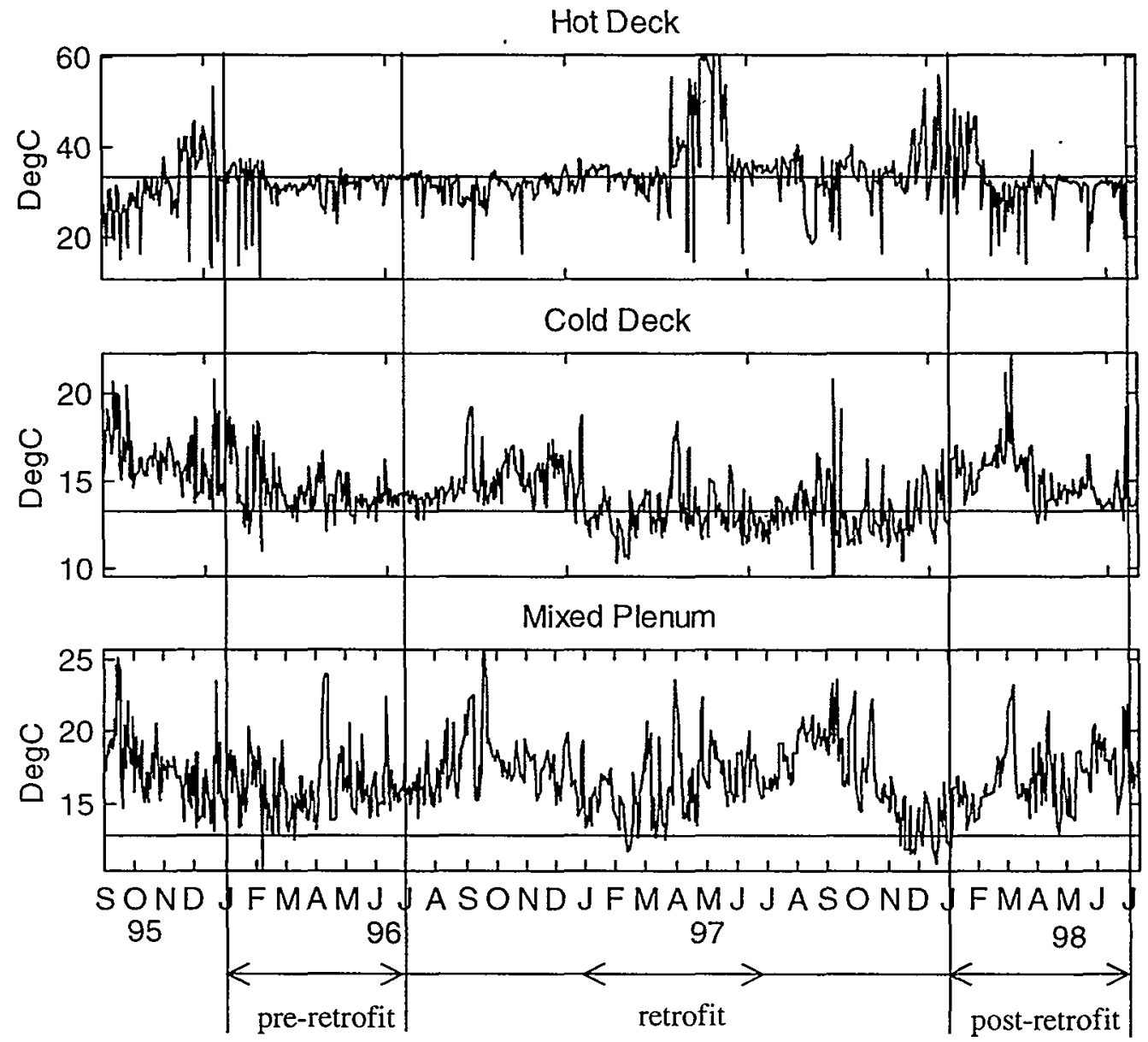

Figure 5-1: Mean daily values of the controlled temperatures in one AHU

The mean absolute errors (MAE) were calculated for each controlled variable assuming the following setpoints, as specified in the as-built sequence of operations:

- $\quad$ Hot deck $-33.33^{\circ} \mathrm{C}$

- $\quad$ Cold deck $-13.33^{\circ} \mathrm{C}$

- $\quad$ Mixed plenum $-12.78^{\circ} \mathrm{C}$

The MAE values were calculated using all available data samples and the results are shown in Table 5-1 along with the controlled variable means.

Table 5-1: Mean absolute errors (MAE) and means of AHU controlled variables

\begin{tabular}{|l|r|r|r|r|r|r|}
\hline \multirow{2}{*}{ Period } & \multicolumn{2}{|l|}{$\begin{array}{l}\text { Hot Deck } \\
\text { Temperature }\end{array}$} & \multicolumn{2}{l|}{$\begin{array}{l}\text { Cold Deck } \\
\text { Temperature }\end{array}$} & \multicolumn{2}{l|}{$\begin{array}{l}\text { Mixing Plenum } \\
\text { Temperature }\end{array}$} \\
\cline { 2 - 7 } & $\begin{array}{l}\text { Mean } \\
(\mathrm{K})\end{array}$ & $\begin{array}{l}\text { MAE } \\
(\mathrm{K})\end{array}$ & $\begin{array}{l}\text { Mean } \\
(\mathrm{K})\end{array}$ & $\begin{array}{l}\text { MAE } \\
(\mathrm{K})\end{array}$ & $\begin{array}{l}\text { Mean } \\
(\mathrm{K})\end{array}$ & $\begin{array}{l}\text { MAE } \\
(\mathrm{K})\end{array}$ \\
\hline Pre-Retrofit & 31.4 & 4.3 & 14.6 & 1.9 & 16.1 & 3.4 \\
\hline Retrofit & 37.6 & 8.1 & 13.5 & 2.8 & 16.1 & 3.4 \\
\hline Post-Retrofit & 32.7 & 6.7 & 15.2 & 2.7 & 16.1 & 3.4 \\
\hline
\end{tabular}


Figure 5-2 presents the control performance is presented graphically. The figure shows that there is no change in the MAE of the mixed air temperature. Since the setpoint is unattainable for the large majority of the time, the MAE is dominated by the outside air temperature, which does not change significantly between the three considered periods. There is an increase in both the hot and cold deck temperatures from the pre- to postretrofit periods. Both of these controlled variables experience larger MAE values in the retrofit period, this probably being due to operational interruptions and the changes made during this period to other systems in the building.

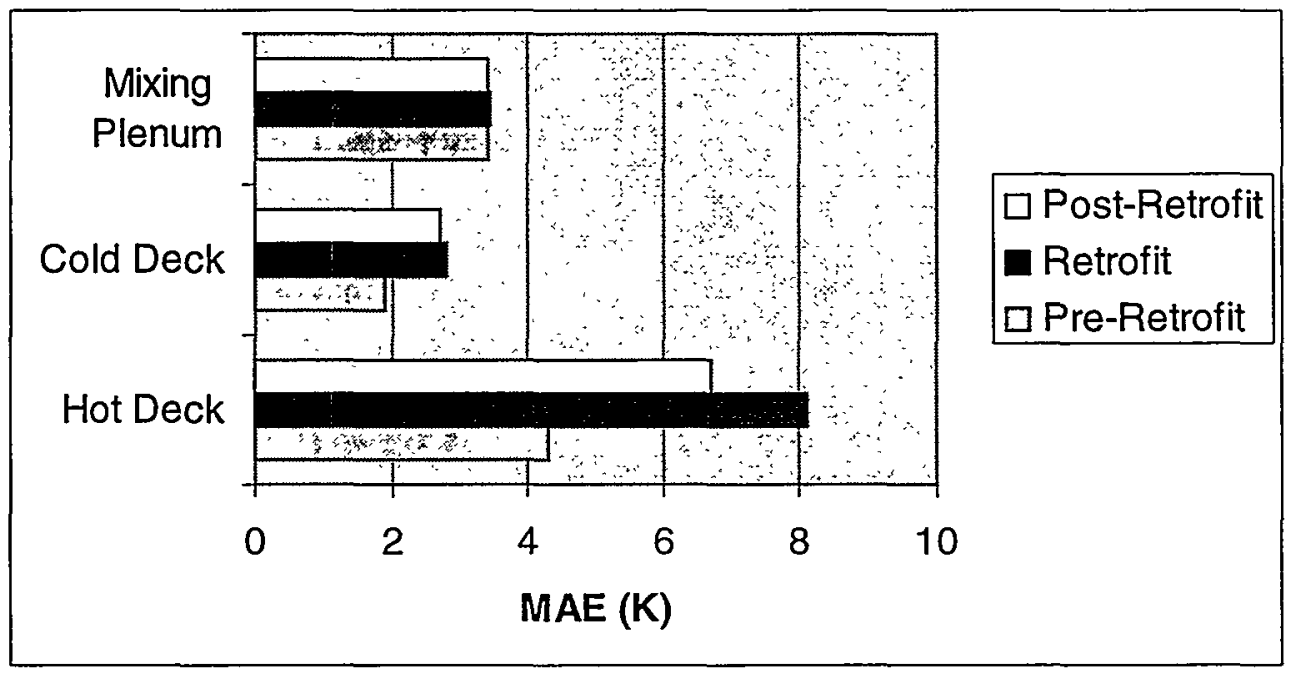

Figure 5-2: Mean absolute errors of AHU controlled variables

Closer inspection of the monitored data revealed that the control loops for the AHU appeared were poorly tuned in the post-retrofit period. Figure 5-3 illustrates this, which shows the three controlled temperatures in the monitored AHU. It can be observed that the cold-deck and mixed plenum temperatures both undergo severe oscillations during the period shown. This indicates that the gain in the controllers was set too high. It is interesting to note that oscillations of this degree sort were not observed in the pre-retrofit period. 
COLD-DECK
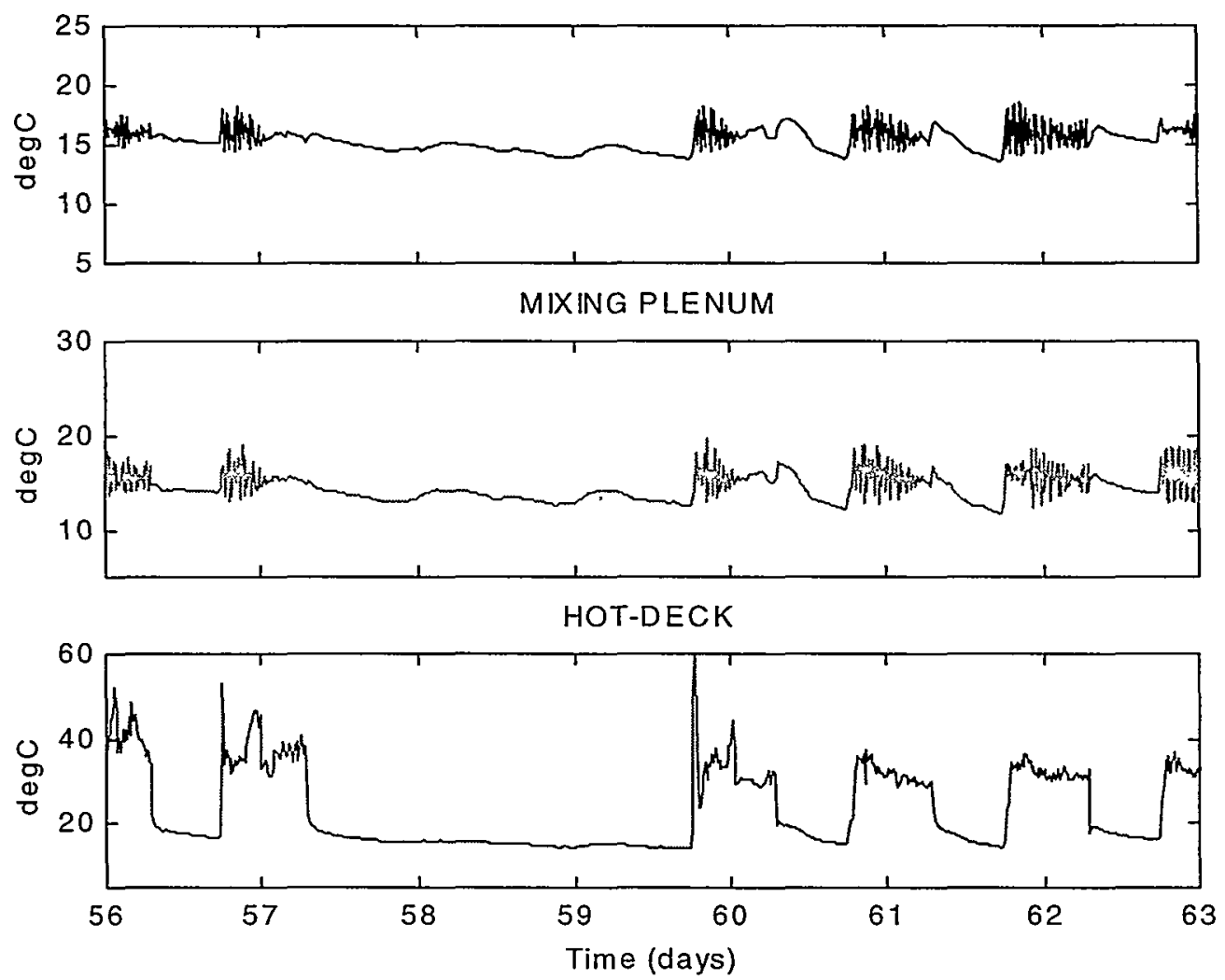

Figure 5-3: Controlled temperatures in the monitored AHU in the post-retrofit period

\subsection{Automated Scheduling}

Before the retrofits, the HVAC systems in the building were switched on and off manually each day; the retrofits introduced automatic time-of-day (TOD) scheduling. The ability of the new automated procedures to switch the systems on and off is assessed by examining data associated with the large supply fan in the air-handling unit SSBW2. Since direct power measurements to this fan were logged, the activation and deactivation times were estimated assuming that the fan was on if its monitored power rose above a threshold, selected to be $5 \%$ of its maximum power rating. A non-zero threshold was selected in order to account for current leakage and other inaccuracies in the measurements.

Figure 5-3 shows the results of the fan scheduling. In the graphs, a " + " indicates the time when the fan was switched on and a "o" indicates the off time. The data have been separated, with the top graph in the figure showing the weekdays and the bottom graph the weekend days. The systematic one-hour changes in the off times are due to daylight saving time. Interestingly, the on-times do not appear to be affected in the same systematic way. 


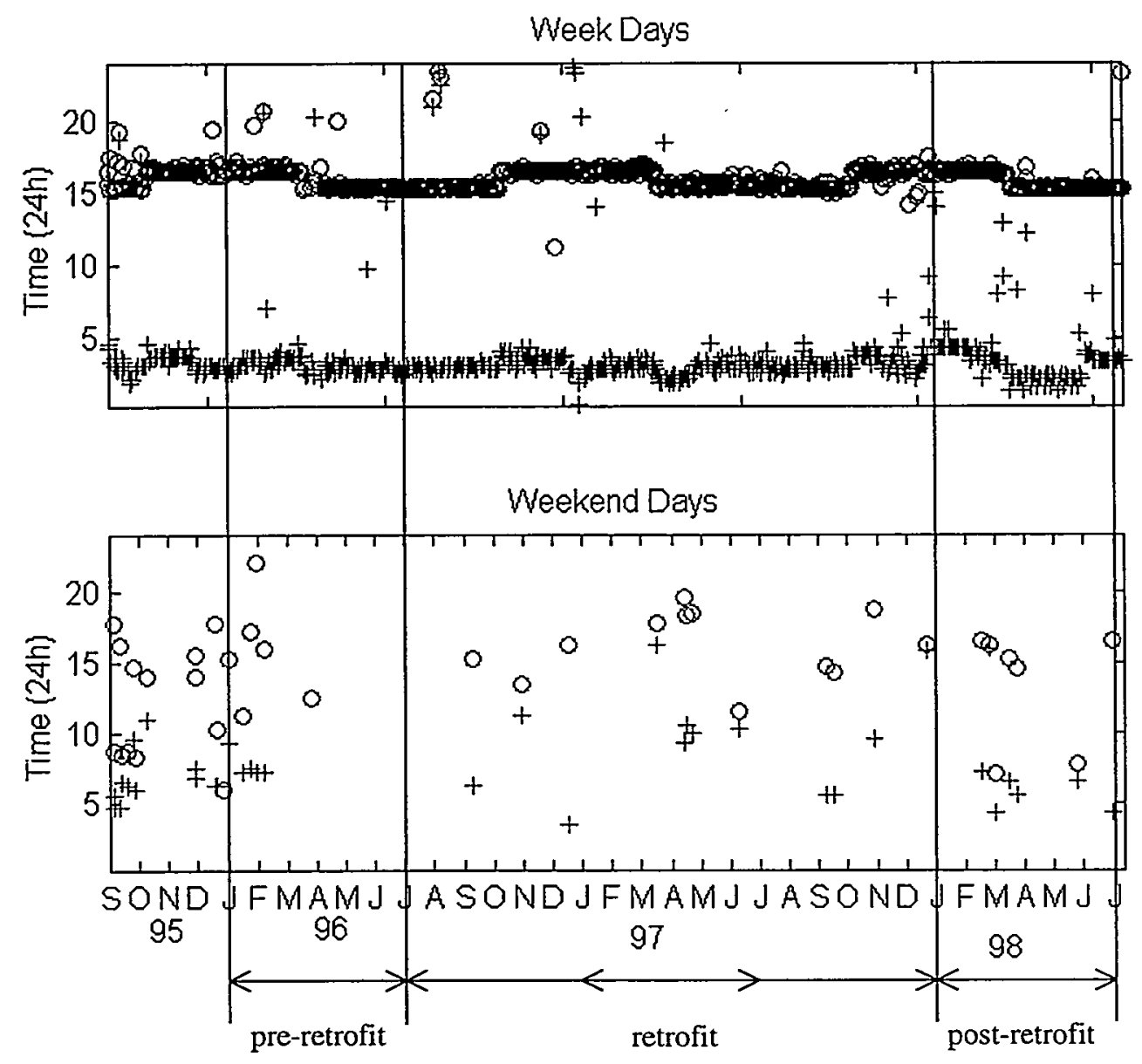

Figure 5-4: Scheduled start-stop times

Figure 5-3 indicates that the scheduling appears to have been carried out effectively before the retrofits, as inferred by the presence of only a few outlying points on the weekdays. There are more occasions in the time prior to the pre-retrofit period where the system was operated at the weekend, but this may have been due to occupant-requested out-of-hour operation. The most important observation from Figure 5-4 is that the onand-off scheduling appears to have deteriorated following the retrofits. Feedback from the building operators confirmed that a problem existed in the automated scheduling during the designated post-retrofit period.

\subsection{Fan Control}

Direct evaluation of the fan control was not possible using the logged data as no measurement of static pressure was available. It was therefore not possible to examine how well the variable speed drives were able to track the static pressure setpoint. However, as shown in Section 3.2, the fan performance improved in terms of energy. 


\subsection{Damper Control}

As mentioned in Section 4, the controller for the mixing dampers is rarely able to meet the mixed air temperature setpoint. However, there is evidence that the control has improved following the retrofits. A greater portion of the total AHU energy was attributed to the mixing box in the post-retrofit period (Figure 3-10) and the operational profile during the winter months indicated more reliable control (Figure 3-9). 


\section{The Building Operator's Perspective}

Part of our task in studying the performance of the building was to understand the building operators' satisfaction with the EMCS retrofit. To do this we conducted informal interviews with two building operators, six and ten months after the EMCS was installed.

The primary goal of the interviews was to understand how well the EMCS with BACnet performed from the building operator's perspective. In general, the building operators find that the EMCS performs very well and greatly improves the facility's operation.

\subsection{Background of the BACnet Control System}

The BACnet system is not itself an energy-efficiency feature, but is a communications protocol that allows an EMCS front end (user interface) to communicate with equipment from different vendors. Our task was not to evaluate the performance of how well the BACnet system works internally-that has been studied by others (Applebaum and Bushby 1998) - but to learn how the building operators manage an EMCS that is BACnet compliant.

The facility's original control systems were primarily pneumatic types including systems from Johnson Controls, Inc. (JCD) and Honeywell. There is a small DDC system, (Johnson Controls' Metasys), that controls about a dozen rooms on one floor of the building. The Trane Company also had some VAV boxes that were locally controlled by an on-board DDC program.

To date, the installation of the BACnet compliant system has only integrated the Trane VAV boxes with the new, native BACnet DDC system by Alerton. Additional details about the EMCS retrofits can be found in (Applebaum and Bushby 1998). There is no Johnson Controls BACnet-compliant gateway that would allow the facility operators to "see" the Johnson Metasys. Further, due to restricted access on those floors, the original Johnson pneumatic controls have not been upgraded either to the METASYS DDC system or to a native BACnet system in the facility.

\subsection{Interview Questions}

Interview questions were posed to two building operators at the building. Each interview was prefaced with an introductory statement and followed by a series of questions in these categories:

- Background

- Daily Routine

- Control System Interface

- Wrap-up

The first set of interviews was conducted in person, soon after the new Alerton EMCS was fully operational (but lacking all the alarm capabilities). The follow-up interviews 
were conducted, by telephone call, about four months later. The spacing of the interviews allowed us to learn how the operators' experience and familiarity with the system changed over time.

The nine Background questions were designed to establish each operator's involvement at 450 Golden Gate, job experience level, and general discussion about their activities and responsibilities.

The eight questions on Daily Routine centered on what tasks were typically performed during an operator's shift, including serving clients and building systems. With this set of questions, we began to ask how the EMCS was becoming a part of their daily routine.

Fifteen questions were asked regarding Control System Interface, which constituted the majority of the interview sessions. Along with questions about how, when, and what the EMCS interface provided, inquiries concerning dispatching maintenance personnel and improvements to the EMCS were also asked.

The interview sessions were completed with five questions that summarized the operator's experience with the new EMCS.

\subsection{Responses from the First-Round Interviews}

The building operators had a great deal of experience with the building operation prior to the retrofit. Each operator felt that their daily routine had changed for the better with the introduction of the new EMCS. After the initial "shake-down" period, the first level of the unfamiliar EMCS interface was quickly incorporated into their daily tasks. The operators immediately recognized the benefits of a centralized interface, and the advantages of being able to manipulate the building's operating parameters remotely. Importantly, when a problem arose that could not be corrected remotely, the operators were now able to dispatch maintenance personnel having more specific information about the problem, and a clearer set of instructions in order to fix the problem. Efficient dispatching of personnel was very important to the operators, given that their staff levels were reduced.

Each interviewee had specific ideas about how the information presented by the EMCS could be improved. They proposed changes to both the type and the position of textural information presented on the screen. In addition, the operators felt the need for more training on the system, specifically, training on programming. At present, programming problems and deficiencies are fixed under the one-year warranty agreement with Alerton. After this period, the operators should be capable of handling these adjustments.

Suggested enhancements proposed by the operators to the user interfaces included:

- Incorporate complaint history and other maintenance histories into interface

- Include more plant physical information, such as sensor location in zones

- Include a history of any changes made in setpoints or other control parameters

- Embed more short-cut keys 
- Generic screen layout

- Procedure for addressing alarms is confusing, need on-screen history

Other improvements that were suggested by the operators:

- More training on use and programming of the system

- Knowledge of how to make control strategy changes

- Remote paging of alarms to maintenance personnel

- Simplified remote access via palm-top computers or cell phone

The operator responses to the "wrap-up" questions clearly revealed that they feel that the EMCS significantly helps and improves building operation. In addition, they feel that Alerton has demonstrated a strong commitment to ensure that they, the operators, are well supported in their use of the new system. The operators believe that other GSA facilities would benefit from a similar EMCS installation.

\subsection{Responses to the Follow-Up Interviews}

The questions for the follow-up interview sessions were similar to those from the initial interviews, with modifications to reflect changes in the operator's function, duties, and daily routine. The only significant change in operator duties was that one operator had increased responsibilities to provide data from the EMCS to allow other facility members to complete their tasks.

Each operator interviewed felt that their daily routine has been significantly and permanently changed due to the EMCS. They have found that tenant complaints about temperature problems have decreased. Alarms were installed in the system since the initial interviews, allowing early response to trouble calls, providing an "early warning system" to help operators keep ahead of maintenance issues.

The follow-up questions addressing the control system interface were arranged to specifically evaluate the interoperability of the new EMCS, since it is fully BACnet compliant. However, as noted above, the new Alternon EMCS only integrated the Trane VAV boxes. Consequently, since no existing EMCS were upgraded to BACnet, we were unable to assess BACnet's interoperability over a wide range of systems.

The EMCS makes it easier for work crews to respond quickly to tenant problems and to diagnose problems more efficiently. The EMCS alarm features often let building operators know when there is a problem before a tenant registers a complaint. Remote responses to problems has become increasingly common - the operator now needs to call the tenant back to let them know that someone has paid attention to their complaint.

Importantly, the operators interviewed continue to recommend that the GSA install EMCSs in other GSA buildings, especially when staff size is reduced. 


\subsection{Overall Findings from the Operator Interviews}

The operators' initial interest and curiosity about the new EMCS has evolved into their daily reliance on the new system. Typically the use of an EMCS by operators goes through the following stages: from skepticism, to gradual acceptance, and then to dependence. Also, handling trouble calls and alarms reported by an EMCS is a complicated mix of the type of call or alarm, its criticality, the individual required to respond, the time of day, and the trouble-shooting ability of the respondent. The comfort level of the operator with the EMCS PMI (Person Machine Interface) is the major variable in the response to alarms and trouble calls.

Data retrieved and stored by the EMCS has become valuable to other organizations at the building. The facility-planning estimator is now setting up a structure that will recharge tenants for HVAC use. One of the operators interviewed is providing information from the EMCS of equipment and energy-use information. Eventually, real-time pricing will be put into effect for the facility that will incorporate the EMCS.

Clearly, the EMCS is a valuable tool at the facility. The ability to dispatch maintenance personnel more efficiently, to perform remote equipment surveillance, and to gather historical operating information has been immediately helpful to the building operators. They also view the new system as a commitment from building management to help them to do their jobs better-they feel the new system was a real morale booster.

One downside to the implementation of the new system was the reduction in staff assigned to operations and maintenance, a decrease from a staff of 18 to 8 . Whether this was due to the belief that better building automation required less human staff, or other reasons, was not clear from the interviews. In addition, the staff recently assigned to building operation and maintenance has had less experience and education than the previous staff, making it harder for the operators to use the full capabilities of the EMCS. The consequences of these actions are not clear, but it would be unfortunate if the reaction to smarter building controls is to have fewer qualified staff to take advantage of their capabilities.

Another significant finding from the interviews is that the EMCS has not been viewed as a tool for energy management. The operators did not mention using the EMCS to track energy consumption, or to track the energy performance of building systems or end-uses. They feel that their job is to operate the building to minimize occupant complaints. There is no incentive to them for reducing energy use, nor is there a "culture" of energy efficiency as regards building management-energy savings are not a priority, occupant comfort is most important. We discuss the implications of this situation in the next section 


\section{Conclusions}

\subsection{Energy Benefits}

Based on the monitored data, the overall energy use in the building fell by $8 \%$, comprised of an $18 \%$ reduction in the gas consumption and a $1 \%$ reduction in electricity use. The utility billing records indicated slightly higher savings of $10 \%$, comprising $20 \%$ in gas savings, and $1 \%$ in electricity. Differences in the gas savings are due to missing monitored data in January 1996 and variations in the heat content of the gas not fully accounted for in the monitored data. The cost savings from the utility data were $4 \%$, as most of the savings were in gas and most of the cost is in electricity.

The analysis in Section 3 shows that almost 3\% of the savings from the HVAC system may have been masked by increases in the electricity used by unmonitored systems in the building. Based on extrapolations of the unmonitored fans in the building, the total savings from the HVAC (electricity and gas) is estimated to be approximately 10,000 $\mathrm{kWh} /$ day, which is a reduction of $20 \%$ from pre-to post-retrofit (Table 3-6). The savings in the total monitored gas and electricity were only about 6,603 (gas) +367 (electric) $=$ $6,970 \mathrm{kWh} /$ day (Table 3-5). Savings in the gas consumption were accentuated due to the mixed air control in the main air-handlers operating at $100 \%$ outside air during the first few months of the pre-retrofit period. Based on simulation results, we corrected for the lack of mixing control in the monitored data. The correction led to a fall in the total gas savings from $18 \%$ to $11 \%$; the total building energy savings also fell from $8 \%$ to $5 \%$.

Conversion of the existing constant volume HVAC system to a variable-air-volume system represented the most significant change to the control strategy as regards energy consumption. In the monitored data, significant reductions in energy usage were evidenced in the fans and the primary cooling and heating plant. The simulation results suggested that a VAV capability in isolation benefited only the cooling plant, while the load of the heating plant was marginally increased. In a VAV strategy, the volume of air brought through the air-handlers is related to the loads in the zones. Relatively strong coupling thereby exists between zonal loads and the energy ultimately used. In the preretrofit mode of operation, the main air-handler fans were operating at a constant $80 \%$ of their maximum load, and hot and cold decks were regulated to fixed-air temperature setpoints. Since the air-handlers were also operating on $100 \%$ outside air, this pre-retrofit strategy had no coupling between building loads and plant energy. The plant power consumption was instead dependent on outside air conditions. Installation of VAV therefore greatly improved building energy efficiency.

According to the results of the simulation, the savings in the gas consumption in the building were mostly attributed to the activation of the controller for the mixing dampers in the AHU's. However, a comparison of the simulation and monitored data results indicated that a significant proportion of the savings in gas may have been due to other changes made to the boiler plant. These changes included installation of electric hot water heaters and an EGR exhaust return system fitted on boiler \#1. The savings in the chiller plant are negligible for mixing control. This is because the control of the mixing 
plenum was set up so the setpoint was lower than that of the cold deck. The idea behind this is to provide mixed air at approximately the same temperature as the cold-deck setpoint, taking account of a temperature rise across the supply fan. This strategy therefore eliminates the chiller cooling when the mixing box controller is able to achieve the setpoint. Since the mixed-air setpoint is low relative to the ambient-air temperature range, the mixing dampers deliver $100 \%$ outside air for the majority of the annual cycle. When the dampers do begin to re-circulate, return air to meet the setpoint, the cooling coils are already deactivated and do not therefore benefit. Analysis of the data indicated that mixing dampers were being regulated during the three colder months of the year. The analysis also revealed damper activity in the pre-retrofit period. It has yet to be ascertained whether this was due to manual override.

Automated scheduling of system operating times did not lead to discernible savings as the manual operation previously employed was of a high standard. In fact, problems with the automatic scheduling were evident in one of the main air-handlers in the post-retrofit period. From the analyzed data, it was evident that the switching on of this unit was delayed on a number of occasions. Although this leads to reductions in energy use, the comfort conditions in the building may be detrimentally affected. The building operators confirmed that a problem existed during this time.

\subsection{Control Benefits}

Benefits to the control performance as a result of the retrofits are more difficult to evaluate than changes in energy usage. Occupant comfort is one important measure of control performance, but no quantitative measurements of this were made during the course of this research. Further research might address this by evaluating complaint logs.

System variables that came under new regimes of control because of the retrofits include:

- Duct static pressures, as a result of variable-frequency drives installed on the fans

- Zone temperatures, due to terminal units being operated in VAV mode

- Mixed plenum air temperature, due to activation of the damper controllers

- Virtually all variables, due to implementation of automatic scheduling

Evaluation of the closed-loop static-pressure control loops in the main air-handling units could not be carried out due to no static-pressure measurements being available in the archived data. We were also unable to evaluate control of the VAV terminal units due to insufficient measurements. Regulation of the mixed-air plenum temperature was evaluated in terms of the mean absolute error (MAE) during operational periods. In the air-handling unit considered, there was no change in the MAE from the pre- to postretrofit periods. The on and off scheduling of the plant was carried out to a high standard prior to the retrofits, the implementation of automatic scheduling led to less accurate scheduling due to problems with the automated system.

Interestingly, the closed-loop control of the hot- and cold-deck temperatures in the main air-handlers appeared to have deteriorated as a result of the retrofits, based on the MAE figures. This result may have been due to these loops being badly re-tuned. An 
unconfirmed possibility is that with the advent of a more open system, operators are more prone to try and perform tasks such as re-tuning themselves. One hypothesis is that more accessibility may lead to more unwarranted intervention.

Although physically quantifiable aspects such as setpoint tracking reveals something of system controllability, other aspects such as how the speed of response to system problems is affected are also part of control performance in the broader context. Essentially, problems/faults in the HVAC system may be viewed as disturbances, correction, and thus rejection of these disturbances is part of the overall system control. One of the potential benefits of a BACnet-based system is that performance and operation is made more accessible to the operators. Hence, faults and problems should therefore be detectable, diagnosable, and thus be able to be remedied more quickly. Although no quantitative assessment of these benefits was possible in this research, the results of the questionnaires indicate improvements in operator supervision capabilities.

In summary, the results of the analysis indicate that quantifiable control performance has deteriorated following the retrofits. Both operation scheduling and closed-loop performance have been detrimentally affected. These may be due to inevitable set-up problems encountered when a new system is installed. There is a definite learning period associated with a new system and a later evaluation of control performance may yield a fairer assessment of the retrofit benefits. We were unable to assess operator responsiveness fully during the course of this research.

\subsection{Operator Usage Benefits}

One of the main findings from the questionnaires distributed among operators is that they felt better able to respond to complaints from occupants in the building. Once a complaint had been received, the EMCS could be interrogated to isolate the problem more accurately than had been previously possible. Although there were several enhancements that the operators would like to have seen made to the user interfaces, the general feedback was positive. A boost to the morale of the personnel was reported and the interviewees were excited about working with the new technology. There were, however, reported shortages in human resources assigned to work with the new system. In fact, the number of personnel had been reduced about the same time as the introduction of the new system. The building operators also identified additional training of the EMCS users as desirable; the introduction of a more automated system may allow management to assign less educated personnel to the operations and maintenance task. 


\section{Recommendations}

From their inception, energy management and control systems (EMCS) have promised improved comfort conditions, energy savings, and better system supervision capabilities. Integration is the main idea behind an EMCS; previously isolated controllers and instrumentation are made accessible through a communication network. This facilitates integrated control solutions and improved supervision capabilities. In large buildings, such as the Philip Burton Federal Building, different EMCSs and/or dedicated controllers were installed over a period of time. BACnet is intended to realize the original integration goal by allowing interoperability between EMCSs from different manufacturers. Although the goal of systems integration is generally being realized, the benefits of an integrated system are not being fully achieved. This section identifies areas in which this problem could be addressed.

\subsection{Operator Usage}

The building operators and users of the EMCS have a key role to play in maximizing the benefits of the system. Improved accessibility and integration have made vast amounts of information available to the operators. In addition to real-time sensor signals and measurements large amounts of trended data are also now made available. The main problem is that of information overload. There is generally too much information to be usefully processed. One example is where the hot deck temperature in one of the main air-handling units was $20 \mathrm{~K}$ above its setpoint for about 6 weeks. An alarm should have been generated for this condition, but it is conceivable that this was not set up. In any case, the problem was not resolved for the main reason that it probably did not lead to occupant complaints. Zonal conditions may not have been affected due to compensatory action of other equipment in the HVAC installation.

The results of the questionnaires indicated that there are a number of ways in which the interaction between the operators and the system may be improved:

- Improvements to user interface

- Better operator training

- Energy-saving incentives

- Better utilization of trend data

The way in which system information is presented through the user interfaces on an EMCS network has an important effect on how operators interact with their system. The most common approach employed is to make schematic diagrams of different subsystems available along with real-time sensor values. Users may then navigate through the various parts of the system. The questionnaires revealed that the operators would like to see more historical information in the user interfaces related to maintenance changes and alarm handling. Instead of presenting only sensor signals and system diagrams, operators would like to see the EMCS become more integrated with the maintenance carried out in the building. Another important aspect identified in the questionnaires is that of interface consistency. Operators want each display screen to have generic layouts and short-cut keys. In addition, embedding of more physical information about systems, such as sensor 
positions in zones was identified as a feature that would improve user-system interaction. In summary, user interfaces are still evolving and operator feedback is very important in deciding on the nature of the improvements. It is clear from this research that in addition to the integration of control systems and instrumentation, EMCS should also be a means for integrating information from other life-cycle processes, such as design, commissioning, and maintenance.

Training of operators is very important in achieving better system utilization. It seems that one trend is for management to cut the human resources assigned to operating and supervising building services in response to the installation of a more automated EMCS. In the Philip Burton Federal Building, the education level of personnel assigned to operations and maintenance (O\&M) was reduced when the new EMCS was installed. This created problems for O\&M supervisors, and a major complaint was that insufficient training was available for all users of the system. It was felt that installation of the new system meant that more could be accomplished in terms of system supervision and maintenance. However, this widened the scope of work resulting in manpower shortages.

The main priority of the operators in the building was occupant satisfaction. In this respect, the new EMCS was identified as a success. Response times were shortened and it was felt that personnel were providing a better quality service. Energy efficiency was not of high priority. In the current climate of relatively low cost energy, it is unlikely that energy efficiency will figure high on operators' priority lists. However, one step that could be taken to raise the awareness among EMCS users is to integrate more energy usage figures and targets into the user interfaces. Operators should have the facility to track energy usage and compare with ideal operation targets. This feature should be available not only at the whole building level, but also at the subsystem and component levels.

In the Philip Burton Federal Building, a large number of sensor-points were being logged by the EMCS. Most of these data are redundant to the operators, although an alarm generated on a particular sensor might cause the operators to analyze the point history of that sensor. It seems that there is significant potential for better processing of historical trend data. Performance characteristics and indices key subsystems could easily be calculated using measured sensor signals. This "condensing" of information could improve the usefulness of trend data and reduce the overhead associated with its handling.

\subsection{Control Strategies}

One of the purposes of an integrated control system is to facilitate more advanced control strategies. These strategies make use of information from various loops in the system in order to better co-ordinate and optimize operation. In the Philip Burton building, control strategies were not changed significantly from pre- to post-retrofit, although retrofits still to be completed do represent strategic changes. It is clear that the concept of integration creates many new possibilities for improved control and energy management. Areas for improvement are listed below. 
- Setpoint scheduling

- Sequencing to reduce the canceling effect of different subsystems

- Coordination of control loops and operational times

- Optimization of setpoints and operational schedules based on energy/comfort criteria

\subsection{Application of New Technologies}

The advances that have been made in facilitating access to information from distributed building systems and controllers have outpaced the development of ways in which to handle and process this information. Numerous research projects have demonstrated that EMCS data can be used for applications such as fault detection and diagnosis, advanced control strategies, preventative maintenance, performance optimization, etc. In practice, little analysis of EMCS data is carried out and the full potential of the EMCS is therefore not realized.

Three new technologies are cited below, which are at a stage of development where application in real buildings is viable. Each of these technologies could be developed to operate using the currently available EMCS hardware.

- Fault detection and diagnosis

- Advanced control solutions

- Building life-cycle information integration

Fault detection and diagnosis (FDD) ranges in complexity from carrying out limit checking on critical variables to model-based methods. Limit checking is currently the state-of-the-art in most EMCS's. There are extensive possibilities for applying more advanced techniques to achieve a better insight into system performance. The simplest and most logical step to make from the current limit-checking procedures would be to combine sensor information in order to generate performance indices for various systems. Limit checking on these indices could then be carried out. More advanced, yet still technically viable, possibilities include the use of on-line simplified models of the system and its components. Predictions generated by models of "correct operation" may be compared with measurements of actual performance in order to evaluate behavior.

The availability of sensor information from various control loops distributed throughout the building on a single network opens up various possibilities for new strategic control solutions. Examples include the implementation of optimal control strategies that coordinate subsystem operation and select control-loop setpoints based on criteria such as energy and/or comfort. These strategies may conceivably use system models or building simulations in order to perform optimization. At the local-loop level, greater computing power could facilitate the implementation of improved control algorithms to deal with plant non-linearity, which is a frequent problem in HVAC systems. Examples of possible alternatives to conventional controllers at the local-loop level include model-based and adaptive controllers. 
A third major opportunity for technology application is in the area of life-cycle information integration. The idea is to standardize the way in which building and system information is represented and handled throughout the building life cycle. Recent initiatives, such as those of the International Alliance for Interoperability (IAI) have demonstrated successful application of this concept. Data models/classes have been developed in the IAI in an effort to allow software from various stages in the building life cycle to interoperate. Standardization of the way in which information is handled from processes such as design, commissioning, and maintenance would open up the possibility for allowing an EMCS to more readily access and utilize this information. This approach could help to facilitate some of the enhancements identified in the questionnaire study, such as: making system (design) information available through the EMCS user interface, integrating maintenance histories and records, and defining performance targets from design information.

\section{4. "Classic" Recommendations}

The following recommendations are given because we find they apply to nearly every project we evaluate. As basic as they may seem, we rarely find that they have been carried out in practice. By explicitly requiring these steps the building owners and operators will be in a far better position to realize the energy goals for their projects. These recommendations are to:

Document the design intent. The designer needs to document design intent for every retrofit measure. A description of the measure, how it operates and why, are basic requirements that should be spelled out in plain English for every project.

Document the predicted savings. Similar to above, the designer should spell out how the measure will achieve energy savings, what baseline was used for comparison and what assumptions were made.

Document the sequence of operations. For control retrofits, the sequence of operations needs to be spelled out in plain English and specified in the contract documents. It is important that there be "as built" specs so the actual sequences can be compared to the original design intent. For control retrofits there should be as much documentation as possible of the pre-existing control sequences.

Document the Commissioning Plan. A thorough commissioning plan and operations manual are essential to ensure correct operation of the building's systems. Too often the equipment is "commissioned" but the overall systems performance is neglected. Owners should require a complete commissioning plan and implementation strategy.

If these measures were adopted in more buildings we would see higher quality projects, greater energy savings, and more credible stories to tell industry and building owners about the benefits of energy efficiency. 


\section{Bibliography}

Alerton Technologies, Inc. 1996. "Controls Contract Awarded for GSA BACnet Pilot Project, Phase II, 1996.

Applebaum, M. A., S. T. Bushby. 1998. "BACnet's First Large-Scale Test." ASHRAE Journal. July 1998.

Bosek Gibson \& Associates, The Technical Energy Audit Report, final report, March 7 1997.

Bosek Gibson \& Associates, DOE-2 Final input files and parametric runs, March, 1997.

Energy User News, "GSA puts BACnet to the test in SF facility", November 1996.

ESS, Inc., "EMS and Chiller Design Protocols for the PBFB, December 15, 1994.

ESS, Inc., EMS Schematic Design, Phillip Burton Federal Building, 90\% Submittal, June $19,1995$.

ESS, Inc., EMS Project Manual, Phillip Burton Federal Building, April 22, 1996.

ESS, Addenda 1-5 to EMS Project Manual, April-June, 1996.

ESS, Inc., Meeting Minutes: Progress Meetings 1-35, 1996-1998.

ESS, Inc., EMS control drawings and sequence of operations, Phillip Burton Federal Building.

Rubinstein F., Jennings J., Avery D., Blanc S. 1998. "Preliminary Results from an Advanced Lighting Controls Testbed". Pending publication in the Journal of the Illuminating Engineering Society.

SBW Consulting, PBFB Monitoring and Data Verification, no date. 


\section{Appendix A: Analysis Plan}

Rick Diamond, Geoffrey Bell, Joe Huang, Kris Kinney, Steve Kromer, Mary Ann Piette and Dale Sartor Lawrence Berkeley National Laboratory

December 1997

\section{Background}

The Phillip Burton Federal Building (PBFB) in San Francisco is the site of several significant energy retrofits and technology demonstrations. This analysis plan provides a background for the evaluation of the retrofits, specifically the energy management control system that will be using the BACNet protocol.

The building's HVAC systems are currently operated by a variety of control systems, including the original 1960 pneumatic Honeywell system--the cold deck side of the eight main air handlers--and a recent Johnson Controls, Inc., pneumatic system--the hot deck of the dual duct system (Bosek Gibson 1996 p. 43). The dual duct mixing boxes were designed to be variable volume, but have been operated as constant volume. Exhaust fans are on set schedules for the different uses of the building.

The new Energy Management Control System (EMCS) is designed to provide enhanced level of control of the mechanical systems by implementing finer and more sophisticated control strategies, including optimum start-stop, advanced scheduling, reset routines and sequence operations (Bosek Gibson 1996 p. 71). This system is a Direct Digital Control (DDC) and will not only monitor the HVAC equipment, but will help detect and diagnose component failures (see Appendix $A$ for more detail).

The implementation of the BACnet communication protocol as part of the EMCS retrofit is designed to assist the operator in accessing various systems (from different vendors) for monitoring and control. This system should lead to improved performance through early detection of problems as well as fine-tuning of the different systems. The graphics users' interface package with the EMCS is designed to improve the owner's scheduling capabilities and provide system diagnostics (Bosek Gibson 1996 p. 72).

\section{Objective}

The U.S. Department of Energy and the GSA are interested in evaluating the performance of the EMCS retrofits in the building. Because the site is a major federal facility (GSA), DOE's Federal Energy Management Program is keen on communicating the lessons learned from the retrofit to other federal agencies. And as the building is a major demonstration of the BACnet protocol, DOE's Commercial Buildings Research Program would like to show the lessons learned from the retrofit to a wide audience of the commercial building energy community.

LBNL's objective is to evaluate the energy performance of the building, specifically the performance of the EMCS retrofits. 


\section{Approach}

There are three basic questions we are asking about the project:

1. How did the energy use in the whole building change after the EMCS retrofit?

2. How much energy did the new EMCS system save?

3. How well does the EMCS system perform from the building operator's perspective?

Each of these questions requires a different analytical approach.

\section{How did the energy use in the whole building change after the EMCS retrofit?}

The first question looks at the big picture: The client (GSA) wants to know how successful were their efforts to reduce energy use. We need to understand the variables that effect energy use over time at the building. We need to document the recent history of the building and to determine what factors were important to energy use during the pre- and post-retrofit period.

Method. We will continue to track the utility bills for the building and collect local weather data. We will compare pre-and post retrofit periods. We will also collect anecdotal data about the changes in the use, occupancy and construction of the building during this period in order to see what effect--if any--they played in the changes in energy consumption.

Tasks for Question 1:

1. Collect utility bill information through July 1998

2. Identify pre-retrofit baseline period (e.g., July 1995-June 1996) \& post-retrofit period (October 1997July 1998)

3. Interview building operators for pre-retrofit building conditions and operation

4. Determine baseline consumption from utility trends, building operation and monitored data.

5. Compare pre- and post-retrofit energy use

6. Document results for interim report on baseline conditions (September 1997) and final report, September 1998.

\section{How much energy did the new control system save?}

The major retrofit to the building that we are evaluating is the conversion from the pneumatic control systems to a direct digital control (DDC) system that will control the air handlers, cooling system and boilers. We want to find out how the building was operated prior to the DDC system and how the DDC system will allow for improved control and performance of the HVAC systems.

Method. To evaluate the performance of the new energy management control system (EMCS) we will use the DOE-2 simulation of the building developed by Bosek Gibson. We will first run the program to model the savings predicted for the implemented control strategies. This step will give us familiarity with the model and verify that we can actually model the control strategies implemented in the building, using the monitored data to "tune" specific elements (see Appendix B for a list of the outputs from the monitored data collection). Six months after the retrofits are in place we will calibrate the model either with the data collected from the monitoring systems (if available) or the utility billing data.

This version of the model represents how the building is actually operating with the new EMCS. We will then change the control strategies in the model back to what they were prior to the retrofit to determine what the energy use would have been without the new EMCS. The difference between these two models will be our estimate of the energy savings due to the control system. 
Tasks for Question 2:

1. Run the Bosek Gibson DOE-2 model to understand the pre-and post-retrofit control sequences.

2. Review the pre-retrofit monitored data using Electric Eye and compare it to the DOE-2 model output

3. Collect information on the installed DDC control sequences

4. Modify the DOE-2 model to reflect the installed DDC control strategies

5. Tune the DOE-2 model using the monitored \& utility data, both whole building and by system where available

6. Compare the "tuned" DOE-2 model with the same model run using the pre-retrofit control strategies

7. Analyze the results

8. Document the findings for the final report, September 1998.

3. How well does the EMCS system with BACNet perform from the building operator's perspective?

The BACnet system is not an energy-efficiency feature, but is a communications protocol that allows an EMCS front end (user interface) to communicate with equipment from different vendors. We will not be evaluating the performance of how well the BACnet system works internally (that will be done by others) but we are interested in learning how the building operator manages an EMCS system that is BACnet compliant. Our approach will be to interview the building operators and to observe how having the inter-operability features improves the building operation.

Tasks for Question 3.

1. Interview building operators about how the building was controlled pre-retrofit

2. Interview building operators about their post-retrofit experience

3. Observe how frequently control strategies are modified or changed based on improved feedback provided by the EMCS

4. Document results for final report.

\section{Expected Savings from the EMS Retrofits}

The original estimate [ESS 3/30/94] for the savings from the EMS retrofit were for an $18 \%$ reduction in annual utility costs, based on the 1993 utility costs of $\$ 1,975,000$. Seventy percent of the savings were predicted due to the DDC air side control, $25 \%$ due to lighting control and the remaining $5 \%$ due to improved control of the boilers and chillers.

This allocation of savings puts savings at their "point of origin". So, for example, DDC of air handlers will reduce building heating and cooling loads (by reducing re-heat and re-cool loads, improved economizer controls, etc.) in addition to reducing fan energy (through optimum start/stop and improved VAV control). Thus the savings associated with heating and cooling are allocated to DDC air side control not Chiller and Boiler optimization.

The annual energy savings were predicted as $3,687 \mathrm{mWh}$ and 108,460 therms, for a yearly savings of $\$ 348,880$. [the updated Phase II summary attached to the 6/2/97 Progress Meeting notes gives the savings estimate for the controls retrofit as $\$ 536,000]$ The 1994 estimated cost for the retrofits and repair was $\$ 2,320,000$. [the updated summary gives $\$ 3.5$ million as the cost] 


\section{Analysis questions}

- Which control strategies are being implemented? How? Where?

- Which control strategies can be modeled by DOE-2?

- Can we model both optimal and actual control strategies?

- What monitored data from the building do we need to model or analyze these retrofits?

\section{Control Strategies for HVAC systems at $450 \mathrm{GG}$}

\section{Pre-retrofit notes}

1. Eight large dual duct air handlers provide conditioned air to the building; thirteen packaged chilled water and steam heated units provide conditioned air for the courtrooms (BGA 97, p.35).

2. Main air handlers were on constant volume, $100 \%$ outside air until March 1996, when the economizers became operational (BGA 97, p.44).

3. Additional boiler use was needed for the increased air flow during the $100 \%$ OA period (personal communication, W. Sitterly 5/1997)

4. The dual-duct and single-duct VAV terminal units are operated at constant volume (BGA 97, p.45).

5. $50 \%$ of the VFDs are in "by-pass" mode [ESS 3/30/94 p8]

6. Remaining VFDs are manually set and held at $80 \%$ load [ibid.]

7. Exhaust fans run 24 hours per day; supply and return fans are on time-of-day schedules (BGA 97, p 43)

Post-retrofit control strategies [BGA 97, p. 62]

\section{Air Handling Systems Controls}

1. Scheduled Start/Stop - This control will allow the air systems to start and stop based upon a programmable time-of-day control.

2. Optimum Start/Stop - This control will allow the EMS to calculate the required start time to heat up or cool down the building to the desired setpoint at the desired occupancy time.

3. Night Setback - During unoccupied periods the thermostat setpoints shall be set back to $65^{\circ} \mathrm{F}$ during the heating season and $82^{\circ} \mathrm{F}$ during the cooling season. During occupied periods the thermostat will be initially set to $75^{\circ} \mathrm{F}$.

4. Supply Air Reset - The cold duct supply air temperature will be reset to the warmest temperature required to satisfy the zone requiring the most cooling. The hot duct supply air temperature will be reset to the coolest temperature required to satisfy the zone requiring the most heating.

5. VAV Box Control - This controls the minimum and maximum air flow of the VAV boxes and operates them as a VAV box rather as a CV box. Although the control drawings in the plans showed the existing system control of the dual duct mixing boxes to be variable volume, a field change order resulted in the installation of constant volume controls. The 
boxes are equipped for VAV control, but were field modified to provide CV control. The space thermostat was originally intended to modulate both the hot and cold damper. However, the thermostat connection to the hot damper controller has been removed and results in a hot damper operating to maintain a constant air flow from the box, compensating for the amount of cold air being delivered as a function of the space temperature.

6. Economizer Control - The economizers are controlled based upon the supply air setpoints, the return air temperature and the outside air temperature. When the majority of the system is in the cooling mode, the outside air is used if the outside air temperature is less than the return air temperature. $\mathrm{CO} 2$ sensors will override economizer operation and provide $100 \%$ outside air when CO2 levels exceed $800 \mathrm{ppm}$.

7. Exhaust Fan Control - All exhaust fans will operate on a TOD schedule.

8. Garage Exhaust - Garage exhaust fans will operate during occupied hours. During unoccupied hours fans will operate if the CO sensor exceeds a specified limit.

\section{Central Plant Controls [BGA 97, p. 63]}

1. Scheduled Lead/Lag - The smallest chiller will initially supply chilled water. The lag chiller will start when the initial chiller reaches $95 \%$ of the full load power or when the chilled water supply temperature setpoint is no longer attainable. The lag chiller will shut down as the demand is met and the load reduces.

2. Courtroom chillers will be loaded based upon courtroom chilled water demand.

3. Cooling towers will be cycled on and off based upon wetbulb reset. The minimum condenser water temperature they can deliver is $65^{\circ} \mathrm{F}$ while the maximum is $75^{\circ} \mathrm{F}$.

4. Chilled Water Reset - The supply chilled water temperature will be allowed to reset between the limits of $42^{\circ} \mathrm{F}$ and $52^{\circ} \mathrm{F}$. The reset will be controlled based upon the air handler requiring the most cooling. If the chilled water supply temperature can be reset and still supply cooling to the controlling air handler, with the cooling coil control valve not opening more than $80 \%$, then the reset routine will be implemented. This routine reset the chilled water setpoint of all operating chillers

5. Boiler Plant Control - The boilers will continue to be controlled manually.

6. DHW Control - The DHW pumps will start/stop based on TOD routines and the steam valve will modulate to maintain a $140^{\circ} \mathrm{F}$ supply hot water temperature.

7. Drinking CHW System - TOD controls will operate these systems. 


\section{Appendix B: Data Channels}

The Point Index (January 13, 1997):

\begin{tabular}{|l|l|l|l|}
\hline ID\# & Description & Units & Notes \\
\hline & DATE & & \\
\hline 1 & Date/time & & \\
\hline 2 & Year & & \\
\hline 3 & Month & & \\
\hline 4 & Day & & \\
\hline 5 & Hour & & \\
\hline 6 & Minute & & \\
\hline 7 & Day of week & & \\
\hline 8 & Calendar date & $\mathrm{kW}$ & \\
\hline & MAIN CHILLERS & $\mathrm{kW}$ & \\
\hline 9 & Chiller \#1 & $\mathrm{kW}$ & \\
\hline 10 & Chiller \#2 & $\mathrm{kVA}$ & \\
\hline 11 & Chiller \#3 & $\mathrm{kVA}$ & \\
\hline 12 & Chiller \#1 & $\mathrm{kVA}$ & \\
\hline 13 & Chiller \#2 & $\mathrm{gpm}$ & \\
\hline 14 & Chiller \#3 & $\mathrm{deg} \mathrm{F}$ & \\
\hline 15 & Chiller \#1 flow & deg F & \\
\hline 16 & Chiller \#1 evap input temp & gpm & \\
\hline 17 & Chiller \#1 evap output temp & \\
\hline 18 & Chiller \#2 flow & deg F & \\
\hline 19 & Chiller \#2 evap input temp & & \\
\hline 20 & Chiller \#2 evap output temp & deg F & \\
\hline 21 & Chiller \#3 flow & gpm & \\
\hline 22 & Chiller \#3 evap input temp & deg F & \\
\hline 23 & Chiller \#3 evap output temp & deg F & \\
\hline 24 & Chill water supply 1 & deg F & \\
\hline 25 & Chill water supply 2 & deg F & \\
\hline 26 & Chiller \#1 cond return temp & deg F & \\
\hline 27 & Chiller \#2 cond return temp & deg F & \\
\hline 28 & Chiller \#3 cond return temp & deg F & \\
\hline 29 & & & \\
\hline & Whole Building & & \\
\hline 30 & Whole bldg electricity \#1 & $\mathrm{kWh}$ & meter \#Y1108 \\
\hline 31 & Whole bldg electricity \#2 & $\mathrm{kWh}$ & meter \#Y1109 \\
\hline 32 & Chiller \#1 & Btu/h & \\
\hline 33 & Chiller \#2 & Btu/h & \\
\hline 34 & Chiller \#3 & Btu/h & \\
\hline & Courtroom \& FBI chillers & & \\
\hline 35 & Court chiller \# 1 & $\mathrm{kW}$ & \\
\hline & & & \\
\hline
\end{tabular}




\begin{tabular}{|c|c|c|c|}
\hline 36 & Court chiller \#2 & $\mathrm{kW}$ & \\
\hline 37 & FBI chiller \#1 & $\mathrm{kW}$ & \\
\hline 38 & FBI chiller \#2 & $\mathrm{kW}$ & , \\
\hline 39 & Court chiller \#1 & $\mathrm{kVA}$ & \\
\hline 40 & Court chiller \#2 & $\mathrm{kVA}$ & \\
\hline 41 & FBI chiller \#1 & $\mathrm{kVA}$ & \\
\hline 42 & FBI chiller \#2 & $\mathrm{kVA}$ & \\
\hline 43 & CRC input temp & $\operatorname{deg} \mathrm{F}$ & \\
\hline 44 & CR1 outlet temp & $\operatorname{deg} F$ & \\
\hline 45 & CR2 outlet temp & $\operatorname{deg} F$ & \\
\hline 46 & CHCP CHWST 1 & $\operatorname{deg} F$ & \\
\hline 47 & FBI input temp & $\operatorname{deg} F$ & \\
\hline 48 & FBI1 outlet temp & $\operatorname{deg} F$ & \\
\hline 49 & FBI2 outlet temp & $\operatorname{deg} F$ & \\
\hline 50 & FBICP CHWRT & $\operatorname{deg} F$ & \\
\hline 51 & FBI CHW supply temp & $\operatorname{deg} \mathrm{F}$ & \\
\hline 52 & PENTHOUSE & & \\
\hline 53 & SUPH-10 & $\mathrm{kW}$ & \\
\hline 54 & $\mathrm{XPH}-10$ & $\mathrm{~kW}$ & \\
\hline 55 & SUPH-10 & $\mathrm{kVA}$ & \\
\hline 56 & $\mathrm{XPH}-10$ & kVA & \\
\hline 57 & PH outside air temp & $\operatorname{deg} \mathrm{F}$ & \\
\hline 58 & PH OA relative humidity & $\% \mathrm{RH}$ & \\
\hline 59 & PH-10 mixed air RH & $\% \mathrm{RH}$ & \\
\hline 60 & PH-10 mixed air temp & $\operatorname{deg} \mathrm{F}$ & \\
\hline 61 & PH-10 supply air RH & $\% \mathrm{RH}$ & \\
\hline 62 & PH-10 supply air temp & $\operatorname{deg} \mathrm{F}$ & \\
\hline 63 & PH-10 return air RH & $\%$ RH & \\
\hline 64 & PH-10 return air temp & $\operatorname{deg} \mathrm{F}$ & \\
\hline \multicolumn{4}{|l|}{65} \\
\hline & AIR HANDLER 2 & & \\
\hline 66 & SSBE-2 Outside air temp & $\operatorname{deg} \mathrm{F}$ & AHU 2 Supply side \\
\hline 67 & SSBE-2 Outside air $\mathrm{RH}$ & $\% \mathrm{RH}$ & \\
\hline 68 & SSBE-2 ADMAT & $\operatorname{deg} \mathrm{F}$ & \\
\hline 69 & SSBE-2 MARH & $\%$ RH & \\
\hline 70 & SSBE-2 MAT & $\operatorname{deg} F$ & \\
\hline 71 & SSBE-2 ADSCAT & $\operatorname{deg} F$ & \\
\hline 72 & SSBE-2 CSARH & $\%$ RH & \\
\hline 73 & SSBE-2 CSAT & $\operatorname{deg} \mathrm{F}$ & \\
\hline 74 & SSBE-2 ADHSAT & $\operatorname{deg} F$ & \\
\hline 75 & SSBE-2 HSARH & $\% \mathrm{RH}$ & \\
\hline 76 & SSBE-2 HSAT & $\operatorname{deg} \mathrm{F}$ & \\
\hline 77 & RSBE-3 RARH & $\%$ RH & AHU-2 Return side \\
\hline 78 & RSBE-3 RAT & $\operatorname{deg} \mathrm{F}$ & \\
\hline
\end{tabular}




\begin{tabular}{|l|l|l|l|}
\hline 79 & RSBE-3 RARH & $\%$ RH & \\
\hline 80 & RSBE-3 RAT & deg F & \\
\hline 81 & (check) & & \\
\hline 82 & Steam mass flow & lb/hr & \\
\hline 83 & Condensate water flow & gpm & \\
\hline 84 & Cond. water temp & deg F & \\
\hline 85 & Cond. water temp check & deg F & \\
\hline & & & \\
\hline 86 & Air handler fan SSBW-2 & $\mathrm{kW}$ & AHU 2 power \\
\hline 87 & Air handler fan RSBW-3 & $\mathrm{kW}$ & \\
\hline 88 & Air handler fan RSBW-4 & $\mathrm{kW}$ & \\
\hline 89 & Air handler fan SSBW-2 & $\mathrm{kVA}$ & \\
\hline 90 & Air handler fan SSBW-2 & $\mathrm{kVA}$ & (RSBW-3?) \\
\hline 91 & Air handler fan SSBW-2 & $\mathrm{kVA}$ & (RSBW-4?) \\
\hline & & & \\
\hline 92 & SSBW-2 Outside air temp & deg F & \\
\hline 93 & SSBW-2 OA humidity & $\% \mathrm{RH}$ & \\
\hline 94 & SSBW-2 duct temp mixed & deg F & \\
\hline 95 & SSBW-2 duct RH mixed & $\% \mathrm{RH}$ & \\
\hline 96 & SSBW-2 duct temp mixed & deg F & \\
\hline 97 & SSBW-2 avg duct temp cooling & deg F & \\
\hline 98 & SSBW-2 duct RH cooling & $\% \mathrm{RH}$ & \\
\hline 99 & SSBW-2 duct temp cooling & deg F & \\
\hline 100 & SSBW-2 avg duct temp heating & deg F & \\
\hline 101 & SSBW-2 duct RH heating & $\%$ RH & \\
\hline 102 & SSBW-2 duct air temp & deg F & \\
\hline 103 & RSBW-3 duct RH & $\% \mathrm{RH}$ & \\
\hline 104 & RSBW-3 duct air temp & deg F & \\
\hline 105 & RSBW-4 duct RH & $\% \mathrm{RH}$ & \\
\hline 106 & RSBW-4 duct air temp & deg F & \\
\hline 107 & (check) & & \\
\hline 108 & SSBE-2 & $\mathrm{kW}$ & \\
\hline 109 & RSBE-3 & $\mathrm{kW}$ & \\
\hline 110 & RSBE-4 & $\mathrm{kW}$ & \\
\hline 111 & SSBE-2 & $\mathrm{kVA}$ & \\
\hline 112 & RSBE-3 & $\mathrm{kVA}$ & \\
\hline 113 & RSBE-4 & $\mathrm{kVA}$ & \\
\hline & & & \\
\hline 114 & Main gas corrected & $\mathrm{ft3/hr}$ & \\
\hline 115 & Main gas uncorrected & $\mathrm{ft3/hr}$ & \\
\hline & LIGHTING \& PLUGS & & \\
\hline 116 & Lighting 7A & & \\
\hline 117 & Plugs 7A & & \\
\hline 118 & Lighting 7A & \\
\hline & & & \\
\hline
\end{tabular}




\begin{tabular}{|l|l|l|l|}
\hline 119 & Plugs 7A & $\mathrm{kVA}$ & \\
\hline 120 & Lighting 7B & $\mathrm{kW}$ & \\
\hline 121 & Plugs 7B & $\mathrm{kW}$ & \\
\hline 122 & Lighting 7B & $\mathrm{kVA}$ & \\
\hline 123 & Plugs 7B & $\mathrm{kVA}$ & \\
\hline 124 & Lighting 7C & $\mathrm{kW}$ & \\
\hline 125 & Plugs 7C & $\mathrm{kW}$ & \\
\hline 126 & Lighting 7C & $\mathrm{kVA}$ & \\
\hline 127 & Plugs 7C & $\mathrm{kVA}$ & \\
\hline 128 & Lighting 7D & $\mathrm{kW}$ & \\
\hline 129 & Plugs 7D & $\mathrm{kW}$ & \\
\hline 130 & Lighting 7D & $\mathrm{kVA}$ & \\
\hline 131 & Plugs 7D & $\mathrm{kVA}$ & \\
\hline & CHILLER TOTAL & & \\
\hline 132 & Chiller 1-3 power & $\mathrm{kW}$ & chiller combined power central plant \\
\hline 133 & Chiller 1-3 flow & $\mathrm{gpm}$ & chiller combined flow \\
\hline 134 & Chiller 1 power factor & $\%$ & \\
\hline 135 & Chiller 2 power factor & $\%$ & \\
\hline 136 & Chiller 3 power factor & $\%$ & \\
\hline 137 & Chiller 1 evaporator delta T & $\mathrm{deg} \mathrm{F}$ & delta T used to calculate tons \\
\hline 138 & Chiller 2 evaporator delta T & $\mathrm{deg} \mathrm{F}$ & \\
\hline 139 & Chiller 3 evaporator delta T & $\mathrm{deg} \mathrm{F}$ & \\
\hline 140 & Total building demand & $\mathrm{kW}$ & total building kW (sum of loads) \\
\hline 141 & Total chiller output & $\mathrm{kBtu} / \mathrm{h}$ & chiller combined power (2) court (kW) \\
\hline 142 & Court chillers power & $\mathrm{kW}$ & chiller combined power (2) \\
\hline 143 & Court chiller 1 power factor & $\%$ & \\
\hline 144 & Court chiller 2 power factor & $\%$ & \\
\hline 145 & FBI chillers power factor & $\mathrm{kW}$ & chiller combined power (2) \\
\hline 146 & FBI chiller 1 power factor & $\mathrm{kW}$ & \\
\hline 147 & FBI chiller 2 power factor & $\mathrm{kW}$ & \\
\hline 148 & Court chiller 1 evap delta T & $\mathrm{deg} \mathrm{F}$ & \\
\hline 149 & Court chiller 2 evap delta T & $\mathrm{deg} \mathrm{F}$ & \\
\hline 150 & FBI chiller 1 evap delta T & $\mathrm{deg} \mathrm{F}$ & \\
\hline 151 & FBI chiller 2 evap delta T & $\mathrm{deg} \mathrm{F}$ & \\
\hline 152 & SSBW-2 power factor & $\%$ & \\
\hline 153 & RSBW-3 power factor & $\%$ & \\
\hline 154 & RSBW-4 power factor & $\%$ & \\
\hline 155 & SUPH-10 power factor & $\%$ & \\
\hline 156 & SPH-10 power factor & $\%$ & \\
\hline 157 & SSBE-2 power factor & $\%$ & \\
\hline 158 & RSBE-3 power factor & $\%$ & \\
\hline 159 & RSBE-4 power factor & $\%$ & \\
\hline 160 & Total Floor 7 lighting power & $\mathrm{kW}$ & \\
\hline 161 & Total Floor 7 plug power & $\mathrm{kW}$ & \\
\hline
\end{tabular}




\begin{tabular}{|c|c|c|c|}
\hline 162 & Lighting panel 7A pwr factor & $\%$ & \\
\hline 163 & Lighting panel 7B pwr factor & $\%$ & \\
\hline 164 & Lighting panel $7 \mathrm{C}$ pwr factor & $\%$ & \\
\hline 165 & Lighting panel 7D pwr factor & $\%$ & \\
\hline 166 & Plug panel 7A pwr factor & $\%$ & \\
\hline 167 & Plug panel 7B pwr factor & $\%$ & \\
\hline 168 & Plug panel $7 \mathrm{C}$ pwr factor & $\%$ & \\
\hline 169 & Plug panel 7D pwr factor & $\%$ & \\
\hline 170 & SSBW mixing ratio hot air & $\%$ & \\
\hline 171 & SSBE mixing ratio hot air & $\%$ & \\
\hline 172 & Main chiller \#1 & tons & tons (load) assuming calculated \\
\hline 173 & Main chiller \#2 & tons & \\
\hline 174 & Main chiller \#3 & tons & \\
\hline 175 & Main chiller \#1 & $\mathrm{kW} /$ ton & $\mathrm{kW} /$ ton (efficiency) \\
\hline 176 & Main chiller \#2 & $\mathrm{kW} /$ ton & \\
\hline 177 & Main chiller \#3 & $\mathrm{kW} /$ ton & \\
\hline 178 & Condensate mass flow & $\mathrm{lb} / \mathrm{hr}$ & \\
\hline 179 & Condensate return & $\%$ & \\
\hline 180 & Steam production & Btu/h & \\
\hline 181 & Natural gas consumption & $\mathrm{Btu} / \mathrm{h}$ & \\
\hline 182 & Boiler efficiency & $\%$ & \\
\hline 183 & Weighted return air temp RSBW- & $\operatorname{deg} F$ & \\
\hline 184 & Percent OA SSBW-2 & $\%$ & \\
\hline 185 & Cooling coil delta T SSBW-2 & $\operatorname{deg} \mathrm{F}$ & \\
\hline 186 & Cooling coil delta RH SSBW-2 & $\%$ & \\
\hline 187 & Heating coil delta T SSBW-2 & $\operatorname{deg} \mathrm{F}$ & \\
\hline 188 & Heating coil delta RH SSBW-2 & $\%$ & \\
\hline 189 & Weighted return air temp RSBE- & $\operatorname{deg} F$ & \\
\hline 190 & Percent OA SSBE-2 & $\%$ & \\
\hline 191 & Cooling coil delta T SSBE-2 & $\operatorname{deg} \mathrm{F}$ & \\
\hline 192 & Cooling coil delta RH SSBE-2 & $\%$ & \\
\hline 193 & Heating coil delta T SSBE-2 & $\operatorname{deg} F$ & \\
\hline 194 & Heating coil delta RH SSBE- 2 & $\%$ & \\
\hline 195 & $\%$ OA courtroom air handler & $\%$ & \\
\hline 196 & Coil delta $\mathrm{T}$ courtrooms & $\operatorname{deg} F$ & \\
\hline 197 & Coil delta RH courtrooms & $\%$ & \\
\hline 198 & Court chiller 1 delta $T$ & $\operatorname{deg} F$ & \\
\hline 199 & Court chiller 2 delta $T$ & $\operatorname{deg} F$ & \\
\hline 200 & FBI chiller 1 delta $T$ & $\operatorname{deg} F$ & \\
\hline 201 & FBI chiller 2 delta $T$ & $\operatorname{deg} F$ & \\
\hline
\end{tabular}

